
A $2.5 n$ 


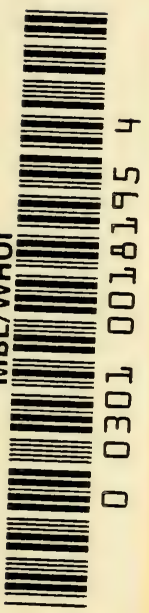




\section{The grigrations of Birds}

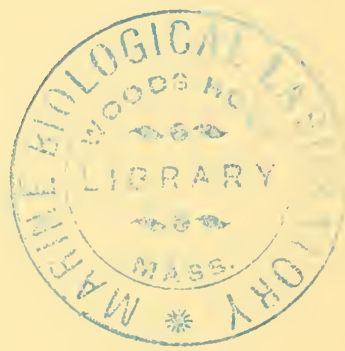


LONDON : HUMPHREY MILFORD OXFORD UNIVERSITY PRESS 



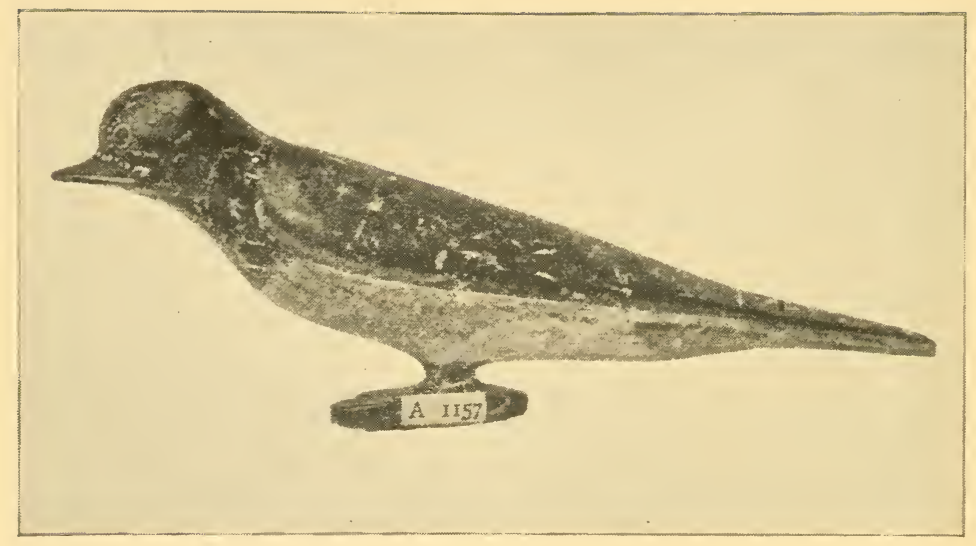

Figure I

Wooden image of swallow used in Macedonia as an emblem of spring.

(After Keller.) 


\title{
THE MIGRATIONS OF BIRDS
}

\author{
BY \\ ALEXANDER WETMORE \\ ASSISTANT SECRETARY, SMITHSONIAN INSTITUTION \\ FELLOW, AMERICAN ORNITHOLOGISTS' UNION
}

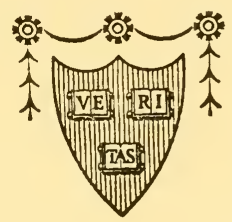

CAMBRIDGE

HARVARD UNIVERSITY PRESS

I927 
COPYRIGHT, I926

BY THE PRESIDENT AND FELLOWS OF

HARVARD COLLEGE

Second impression

PRINTED AT THE HARVARD UNIVERSITY PRESS

CAMBRIDGE, MASS., U.S. A. 


\section{PREFACE}

7 HE observations on the migration of birds pre-

1 sented in the following pages were delivered in six lectures before the Lowell Institute in Boston on October 26 and 28, and November 2, 4, 16 and I8, 1925. The manuscript as here published is unchanged except for the inclusion of a few paragraphs that time did not permit to be presented during the course of the lectures.

The material included is based on study and observation on the part of the author during a period of more than twenty years. It is intended as a summary of present knowledge of migration, with the various factors that affect it in its broader aspects, without entering upon precise statistics of movement for the many species involved. Such figures may be left for treatises of another character.

After careful consideration of the subject the writer is profoundly impressed by the mass of detail regarding the movements of birds that has been assembled and the little that has been definitely ascertained regarding the underlying principles that control migration. There is much that remains to be established in this phase of the subject.

In conclusion the author desires to express appreciation to the Bureau of Biological Survey, United 
States Department of Agriculture, for permission to reproduce plates from its publications, and to the Museum of Vertebrate Zoölogy, University of California, for the privilege of reprinting a map by Mr. H. S. Swarth to show the distribution of fox sparrows. Mr. Gregory Mathews, the well-known authority on Australian birds, has read the sections dealing with Australia, and I am indebted to other friends for suggestions.

\section{Alexander Wetmore}

Washington, D. C.

May I, 1926. 


\section{CONTENTS}

\section{CHAPTER I}

INTRODUCTION . . . . . . . . . . . . . . 3

Historical Account. . . . . . . . . . 4

Theories of Migration .......... . . . I5

Superstitious Beliefs .......... . . I5

Scientific Hypotheses of Migration . . . . 21

\section{CHAPTER II}

Nocturnal and Diurnal Migration . . . . . 39

Altitudes at which Migrating Birds Travel . . 46

Weather and Migration . . . . . . . 52

Speed of Flight in Birds . . . . . . . . 58

The Sense of Direction in Birds....... 62

\section{CHAPTER III}

Regularity of Migration . . . . . . . . . . . 73

Segregation during Migration . . . . . . . . 79

Migration Among Supposedly Resident Birds . . 84

Irregular or Vagrant Migration . . . . . . 89

Casual Records. . . . . . . . . . . . . 99

\section{CHAPTER IV}

Altitudinal or Vertical Migration.... . 106 Rapidity of Migration Movement ...... . ilo

Distances Travelled by Migrants ...... . II 5

Mortality Among Migrant Birds ...... . I2I 


\section{CHAPTER V}

General Observations on Lines of Migratory

FlIGHT . . . . . . . . . . . I34

\section{CHAPTER VI}

Migration Among Shore-birds . . . . . . . 165 The Seasonal Flight of Ducks . . . . . . . I 80 The Migrations of Some Other Birds . . . . 195 Conclusion . . . . . . . . . . . . . 217 
The Migrations of Birds 



\section{CHAPTER I}

\section{Introduction}

7 HE regular movements of birds during their 1 migratory flights between their summer and winter homes are among the striking natural phenomena of the temperate regions of the earth that attract almost universal attention. Lines of geese, ducks, or cranes crossing the sky stir the heart of civilized and savage man alike, and in all quarters are greeted as indicators of changing season. The return of robins to our lawns, almost as soon as the ground is bare in spring, or the cheerful warblings of the bluebird from roadside fences, are events recorded in speech and in the press, and are greeted with pleasure as the vanguard of advance against winter. The country dweller in Europe, Africa, Argentina, or Australia welcomes a swallow as the certain harbinger of warmer weather, and rejoices accordingly. Movements among nomadic peoples, migratory themselves in one sense of the word, have been controlled by the flights of birds. Savage tribes have named months for birds that regularly appear during their course; and migratory flights of 


\section{THE MIGRATIONS OF BIRDS}

different species in former times were used as omens, a custom that prevails to-day in certain sections of the earth.

\section{Historical Account}

Historical allusions to the migratory flights of birds are innumerable, and we may suppose that these regular movements have been observed by man and correlated with the change of season since the Pleistocene. On turning to the Bible, we find in the Old Testament what is considered the earliest definite written reference to migration when Job (XXXIX, 26) remarks: "Doth the hawk fly by thy wisdom, and stretch her wings toward the south?" Jeremiah (VIII, 7), in an exhortation to Judah, is more explicit in the statement, "Yea, the stork in the heaven knoweth her appointed times; and the turtle and the crane and the swallow observe the time of their coming." The Israelites wandering in Sinai were saved from starvation when "at even the quails came up and covered the camp" (Exodus, XVI, I3); and again, a year later, when " there went forth a wind from the Lord, and brought quails from the sea." (Numbers XI, 3I.) Canon Tristram has calculated that this cccurred in spring when migratory quail were in flight to the north from their winter home in Africa. Further, he has indicated the date as in the month of April, about I580 B. c., 
which, if authentic, would seem to be our earliest definite migration record.

Apparently quails came in tremendous abundance, since it is stated in the book of Numbers (XI, 32 ), that "the people stood up all that day and all that night, and all the next day, and they gathered the quails: he that gathered least gathered ten homers." Hugh Gladstone ${ }^{\text {I }}$ informs us that the capacity of the unit of measure called the homer has been estimated varicusly at from 48 to 80 gallons. $\mathrm{He}$ assumes that 600 men (said to be the number of heads of households or "tent-holders" that took part in the exodus) were engaged in the capture of birds; on these data the Israelites during thirty-six hours may have taken over 9,000,000 quails!

Persians and Arabs formed part of their calendar cn data taken from the movements of birds, and, with other ancient peoples, celebrated with song and festival the return of spring as marked by the arrival of migrants. In Macedonia to-day, on the first of March, children pass from house to house carrying the figure of a swallow carved from wood, while they sing that the swallow comes and with it spring. (See Fig. I.)

The Chippeway and various tribes of Plains Indians, transposing cause and effect, believed that the bluebird (in this case the Arctic bluebird) bore

× Record Bags and Shooting Records (1922), pp. 59, 60. 
summer to them on its azure wings, and they noted its arrival with appropriate pleasure. The Eskimo of the lower Yukon call the season comprising the latter part of March and the first days of April "the coming of the birds," and the succeeding period, embracing a portion of April and May, "the arrival of the geese." South of the Yukon Delta, October is known as "the month of the flying away," because of the departure of birds.

In the vast Chaco of Paraguay, when the northward flight of shore-birds starts these voyagers on their long journey from their winter homes in South America to their breeding grounds near the Arctic Circle, the Angueté and Lengua Indians, hunting tribes governed in their movements by the availability of water and the presence of game, resort to certain river channels where, from the shelter of low sand-banks, they waylay passing sandpipers and kill them in quantity with throw-sticks of light wood hurtled through the closely flying flocks.

In the writings of Homer, we find reference to the flight of cranes at the approach of winter, and the gathering at that season of hordes of aquatic birds on the marshes of Asiatic rivers. To Hesiod, in the eighth century before Christ, the cries of the crane were a summons to the laborer to plough his land, while Herodotus (about 525 B. c.) supposed that the hawks he saw must have come from some distant 


\section{HISTORICAL ACCOUNT}

land. Anacreon sings of the return of the swallow in spring to its nesting-place.

Aristotle, the first to discourse fully on migration, in his writings on natural history, gives definite accounts of a number of migrant birds. He tells us that the crane flies from the steppes of Scythia to the marshlands at the source of the Nile, south of Egypt; that pelicans migrate, as do the quails, the rock-dove, and the turtle-dove, though of the last three a few may linger during cold weather in protected localities. The swan, the land-rail, and the lesser goose likewise pass toward warmer regions, while the cuckoo goes away in July about the time that Sirius the Dog-star rises. Pliny, the Roman, in his Historia Naturalis, written in the earliest years of the Christian era, in treating of migration repeats much of what has been said by Aristotle, but adds that blackbirds (in this case the common thrush of Europe), thrushes, and starlings pass to neighboring countries; the ring-dove also is migratory to an unknown winter home, as are the storks and cranes, which he believes go to a great distance.

The few known writings during the Dark Ages that pertain to natural history, which include the Bestiaries, accounts of hawking or falconry, and a few other scattered manuscripts, contain little that

I The peregrine falcon (Falco peregrinus) was so called by falconers because it was secured when grown as a "pilgrim" or migrant, and was not taken from the nest when young as were other hawks used in hunting. 
refers to migration except casual mention of species of birds that we know to be migratory. Matthew Paris, monk of St. Albans, in a manuscript preserved at Corpus Christi College, Cambridge, in the year I25I wrote of an invasion of crossbills, and referred to them as birds never before seen in England. Chaucer, in the fourteenth century, described the field-fare, a species of thrush, as "frosty," in allusion to its presence in England only during winter.

Olaus Magnus, Archbishop of Upsala, in I 555 speaks of the flights of swallows, Francis Willoughby in his Ornithology published in I678, mentions various migratory birds; and the writings of Gilbert White, Thomas Pennant, and George Edwards in the succeeding century carry much of interest on this subject. These men in fact kept regular records of arrival and departure. The observations of George Edwards on the migration of birds were collected in his Essays upon Natural History, published in London in I770; while in I780 appeared a Discourse on the Emigration of British Birds, printed anonymously, but since attributed to John Legg, a naturalist previously unknown.

From the beginning of the nineteenth century records of arrival and departure of migratory birds were gathered by many observant naturalists in the northern hemisphere, and the mass of data increased in bulk yearly. 
Dr. Middendorff, in I 855 published a summary of migration records for the Russian Empire, in which he attempted to trace isepipteses, or lines of simultaneous arrival, for individuals of the same species. ${ }^{\mathrm{x}}$ Professor Palmén, in $1874,{ }^{2}$ outlined many supposed routes of migration in Europe, which led to controversy on the subject with von Homeyer, who combated some of his views. Severzoff, ${ }^{3}$ in I880, prepared a similar treatise covering central Asia, and Menzbier ${ }^{4}$ wrote of routes of travel for Eastern Europe.

Bibliographical material dealing with the subject after 1880 is so voluminous that space permits bare mention of only a few authors. Among the most famous records of migratorial phenomena are the observations of Heinrich Gätke, covering fifty years intensive study on the little island of Heligoland standing solitary in the North Sea. These records, published first in German, were in I895 translated into English, ${ }^{5}$ and stand as a classic on the subject. Though modern naturalists do not hold with some of Gätke's theories, his account is rich in

- Die Isepiptesen Russlands. Grundlagen zur Erforschung der Zugzeiten und Zugrichtungen der Vögel Russlands. St. Petersburg, I 855.

- Im Foglarnes Flyttningvägar. Helsingfors, I 874 .

3 Bulletin de la Société Impériale des Naturalistes de Moscou (I 880), pp. $234-287$.

4 Ibid. (1 886), pp. 291-369.

5 Heligoland as an Ornithological Observatory. Edinburgh, 1895; pp. i-xii, I-599. 
valuable information. Wallace and Newton in turn wrote upon migration, followed by Charles Dixon, and by W. E. Clarke whose two volumes ${ }^{\mathrm{I}}$ summarize observations begun as a member of a special committee on Bird Migration, of the British Association for the Advancement of Science, and continued at length after preparation of the reports that cover the voluminous data assembled by that committee. The Hungarian, German, French, and a number of other ornithological organizations have been responsible for coöperative efforts leading to the assembling of much information, which has been published in a long series of papers.

The phenomena of bird migration were so evident to early colonists on the eastern coasts of North America that notes on the movements of birds found a natural place in many accounts that touch on the indigenous life of the region. Waterfowl swarmed in rivers and marshes in such numbers that their migratory movements forced themselves on attention, aside from the regular appearance and disappearance of smaller birds that came in friendly fashion about the crude homes of the pioneers. There were in addition, in those days, great flights of the passenger pigeon, which illustrated migration movement of maximum magnitude.

Data on the migration of North American birds I Studies in Bird Migration. London, 1912, 2 vols. 
were early summarized by Spencer Fullerton Baird, writing in the American Fournal of Science in 1866, and from that time increased steadily in volume year by year. Tremendous impetus was given this branch of ornithology by the formation of the American Ornithologists' Union. At its first congress, held in New York City in September, I883, there was appointed a committee on the Migration of Birds, with Dr. C. Hart Merriam of Locust Grove, New York, as chairman. This committee began active work immediately and during its first year, through a corps of observers scattered through the eastern half of the continent, assembled many data. It was realized within a year that financial assistance would be required to handle the rapidly growing work, which led to a petition to Congress by the Council of the Union, and resulted in the appropriation of five thousand dollars for a Division of Economic Ornithology under the United States Department of Agriculture, established July I, I885, with Dr. Merriam as Chief. Though the scope of the work undertaken by the new division rapidly broadened into the present Biological Survey, study of the migration of birds continued to receive its due measure of attention. Professor Wells W. Cooke, who had organized coöperative observation in the

I "The Distribution and Migrations of North American Birds"; Amer. Fourn. Sci. ser. 2, vol. xli (1866), pp. 78-90, 184-1 122, 337-347. 
Mississippi Valley in I88I, and whose endeavors were incorporated with those of the A. O. U. Committee on its formation in 1883 , became associated early with the work under government auspices, and continued these investigations until his death in I9I6. As a result of his endeavors augmented by the efforts of others, there has been amassed in Washington the most comprehensive mass of data on the subject ever brought together, much of which Professor Cooke summarized in his many publications dealing with the subject.

Literature of the past fifty years dealing with migratory movement in birds is truly enormous and must be left without further comment. It remains to notice briefly the growth of bird-banding as applied to this study. Sporadic attempts to mark individual birds so that they might be identified later began over one hundred and twenty years ago, and have ranged from tiny bells, bits of colored yarn, marks made with indelible inks or paint on certain feathers, metal disks glued to the wing or tail feathers, plain rings of wire and celluloid, and strips of metal on which were stamped texts from the scriptures, to bands of aluminum marked with a serial number and the name and address of the person or organization responsible. Lincoln has called attention to a great gray heron (Ardea cinerea) captured in Germany in I7IO, which carried on the 
tarsus several metal rings, one of which is stated to have been placed on the bird in Turkey several years earlier. This seems to be the first recorded use in bird-marking of a metal ring placed on the tarsus. Sporadic records of birds marked in various ways occur in literature at random, but scientific use of this method did not begin until I899, when C. C. Mortensen in Denmark began systematically to band storks, teal, starlings, and other birds. The results to be obtained from this method were so obvious that it became popular almost at once, so that by I $9 \mathrm{I}_{4}$ eighteen or twenty distinct projects for the marking of birds were in progress or in contemplation in Europe. The work was checked in part by the World War, but is now again in full progress. In the United States early attempts at banding birds, fostered in part by Dr. L. J. Cole, crystallized in I 909 in the organization of the American Bird-Banding Association, conducted from I9I I until I920 by the Linnæan Society of New York, and then taken over by the Bureau of Biological Survey, of the United States Department of Agriculture. Under the present organization bands are issued to members, who report to Washington, with all necessary data, the birds on which they are placed. The work is regularly advertised through the press so that the bands are often recognized when found, or, if not, the finder usually has sufficient interest or curiosity 
to notify the Biological Survey to learn the source of the marker. In this way many thousands of bands have been used, and returns have come from many hundreds. At the present time the work of birdbanding has become so widespread and popular that four regional associations of interested persons have been formed in the United States and Canada, to consolidate the work by geographic areas.

During development of this work attempts at banding birds were directed first mainly to the marking of nestlings, but in the last few years this has been supplemented and largely replaced by the use of traps for the capture of grown individuals. The marking of nestlings, while fruitful, has many disappointments, since mortality among young birds during the fledgling period, before they are sufficiently alert to escape their many enemies, is so heavy that many bands are wasted. Trapping methods at present used were developed early by Mr. S. P. Baldwin, and have attained a high degree of efficiency. The trap is especially valuable since it does not injure the bird and enables consecutive records of the same individual. The method has been extended until now trapping devices are made for the capture of species of the most diverse form and habit.

The great value of bird-banding to the student of migration lies in the data that it affords on the move- 
ments of individual birds, as contrasted with mass observation of a species as a whole. This modern development of the study while still in its infancy has already yielded highly valuable results, and will be steadily productive of new information that will aid in the solution of many problems.

\section{Theories of Migration}

\section{Superstitious Beliefs}

The migratory movements of larger birds, evident in their accomplishment, were understood by the lay mind with comparative ease; but to account for the travels of smaller species, which appeared or disappeared between suns, was a matter of greater difficulty. In I740, J. G. Gmelin was assured by the Tartars of Krasnojarsk, and the Assanians, in Siberia, that each crane carried a corn crake on its back to some warmer land. In southern Europe the peasants hold that the smaller birds congregate on the shores of the Mediterranean Sea, where they await suitable opportunity for passage to Africa on the commodious pinions of storks and cranes - a superstition further correlated with the belief of the Egyptian laborer that these great birds on their journeys carry a living freight of their smaller companions. 
Somewhat more startling is a theory of migration elaborated in an anonymous treatise published in London in 1703, "By a Person of Learning and Piety," entitled in part An Essay Towards the Probable Solution of this Question: Whence come the Stork and the Turtle, the Crane and the Swallow, when they know and Observe the appointed time of their Coming. This author in a wordy statement announces his belief that migratory birds, on leaving England, go direct to the moon, where they pass the winter season - truly an outstanding expression of faith in the power of flight of delicate creatures which, according to others, are not able to span the moderate expanse of one of the seas! To continue, this tract sets forth that the journey may require sixty days, during which the voyagers may have no need of food in the rarefied ether through which they pass, or may subsist on their stored-up body supplies of fat as "bears are said to live upon their summer fat all the winter long in Greenland." The matter of restful sleep is easily arranged since, as they fly "where they have no objects to divert them, [they] may shut their eyes, and so swing on fast asleep." The tract continues that as the moon is not a stationary body, if birds leave at the time of full moon they may fly directly in a straight line upward, and at the end of the allotted sixty days the moon will again be full and at the proper location in the heavens to 
receive them. The author concludes with the sage remark that "if the Moon will not be allowed, some other place must be found out for them" - a statement that we may accept, and that we may hope to confirm in the course of the pages to follow.

In early times, disappearance of certain birds was attributed to hibernation, in which they passed into a torpid state and remained thus through the season of cold, hidden in caves or hollow trees, or embedded in the mud at the bottom of streams, ponds, or marshes. The theory of hibernation seems to find its first expression more than three hundred years before Christ, in the writings of Aristotle, where it is stated that some or all individuals of the swallow, kite, stork, ouzel, turtle-dove, lark, and a number of other species become torpid during winter. Although in early times related of many species, this bizarre custom was attributed later mainly to swallows, swifts, and, in the United States, to the sora rail; and prolonged and learned were the discussions setting forth the merits of both sides of the case; so that Coues in 1878 cited more than 175 titles dealing directly with hibernation in swallows alone. One early writer published several treatises on the subject, under the pseudonym of "Philochelidon"."

The sora rail frequented marshes in abundance until between suns it suddenly disappeared. This

I Thomas Foster, an author who wrote on other subjects than birds. 
strange trait was explained by the statement that overnight the birds had turned to frogs or had sunk in the mud. Naturalists gravely related seeing swallows congregate on reeds until their weight bent down the slender support and the birds were submerged beneath the water. Olaus Magnus wrote that fishermen often found swallows fastened in bunches in the mud of marshes, and gave an illustration depicting two men drawing a net filled with mingled swallows and fishes. (See fig. 2.)

During the eighteenth and early part of the nineteenth century this question was argued with especial vigor, and many instances in which hibernation was alleged were brought forward. Men reported seeing swallows fly into the water, or told of torpid individuals drawn up in seines. It is related in Williams's History of Vermont, published in I794, that about the year I 760 a torpid swallow was dug from a depth of two feet in the salt marsh on the banks of the Charles River at Cambridge, Massachusetts, during the latter part of February, and that this bird revived in half an hour! Several papers on the subject were read before the French Academy, and the Royal Society in London, and John Hunter, the anatomist, as an experiment, one autumn shut several swallows in an outhouse, with tubs of water floored with mud in which rushes had been planted, with death to the birds by starvation 


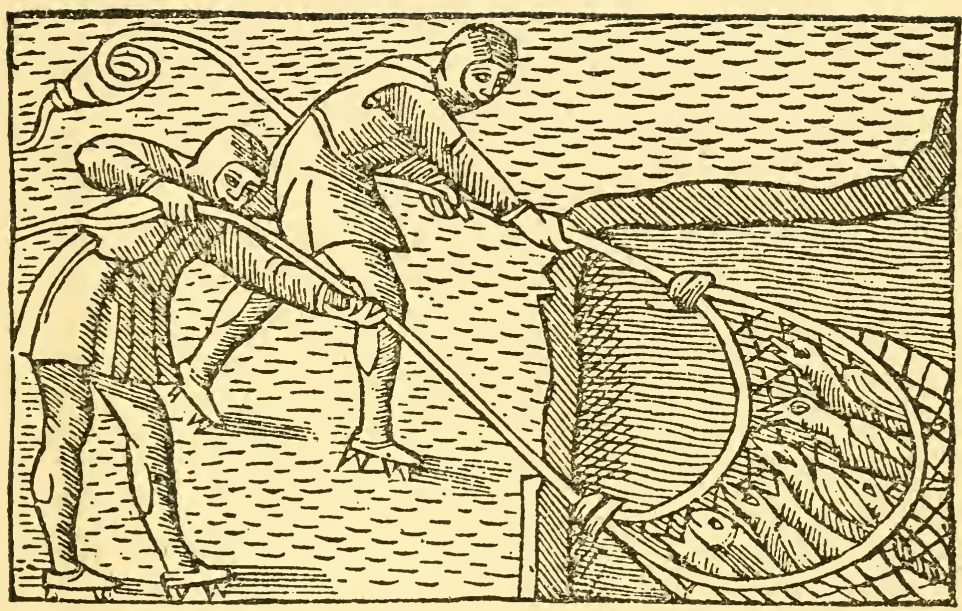

Figure 2

Fishermen drawing nets with a mixed catch of fishes and hibernating swallows. Taken from Olaus Magnus. (After Eagle Clarke.) 

as the only result. Those to whom the theory of submersion in marshes did not appeal stated that swallows and swifts remained in a torpid state in hollow trees or clefts in rocks; and numerous persons in our own country have related with great circumstance the finding of such birds, the manner of their reviving, and their subsequent death if not permitted to resume their slumbers. Even the cautious Coues apparently was inclined to place a certain amount of belief in hibernation, mainly since in his day the chimney swift disappeared in the autumn to some unknown place.

As final comment, attention may be drawn to the fact that hibernation, or its correlate æstivation, is of common occurrence among mammals, reptiles, and amphibians, and even among fishes, if we accept the burrowing of lung-fishes and of some forms of minnows in moist mud during periods of drought as related to the phenomenon under consideration. It is strange indeed, therefore, that hibernation in birds has never yet been scientifically proved in spite of the many cases that have been claimed. The frequent connection of this superstition with swallows is probably explained by the fact that these birds regularly resort to growths of rushes in marshes and swamps for roosts and shelter during late summer and autumn, and that during storms many perish, and fall into the mud and water, but never revive on the approach of more clement weather. 
There may be mentioned here also a transmutation theory held in early centuries which supposed the change of one species to another at the coming of cold and the assumption of proper form with return of summer. This again may be traced to Aristotle, who propounded the belief that the redbreast, or European robin, changed to the redstart, a species of similar size but different color, since the latter was present in winter and the former in summer. Similarly he informs us that the beccafico, possibly the garden warbler, became the blackcap, a related species, and that at the proper seasons birds in transition between the two could be observed. Pliny repeated these tales, and later in popular belief they were still further embroidered by the alleged transformation of certain marsh birds to frogs. In our own country this shift from warmblooded bird to cold-blooded amphibian has been attributed in many quarters to the sora rail, which migrates by night so that its departure is unseen.

All these beliefs, which seem strange and curious to modern vision, arose in the attempt of the human mind to explain observations which demonstrated conclusively that many birds were present one day and had vanished on the one that followed, while their return came in a fashion equally mysterious. With recognition of nocturnal flight as fact, such stories lost credence immediately, save in the case of 
hibernation, which has been alleged sporadically to account for various circumstances at the time not fully understood.

\section{Scientific Hypotheses of Migration}

With the migration of birds recognized as a regular accompaniment of the changing seasons, there arises for consideration the manner in which migration had its origin, and the reasons that lie behind its continuation - matters still of considerable dispute. The various theories that have been advanced may be outlined briefly.

The most commonly accepted explanation of the seasonal movement of birds is that of shifting foodsupply. Failure of food in northern areas in autumn forces certain birds to travel; it is only in a southerly direction that amelioration of the unfavorable condition is encountered, so that the birds affected move south to an area where food is abundant. With the coming of spring the need for reproduction to perpetuate the species becomes paramount. The foodsupply of the southern regions to which these birds have migrated does not permit the easy support of the host of young that must be reared to perpetuate each species, so that the individuals that have come from the north press out in that direction until they arrive at a suitable spot for settlement for the breeding season. 
But little different is the theory that migration is due to changes in temperature through which, with the colder air of autumn warning of the approaching extremes of winter, birds pass south, to return when the season has changed again, so that a period of warmth is approaching. In this hypothesis some have held that the migratory birds originated in the north, were driven south by the advance of ice in the Pleistocene, and have returned to the north with the coming of milder conditions. A love of birthplace calls them now each year to return to the natal home. Observation shows, however, that many birds remain a very brief period on the breeding-ground, merely long enough to permit the rearing of young, - and then immediately begin the return journey south, - so that the period spent in the northern home is short. Many in fact return south long before there is need for them to do so; so that the argument of love of birthplace hardly seems substantiated.

According to a somewhat different hypothesis, all species have arisen in the south and have spread to the north through the natural impact of individual upon individual in the struggle for existence; that this pressure is at its highest point during the period of reproduction, so that individuals then must fare afield to find space in which their families may be reared, and that with this duty accomplished they 
may withdraw once more to their ancient home. According to this conception migrant birds retire in autumn to the original home, and there remain for the winter. With the advent of spring the impulse for reproduction drives them irresistibly out to the area that forms the summer home, where they settle to rear their young. With this accomplished they are again actuated by an overpowering impulse to return to the area from which they originally came, and so return in the autumn migration to the winter home. This has been alleged especially to explain early autumn migration before there is any practical necessity for a shift in base. It is also alleged to explain those instances in which birds tend to follow migration routes that do not carry them directly north and south. The theory has in its favor the fact that many birds breed in areas where they cannot winter, a sufficient basis for migration. To suppose that all have originated in the south is, however, going to a considerable length, as many, if not most of them, in their evolution must antedate the Pleistocene, when physical conditions regulating their distribution were far different from those encountered at present.

Mr. J. T. Nichols, ${ }^{1}$ has summarized certain migration theories akin to this in consideration of the irregular southward flights of the red-breasted nutI Science, Aug. 16, I918, pp. 168-170. 
hatch, a species that comes south in abundance at irregular intervals. He considers that these flights take place only when the species has increased to a point where it is crowding its northern range. It then scatters over a broad area and is found in abundance in regions to the southward. He considers that the majority of these migrants fail to return to their original home. Such movement he terms centrifugal, in distinction from a centripetal movement in which a species has separate breeding and wintering grounds between which its individuals perform regular migratory flights. He considers the condition of indiscriminate wandering the original one, in which the bird may succeed in returning occasionally to its original home, perhaps from a short distance only. With this established as habit, the distance between the winter and summer homes may become greater and greater until the area inhabited in winter may lie without the limits where the species breeds. This in brief is an outline of what has unquestionably taken place in the development of migratory habit, without attempt at explanation of the principles that have controlled it.

A somewhat different belief is alleged by those who support the theory of phototropism, in which it is considered that birds naturally turn to the region of greatest light and retreat from one in which light is curtailed. According to this belief, migratory

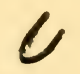


birds simply follow the sun in spring as the centre of its path advances beyond the Equator, and after rearing their young follow the retreating rays of the heavenly orb as it moves southward, to winter quarters where light is at its maximum intensity. The course of migration is, in general, correlated with the advance and retreat of the sun, but it seems that light is a secondary cause, which reacts on the bird through its effect in producing a change in season, and not directly through any organic reaction to the light rays themselves. On the basis of light we cannot, for example, explain a migration south among northern shorebirds during July, as the maximum amount of light, though on the wane, is still to be found in their northern breeding-ground. Also in the case of the few migrant nocturnal birds, for example, various goatsuckers, it would seem advantageous to react against light rather than to follow it, since prolonged darkness is better suited to their activities, which are actually curtailed by lengthening days. In fact, this is probably one of the factors that limits the summer range of some of the strictly nocturnal species. A whippoorwill, for example, would be decidedly out of place near the Arctic Circle, where the hours of night are eliminated or greatly curtailed by the movements of the midnight sun. Further, we should expect birds of such habits to find their optimum conditions as re- 
gards life in equatorial regions, where the hours of the day remain evenly divided between daylight and darkness, and where the favorable period of night is not curtailed as it is in June in the North Temperate Zone.

Among other theories, it has been suggested that migration is the natural outcome of power of flight, a faculty that is so pleasurable and so easy in execution that birds migrate naturally from place to place when not bound by home ties. It has been asserted also that migration has its impetus in a desire for solitude, which causes birds to seek remote islands, isolated lakes, marshes, or distant forests, where they may be free from all disturbing factors during the period of reproduction. Though many birds, particularly those of shy habit, do seek isolation while breeding, there are others with exactly opposite tendency, as the many birds that nest familiarly about the homes of man; so that there are as many points against this argument as for it.

Dr. Alvin R. Cahn, in a recent article ${ }^{\mathrm{I}}$ on the migration of animals, has discussed migratory movements in a highly interesting and instructive manner. He points out that the movements of birds in north and south migration correspond, in general, to advance and retreat to or from the breedingstation, and considers migration due to physiological

× American Naturalist (1925), lix, 539-566. 
change in the gonads, and thus directly activated by the sex hormones. It appears true that the migration north from the winter home is instigated by this factor, which is of powerful influence in maintaining and directing present migration movement; but, though a prime influence at present, this cannot be considered as the ultimate underlying principle that has given rise to migration as we now see it.

The evolutionary line of the bird is tremendously long: on the basis of present knowledge it is known to go back through an enormous reach of time to Archaeopteryx and Archaeornis of the Jurassic period.

That these earliest known birdlike creatures progressed through the air is certain from their structure, but the extent of their powers of flight is problematical. In the Cretaceous, however, we find in Ichthyornis a bird with ability to fly strongly developed, and the flying type has been the dominant one in the millions of years during which our present avian forms have been evolved. The evidence recorded by fossils indicates that many of our modern types of birds were found during the Miocene. It seems probable that the forms shown in many, if not most, of our modern genera, were in existence at that time, though our fossil record is highly incomplete. Bones of many birds not certainly distinguishable from those of living forms are found in the early part of the Pleistocene. 
Habits and reaction to environment in birds must date back through this same long period of years, so that what we now recognize as definite instincts among them, which are merely reactions to the usual stimuli of everyday life, must have had their beginning back in the same remote periods. Birds sought for food, fought for territory, and produced their kind, were subject to seasonal changes, shifts in environment, ecological successions among plants and trees, and climatic variations, then as now. We must consider the present migratory instinct as an outcome of all the various complex circumstances that have affected birds, and for its origin must look to remote ages. The actual migrations now found in the northern hemisphere have been influenced profoundly by the climatic changes of the Pleistocene, but the cause of migratory flight goes so far back in time that we may discuss it, but may not hope to offer more than guess or supposition as to its actual origin.

With this statement in mind it will be understood that hypotheses advanced regarding the origin of migration are merely attempts to explain it on the basis of what may have happened, judging from the observations of our limited human experience. There can be no final proof of the validity of the arguments. They stand as scientific guesses at what is supposed to be the truth. 
Let us now return to the hypotheses that have been outlined. Objection may be raised to any of them, but it appears that an explanation of the phenomena under discussion may be found in a combination of the various forces suggested, working in unison. The entire act of migration is so utterly complex that no single factor may be ascribed as the absolute cause. A logical explanation may, however, be attempted if we hold that the origin of these movements is multiple. It may be advanced as a working hypothesis that migration has arisen from movement induced by seasonal and climatic change developed in certain species until it has become hereditary instinct.

It will suffice to turn to everyday observations on the habit of brief post-breeding wanderings of some of our common birds to record what may have constituted a beginning of migration. A pair of robins, tufted titmice, or white-breasted nuthatches, select a home site, prepare a nest, incubate eggs, and rear a brood of young to maturity. During this period foraging for food is confined to a limited space. As the young grow, the surrounding area must be scanned intensively to procure a sufficient supply of food. When the fledglings leave the nest they may linger for a time in the vicinity; but as the young grow stronger, they begin to wander, at first for a few yards, but gradually extend their area until it 
may cover several miles. This shifting is often noted at the time when the young are thrown on their own resources, as the parents, wearying of importunate calls for food, may harry their offspring and drive them from the immediate vicinity, or may accompany them to some nearby area where food for all is easily procured. In part, the wandering that comes at this period may be considered merely the expression of a restless instinct for exploration on the part of creatures endowed with wonderful freedom of movement, while in part it is necessity subservient to a search for food.

The house wrens of my door-yard form ready examples of the statement just made. They rear a brood in a small bird-house and for several weeks incessantly scan the shrubbery and herbage for food. Spiders disappear from beneath porches and other shelter, multitudes of aphids on the nasturtiums melt away, and with tiny beetles, caterpillars, and moths from grass and vines, go to feed a hungry, growing family. When that family is safely on the wing, the wrens may move to another locality, perhaps only to a neighboring yard, perhaps farther, where a less carefully explored territory is open to them. At intervals the adults may return or may linger to rear other broods, until the time arrives for them to make their retreat to the south; but the young usually disappear. This is movement in its 
simplest phase, a matter often of yards, though it may extend to greater distances.

In some forms of bird-life found in tropical regions the succeeding step may be exemplified. Climatic conditions there are quite uniform, divergence from a level mean being found mainly in the amount of precipitation that marks wet and dry seasons. In careful observation over a limited area certain birds may appear extremely rare for the greater part of a year. Suddenly some forest tree will come into flower or fruit, and immediately these same birds flock, at times in abundance, to feed. They remain common for a period and then disappear. These shiftings among tropical forms are little understood. Many ant-thrushes, flycatchers, and other small brush-birds undoubtedly are wholly sedentary from year to year; but many others are certainly erratic in their occurrence. Years ago Dr. C. W. Richmond found the beautiful snow-white cotinga known as the holy-ghost bird of rare occurrence in a certain section of Nicaragua for a period of several months. Later with a slight change in the season it became almost common. The little euphonias, brilliant gems in the group of tanagers, are governed in their wanderings by the ripening seeds of mistletoes, which form their sole food. Hummingbirds appear and disappear with the flowering of vines, trees, or certain epiphytes, their presence being governed wholly by these phenomena. 
The movement is most easily seen on tropical islands, as in the West Indies, where certain large pigeons shift from the uplands to the coastal plain, or cross between neighboring islands. The whitecrowned pigeon flies between Porto Rico, Vieques, and Culebra with the ripening of the beach plum (Chrysobalanus icaco). The squamated pigeon, in the same manner, crosses the stretch of water that separates Desecheo and Mona from the main islands adjacent. Whether the birds come from Porto Rico or Santo Domingo is open to question. Flocks of parrots wander extensively, but usually return to certain quarters to roost each night. Thrushes, as in temperate regions, follow ripening small fruits and berries, and swifts and swallows shift from place to place.

As yet we have only hints of the migratory movements of birds in the heavily forested areas in the Tropics, hints in many instances so indefinite that many have been prone to consider tropical birds as wholly sedentary. To date the bulk of observations in such regions has been made by collectors who remain for short periods at suitable points and then pass on. Data that will lead to full knowledge of the situation may be expected from prolonged studies at some of the jungle laboratories - as, for example, the one at Barro Colorado - established in recent years. 
For further understanding of the problem of the origin of migration let us turn to Australia, where data are available through records furnished by an increasing number of keenly observant naturalists. This island continent, while it does not have the extremes of climate found in the larger land masses of the northern hemisphere, has sufficient extent for a considerable difference between north and south. The winter in the south, though marked by lowered temperature, is not rigorously severe. Some forms of birds are regularly migratory, but many others may be termed only nomadic, as across broad areas their presence depends upon rains. In some sections, during periods of drought extending sometimes over several years, bird life practically disappears. Rains come and turn the country once more green, trees flower, and plants mature their seeds. Flocks of parrots return to regions from which they have long been absent; honey-eaters appear in the eucalyptus; coots swarm in marshes and swamps, and with ducks and other waterfowl proceed to breed and rear their young. Proper conditions may continue for several years, when these birds will remain common. With the shifting of rains to other sections the birds dependent upon them follow, and desert the area that has given them temporary sustenance.

Though this seems mere vagrancy, it is migration 
of a kind, and needs only to become synchronized with seasonal climatic change to assume the usual rhythm of migration with which we are familiar in the northern hemisphere, and which in Australia is pursued regularly by a number of species, notably swallows and cuckoos.

Migration may also be explained, in part, in terms of what has recently been called "Territory in Bird-life." During much of the year birds have no other responsibilities than search for food, with reasonable alertness to avoid death at the claws of predators. They may be social or solitary according to habit, and may wander, or may remain sedentary. Individuals of the same or different species may range in reasonable proximity without undue bickering or quarrelling. With the approach of the breeding season all this changes. Each male seeks an area on his breeding-ground within which later will be constructed his nest, which he guards closely against encroachment. This is his particular and private domain, within which he permits no prolonged intrusion by rival males of his own kind. In the case of such gregarious species as the sooty tern, which nests in tremendous colonies, this bit of territory may be likened to the narrow quarters of the human dweller in city squares, as it is merely sufficient to permit each individual space to stand free from actual physical contact with its neighbors; in the 
tern its extent is governed by the reach of the daggerlike bill that threatens all who crowd within reach. The cardinal, the mocking-bird, the thrush, meadowlark, or vireo, on the other hand, controls a larger area, a tree or a group of trees, or a stretch of thicket or grassland. Intruders of the same species may come near, but may not tarry within the limits of this tract without doing battle with the one who has preëmpted it.

Let us now turn back some hundreds of thousands of years, to a period in the Tertiary near the close of the Pliocene. Geologists inform us that during the Miocene and Pliocene, when the genera to which our modern birds belong were attaining their development, in North America and elsewhere in the northern hemisphere climatic conditions, though perhaps not especially warm, were more or less equable from the Equator to within the boundary of the Arctic Circle. Zonal bands increasing regularly in warmth to the southward were not as strongly indicated as at the present day, and in those epochs there would not have been necessity for regular migration of the birds then in existence, further than a retreat from the far northern regions of extended night, when the sun was south of the Equator, a seasonal shifting with changing food-supply, or change with expanding range among dominant species such as is found in the Tropics to-day, or as is recorded in the continent of Australia. 
In the next geological period, the Pleistocene or Ice Age, huge sheets or glacial ice spread down from the north across the land, advancing and retreating during tens of thousands of years. Periods of glacial invasion were followed for unknown reasons by times of warmth, during which the ice retreated, when forms that we now consider tropical and subtropical were able to flourish in arctic regions. Following these, the ice again came south. The advance of the glacial front was slow, probably almost imperceptible, so that the hand of cold crept slowly over the land. Life, both plant and animal, shivered in the unwonted chill. Some forms, possibly of wide range and adaptability, retreated slightly; others less pliant, unable to change from their accustomed habit and range, perished and disappeared, leaving no record except as their harder portions were entombed and preserved beneath the ice. Congestion in the steadily decreasing land area toward the Equator crowded others, and through an increasing competition brought about further extermination of individuals and species.

Let us look now for a moment at conditions during the first, or Wisconsin, stage when ice extended across Canada and the northern United States as far as New Jersey, Pennsylvania, and Illinois. With the exception of a few islands of land left bare through some freak or accident, ice covered a vast area where 
to-day there are thousands of square miles of forest, prairie, lake, and marsh. Practically all life had been driven from this space, or, in some cases, had been exterminated in it. Species that persisted had been forced in to the open region to the south of the glacial front. Let us suppose now that after a period the ice, through some change in conditions, begins to recede. The shift is slow. Each year there are regressions in which the ice king seeks to hold his own. Gradually, however, new territory is released, to which vegetation slowly spreads, followed by insects and other invertebrates, with which come the birds.

The dominant species, the one that is successful in life, produces in greater abundance than the home areas can maintain. The surplus individuals are crowded away from the centre of production, and so are forced out to other regions where conditions are perhaps a little less to their liking at first, but to which conditions they adapt themselves. These we may suppose, in the Pleistocene and later, crowded up into the spaces to the north following the retreating glaciers. Summer conditions were such that they might breed. As winter approached they found food scarce, and wandered. Their wandering was restricted to three cardinal directions - east, west, and south. If they went north, they perished. To the south conditions were most favorable, so the majority wandered southward. Seasonal change in 
climate continued; and as centuries passed, momentary necessity became habit, and regular lines of migration were established.

Where glacial action has not figured definitely, we may look to other factors, which affect similar ecologic changes, to explain migratory movements among birds. Extension of forest areas, or of plains, or growth of marshes may permit extension among avian species that seize on the new range as territory in which they may breed. After young are reared, they may wander or withdraw - movements which, with the passage of time, become fixed and hereditary.

Such to me seem logical hypotheses, which afford explanation of the wonderful phenomenon of bird migration. It is admitted that they are not fully satisfactory and that there are a number of points that are not definitely covered. Explanation of these cannot now be attempted. We must recognize that Man's actual experience of these happenings, to which we may look for assistance in considering them, is wholly negligible, since the number of years of our recorded study and observation do not represent a dot of perceptible size in the long procession of centuries that have covered the development of these things. 


\section{CHAPTER II}

\section{Nocturnal and Diurnal Migration}

$\mathbf{M}$ IGRATORY flight among birds is performed by day or by night, or occasionally during either, according to the species concerned. As a general rule, the smaller birds migrate by night and the larger ones by day, or by day or night indifferently. Geese and ducks often fly in migrating flocks by day, but also pass in numbers after dark, especially during great rushes of migration when their movement is at its height. The calls of geese are a common sound from the darkened skies above cities, heard most often in autumn, when a sudden change in weather is hastening their departure for the south. In the city of Washington it is not unusual in March to hear the barking calls of swans at night as these great birds pass in their northward travels. Among my vivid memories of residence and observation on the broad marshes at the northern end of Great Salt Lake in Utah are the flights of ducks that passed overhead in the moonlight, or the multitudes, heralded by whistling wings, that came hurtling down before dawn when severe weather in the north started the flight from regions in Canada. 
Loons and cranes migrate regularly by day, as do pelicans, shore-birds, gulls, and hawks. The stirring bugle calls of the sandhill crane herald the approach of flocks before they are actually within view, and continue faintly to reach the ear long after the birds have passed beyond the range of vision. Flights of large hawks in the Middle West, in which hundreds passed in wheeling flocks across the sky, were common sights twenty years ago, but now are rare because of the gradual extermination of these fine birds. Red-tailed, Swainson's, and roughlegged hawks travel regularly in bands through the western region of plains and prairies, and at times the turkey vulture may be seen migrating in considerable flocks. In the Eastern States sharpshinned and Cooper's hawks fly by day, but, though often common, seldom associate in actual bands. Nighthawks regularly, and various blackbirds occasionally, migrate by day.

The majority of small birds, the great hosts that form the bulk of the migrant hordes that come to our attention, travel by night. We wake in the morning to find groves, hedges, and fields filled with a multitude of warblers, flycatchers, and sparrows, which on the following morning, may have largely disappeared. Rails pursue the same secretive method of travel as do cuckoos, migrant species of woodpeckers, Old World warblers, vireos, and a host of 
others. The method followed by swifts and hummingbirds is uncertain, but it is probable that the former usually move by day. The ruby-throated hummer has been seen flying by day from Point Pelee, Ontario, across Lake Erie.

It has been stated that small birds migrate by night to escape the enemies that otherwise might destroy them. Bluebirds, jays, and blackbirds fly regularly by day without fear of attack, as do kingbirds, fork-tailed flycatchers, and waxwings. It is highly probable, however, that small species, as wrens, chats, ground- or thicket-haunting warblers, and the small flycatchers that inhabit thickets or dense woodland, habitually living in concealment, feel safer under the protecting cover of darkness during their prolonged flights above the earth.

The procurement of food is perhaps a much more weighty factor than timidity in regulating flight by night. The stomach of a bird killed during the day invariably contains remains of food, and often is full, unless the bird is sick, or injured, or is in a situation where food may not be obtained. Digestion is very rapid, so that, to ensure a proper replacement of the energy expended by the bird during its rapid and sprightly movements, it is necessary that food be secured at comparatively short intervals. In studies of the food of starlings Kalmbach and Gabrielson found that stomachs of a considerable 
number taken between eight and ten in the evening, when the birds had been at roost for three to five hours, were almost entirely empty. Stomachs of birds killed by striking obstructions during night flight are nearly always empty, from which fact at times has come the belief that the wanderers had died of starvation. It appears, therefore, that digestion empties the stomach completely when food is not taken at short intervals. If tiny migrant wayfarers flew by day across the great stretches of land and sea that they must necessarily compass in their migrations, they would arrive at nightfall, tired, perhaps almost exhausted, at some destination where they would be unable to procure food until the following morning, as they are diurnal in habit. Such circumstance might lead to unnecessary exhaustion of their powers and so delay their further flights. Or might, if coincident with unusual cold, or exposure to heavy rains or snows, prove fatal, as in a condition of reduced vigor sufficient bodily heat and vital energy might not be available to enable them to weather the unseasonable condition. On the other hand, where migrational flights are pursued by night, when the travellers pause at daybreak, they may rest for a brief space and then may begin a search for food. The entire day may be occupied alternately in feeding and resting, and the travellers may so recuperate that, if it is desired, further flight may be begun at nightfall. 
Swallows, swifts, and nighthawks feed as they travel. Hawks and vultures are so large and robust that fasting for a day or so is no hardship. Ducks feed regularly by night, especially when there is moonlight, and so are not hampered by the time of day of their arrival. Such birds as shore-birds and gulls must be able to endure without food, or must curtail their journey when sustenance is required. We must suppose that the same is true of migrants among strictly nocturnal species like the goatsuckers, of which our whippoorwill and chuckwillswidow, and the nightjars of the Old World, are familiar examples.

Though among most small birds extensive flights are made at night, the close observer soon becomes aware of migration movement among them by day, particularly during the period from the height to near the close of migration. Flocks of warblers, feeding seemingly without particular objective through the tops of the trees, often pursue a regular course in their search for food. Flights are made in the direction in which the change of season is leading them. At times they travel hurriedly and must cover an appreciable amount of territory during the day. These movements may be noted with especial ease at points where there are well-marked migration routes. At Point Pelee on Lake Erie, in the autumn, Swales and Taverner have noted regular 
passage along the sides of the point, which finally terminated in many cases in a flight directly out across the open lake. I have observed this same action on islands in the West Indies where there were established lines of flight, or in continental river valleys that were regular routes of travel for many birds.

Under proper conditions observations on nocturnal flights may be made without particular difficulty. The sight of birds crossing the face of the larger heavenly bodies has undoubtedly been familiar to astronomers since the days of Galileo and the first telescopes, but seems to have come to the notice of zoölogists only in recent years. Tennant, while studying the face of the sun at Roorkee in I875, noted what he thought were kites soaring at a great height. ${ }^{I}$ W. E. D. Scott, during casual inspection in an observatory at Princeton in October, I880, saw a considerable number of birds cross the moon and was able even to identify a few of them. Additional notes were secured by Scott and J. A. Allen in the spring of I88I, and by F. M. Chapman in September, 1887, while observations were made in greater detail by O. G. Libby in $1898,{ }^{2}$ at Washburn Observatory in the City of Madison, Wisconsin. This author gives a record at considerable length of studies made during the height of the autumn migra-

I Stray Feathers, iii, 1875, p. 419. = Auk, 1899, pp. 140-146. 
tion in September, and estimates that birds passed the point of observation at the rate of approximately 9,000 per hour - an indication of the enormous extent of the nocturnal movement.

Similar observations may be made by anyone at the proper season by means of small telescopes or powerful binoculars, though in my own experience as a boy I found such instruments somewhat unsatisfactory, as the field of vision was so small that the moving dots representing birds crossed the illuminated area and disappeared with great rapidity. It is possible to identify an occasional individual among the birds that are detected; but efforts made to estimate the height at which the birds are travelling seem to me to yield highly uncertain results, as there is no simple, definite method of determining the actual distance between passing birds and the point of observation in the brief space in which they are on view.

Records of nocturnal flight are made easily by the ear, as many birds call during these flights by night. During the rush at the height of migration these notes, coming constantly from the darkness, produce a profound effect upon the imagination. Calls come from near and far, some of them easily recognized, and some so distant or so mingled with others that they are indistinct. At times there may be a medley in which half a dozen species may join, or 
again a band of some particular form may pass with their cries coming from all points of the air, to the exclusion of others. The impression given at times is so vivid that instinctively one strains the eyes against the darkness in a vain attempt to pick out the migrants whose vibrant calls come from so near at hand that the birds seem almost within reach.

Though migration flights at times are recorded at lighthouses, and by means of call notes, steadily all night long, usually the bulk of birds pass during the earlier hours of the night and toward day-break in the morning. From eight to twelve in the evening seems to be the favorite period for nocturnal flight, though on a number of occasions particularly in autumn, I have noticed heavy migration between four and six in the morning.

\section{Altitudes at which Migrating Birds Travel}

Actual evidence of the heights above the earth sought by birds during their migrations is scanty, and only since the development of the airplane have definite altitudinal observations become available. Early records have been based largely on inference, or on calculations into which entered a wide margin of estimate.

The older observers, holding firmly that most normal migration took place at heights above I 5,000 feet, attempted as a rule to justify their faith in these 
statements by a somewhat uncertain belief that flying became easier as altitude was gained, and increased in difficulty as the earth was neared. Experience of aviators, however, is directly opposed to this theory, as it is found that with greater altitude there is increasing difficulty in maintaining height and speed. Though part of this difficulty may be due to the changing mixture offered for combustion in the motor, more of it unquestionably comes from the difference in buoyancy as the air becomes more and more rarefied. Birds are not afflicted with the engine troubles that beset humans who invade the air, but must nevertheless feel keenly the lack of buoyancy of the upper reaches. Though less effective in the case of broad-winged hawks, vultures, pelicans, and cranes, whose great pinions afford a large supporting surface compared to the weight of the body, we must believe that the difference indicated would operate more heavily in smaller migrants, who are under necessity of keeping their smaller, shorter wings in constant rapid motion to hold a proper altitude even when flying near the earth.

Observations on the altitudes at which birds fly have been summarized recently by Colonel $\mathrm{R}$. Meinertzhagen, ${ }^{\mathrm{I}}$ who gives a considerable number of records based on the experiences of airpilots. His

I Ibis, 1920, pp. 920-936. 
findings, in brief, are that it is exceptional in flying to meet with birds above an altitude of 5,000 feet, and that the bulk of migration is performed below a height of 3,000 feet from the earth. Though most of the observations that he cites were made during the day, he holds with reason that there is no evident cause for considering that nocturnal migrants pass at a higher plane than those observed by day. Since the observations that he cites were made by pilots who, during several years of war, had the air across broad areas in the Palaearctic region under constant close surveillance, we must accept them as conclusive. In several hundred records by airplane it appears that there were only 32 observations of birds above 5,000 feet, and only seven above 8,000 feet. Meinertzhagen considers that ordinarily birds prefer to descend below cloud level, though this is not universally true. On nights of fog or rain birds pass very near the earth, and it is then that we may obtain some idea of the vast hordes of migrants that fill the air, as their notes and calls come drifting down from the sky.

Day migrants among shore-birds may pass at considerable altitudes, as it is common experience in shooting, particularly in arid regions where suitable feeding grounds are widely separated, to have yellowlegs or black-bellied plover come swiftly down to the decoys from heights at which the eye 
did not perceive them. Aviators have recorded such birds at I0,000 and I2,000 feet. Pelicans, cranes, ducks, and geese often pass at 3,000 to 8,000 feet in travelling from one feeding ground to another, and when crossing mountain chains may fly at enormous heights. Donald notes that in the Himalayas, at I 4,000 feet above sea-level, he observed storks and cranes flying to the northeast at the end of May, when they were so high that they could be seen only through glasses. Meinertzhagen considers that, if these birds were beyond unaided vision, they must have been at least 6,000 feet above the earth, placing them at an actual altitude of 20,000 feet above the mean level of the sea.

Captain C. Ingram ${ }^{\mathrm{I}}$ has assembled other observations by aviators, and has obtained results fully in agreement with those given above. It is of interest to examine the greatest altitudinal records that he gives. Lapwings and ducks were noted up to 8,500 feet, though rarely seen above 6,000 feet. Geese were seen at 9,000 feet, and sandpipers of unknown species at 10,000 and I2,000 feet, above the battlefront in France. Small birds with undulating flight were recorded once at 10,000 feet. These, however, were such unusual occurrences that the aviators making the records took special note of them. Dr. A. F. R. Wollaston, when on the Mount Everest

I Ibis, I9I9, pp. 32I-325. 
Expedition in I92I, recorded a lammergeier at 24,000 or 25,000 feet, and distinguished passing godwits and curlews at 20,000 feet. ${ }^{\mathrm{x}}$ In this instance, however, the birds were flying above elevated land masses, and were forced upward to cross the mountains. Finally, it is recorded that an observer making photographic observations of the sun at Dehra Dun in India obtained a photograph of geese which, it was estimated, were flying at an altitude of 29,000 feet. $^{2}$

The observations above are given to illustrate extremes, and to indicate that birds may occasionally fly at great heights. That there is no apparent advantage in altitude is indicated by the fact that comparatively few attempt it.

I have observed autumn flights of sandpipers crossing the Gulf of Alaska, south of Kodiak Island and the Kenai Peninsula, at heights of not more than 500 feet above the sea, with many at only a few yards above the waves. In fact, a Peale's falcon remained with our ship for a day, perching on a masthead and flying out at intervals to seize some poor sandpiper that came swinging up to examine our vessel. Other observations certify to these results, since where migrants are heard calling at night, if directly overhead, many are within easy range

\footnotetext{
${ }^{1}$ Country Life, March 25, 1922, p. 419.

2 The Field, Dec. 18, 1920, p. 8;6.
} 
of the ear. Some in fact seem barely above the trees. Where small birds have been seen flying by day, as at Point Pelee, Ontario, they are usually at very moderate heights, and numerous recorders of migrants crossing stretches of open water note them frequently as passing barely above the waves. Records from lighthouses also indicate birds flying at comparatively low levels, as do notes made on diurnal movements among small birds at islands. Eagle Clarke, in observations at the Kentish Knock lightship, in the North Sea off the mouth of the River Thames, noted small birds of various sorts passing barely above the crests of the waves - a sort of flight that prevailed even when there was fog or mist, when it would have seemed advantageous to attempt to rise to an altitude where the air was clear.

Weather conditions must affect the heights at which birds travel, as on clear warm days, when warmed air is rising from broad areas, - such days for example as birds of powerful flight use in soaring, - it would be easy to fly at high altitudes, while in periods when the atmosphere is dead and lifeless, high flight would be more difficult. Since rising air currents ordinarily prevail only during the day, and slacken or disappear by night, we may see in this an indication that birds do not travel at excessive altitudes after nightfall. 
Ingram ${ }^{\mathrm{I}}$ has noted that normally the velocity of the wind increases as one rises above the earth, so that it may be doubled in strength at 1,500 feet. Beyond this the amount of increase is lessened. In his experience (apparently mainly in France) an east wind attained its maximum strength at 3,000 feet, while winds from other quarters of the compass may increase up to 30,000 feet. In ascending, the directions of the winds also vary, so that they may be reversed within a few hundred feet of altitude. Both of the factors mentioned are of great importance in considering bird migration.

We may conclude from the evidence that has been presented that the bulk of migration passes below 3,000 feet, and that as a rule only birds of strong flight travel at greater heights unless weather conditions may, for brief periods, favor greater altitudes.

\section{Weather and Migration}

Cooke has well observed that weather conditions have little to do with the migrations of birds, except to permit them to travel or to hold them back, as the case may be. Parula warblers or redstarts wintering in the West Indies, or Old World warblers or wagtails spending the cold season in central Africa, notice no difference in temperature or climatic conditions between November and April, yet in the

$$
\text { I Ibis, I9I9, p. } 323 \text {. }
$$


latter month they regularly move north toward the summer home. Though we may theorize as to the actual origin of migration, the annual movements of migratory birds are now a part of the life-cycle of the individual, and as such occur at the regularly appointed time, actuated by physiological conditions. The spring migration especially has its inception and course distinctly connected with the necessity for reproduction. Food is as abundant in the winter home in spring as through the winter months, so there is no necessity for movement to search for it. Winter is a resting period, during which the bird has no cares save to avoid enemies and search for food. With the approach of spring the reproductive impulse awakens, and the individual is irresistibly driven to initiate a journey that ends in its summer home.

Weather makes only this difference, that the lifecycle has been so adjusted, and the migrations so synchronized, that they agree with major phenomena of weather and climate through the year. Some species find that cold means little to them, so that their northern limit in winter is in regions where the climate is severe. This is true with juncos and tree sparrows, and a number of other birds in the United States, and with many small birds in northern Europe and Asia. Certain waterbirds are hardy and are restricted in winter range only by the line of 
ice. Thousands of canvasbacks, bluebills, and other ducks remain on the Potomac River in winter, even though a large part of the channel is frozen. Mallards and pintails in the Missouri River drainage move north and south regularly during winter with fluctuation in the southern limit of ice, and in spring press northward with every thaw, retreating again if need arise because of freezing weather.

Birds that are not accustomed to cold respond variously to it, some seeming wholly indifferent so long as food is available, unless subjected to undue exposure. This is true even in certain tropical species that normally never encounter cold, as when transported to another climate some do not seem particularly affected. The red blue and yellow macaw (Ara macao), native in tropical America, has lived in outdoor flight cages in the National Zoölogical Park at Washington during severe winters. During the winter of $1924^{-25}$ a great white heron from southern Florida was kept in an outdoor cage, sheltered from northerly and westerly winds but without artificial heat, and seemed as oblivious of cold as a great blue heron that lived as its neighbor. Even the snowy heron and American egret in a wild state are not so sensitive to cold as we usually imagine, since I have seen the former flying in snowstorms in Utah, and the latter penetrates regularly to Patagonia, where the summers are anything but warm. 
Other species, however, have no reaction against cold. The blue and yellow macaw (Ara ararauna) cannot withstand a fall in temperature, and I have a captive blue-headed parrot (Pionus menstruus) from Bolivia, that is sensitive to a degree, and complains of the slightest degree of cold.

Wind is as much a deterrent to migration as rain or snow, as head winds greatly increase the labor of flight and, if at all strong, cut down the speed at which migrants are able to travel. Similarly, strong winds blowing in the direction in which the birds are travelling are equally bad, since they interfere seriously with balance, and disarrange feathers, thus hindering flight. Moderate cross, quartering, or light winds from other directions, seem to offer the best air-movement conditions.

Cooke has indicated that migration among birds is so adjusted to mean weather conditions that each species moves north in spring at a time when the average weather encountered is not unsupportable. Hardy forms move early, unafraid to brave the blasts of retreating winter. More delicate ones come later, when there is less danger of encountering prolonged cold spells. Occasionally, as in the Canada goose, it is found that the advance in migration coincides with advance of certain isothermal lines. The goose keeps closely abreast of the line of 35 degrees average temperature, and moves north as 
this line advances. The majority of species allow spring to forge ahead, and then, travelling rapidly, overtake it, or, in some cases, outstrip it. Hardy forms among our smaller birds press northward with the first indication of spring, so that robins appear as soon as the ground is bare, and blackbirds when the marshes open. Recurrent cold means a certain amount of hardship, but has no other effect unless too prolonged. Delicate species, of necessity, advance more slowly, as they must wait until spring weather is settled.

The northward flight of migrants in general is initiated when wind and temperature are favorable. If a sudden storm arises, the weaker migrants, if over land, must descend to await better conditions. If over water, they may be lost. Storms coming late in spring often overtake the height of the small-bird migration, and may entail much suffering, destitution, and loss of life. Yet such conditions are so regularly met that most species pass through them with discomfort but without particular danger, except when they are unwontedly severe. On many occasions snows during the first week in May greet warblers and flycatchers in the northern states, and for a day or two these small creatures may be seen hopping about in unusual situations where there may be a chance for food or shelter. Though many may perish, usually the weather moderates before 
there is great mortality. Such storms are more dangerous in their effect on food-supply than in the cold that they bring, as most species of birds can endure cold if they are properly fed.

With some species the return southward in autumn comes long before there is any cold. Yellow warblers, Baltimore orioles, kingbirds, the European cuckoo, and many shore-birds, in both eastern and western hemispheres, crowd south before the close of summer, when there is no meteorological change to warrant it. Others linger until cold nights and frosts warn of approaching extremes, and then move south rapidly. Some linger until cold storms actually strike their northern ranges.

Movement among these later migrants is noticed especially in areas immediately south of the belt where cold winters are prevalent. In southeastern Kansas, at the northern edge of the Austro-riparian life-zone, during November and December new arrivals among migrant sparrows, thrushes, and blackbirds are noted with every storm reported in the north, indicating that many birds linger in the north to the last possible moment. Similarly, freezing weather far north is frequently responsible for great flights of ducks or of Wilson's snipe to southern areas, where the birds arrive in abundance before the press of severe conditions in regions to the northward. 


\section{Speed of Flight in Birds}

The speed that birds regularly make in flight, a subject of considerable speculation and theory in the past, but one concerning which there has been little definite information available until recent years, is a matter of pertinent inquiry when considering migration.

Early observers had few definite data at hand regarding speed, but were conservative in their estimates. Gätke, however, in his studies on Heligoland, became obsessed with the idea that most birds performed the greater part of their migration flight in a single night, and with this as a basis, deduced extraordinary rates of travel, which, unfortunately, have been widely quoted and copied. Through ingenious but misleading estimates he rates the migratory flight of the northern blue-throat, a thrush smaller than the American hermit thrush, at I 80 to 240 miles per hour, the hooded crow at 108 miles, the golden plover at 2I 2 miles, and plovers, curlews, and godwits in general at about 4 miles per minute, or 240 miles per hour! These tremendous speeds he believed possible through flight at great altitudes, up to 40,000 feet above the earth, where he supposed that the rarefied air offered less resistance! His statements are exceeded by a correspondent of "The Field" who considers that the "cave-swallow" of 
Ceylon (probably a species of swift) is the fastestflying bird since he states that the noise made by flocks of these birds may be heard as they pass, but that the birds themselves move so rapidly that they

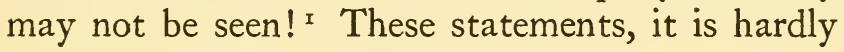
necessary to say, are wholly erroneous.

During the past ten years reliable data on the subject of flight have accumulated slowly. In I9I6 I published records secured by timing the flight of a number of birds by means of the speedometer of an automobile, and in such diverse forms as herons, hawks, horned larks, ravens, and shrikes found the rate to vary from 22 to 28 miles per hour. Flight in all these cases was normal and unhurried. Records of another observer, H. B. Wood, ${ }^{2}$ show speeds of only io to I7 miles per hour for Arkansas kingbirds and scissor-tailed flycatchers. Hugh Gladstone cites other records ${ }^{3}$ in which it was found that the willowwarbler travelled at $23 \frac{1}{2}$ miles per hour, the pied wagtail at 25, the European blackbird over 22, missel thrush 23, and the cuckoo 23 miles per hour.

Passing over scattered notes that verify the figures just cited we come to a far more comprehensive study by Col. R. Meinertzhagen in the "Ibis" p. I 89 .

I Quoted by Gladstone, Record Bags and Shooting Records (1922),

2 Bird-Lore, I923, p. I2I.

3 Record Bags and Shooting Records (1922), p. I85. 
for I92I (pages 228-238), based on observations by means of theodolites designed to estimate the speed of airplanes at anti-aircraft stations, by stop watches along measured courses, and by readings from travelling airplanes. From these notes the following records of speed in flight may be cited.

Miles per hour

Members of the crow family (Corvidae)......... 31 to 45

Smaller perching birds (as larks, pipits, buntings). 20 to 37

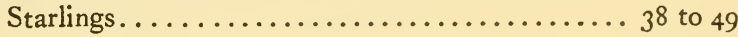

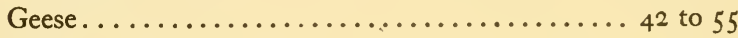

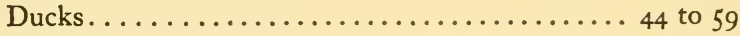

Falcons........................... 40 to 48

Sand Grouse.................... 43 to 47

The greatest speed recorded definitely was that of swifts (apparently the common swift of Eurasia) recorded from an airplane in Mesopotamia. These passed the observing plane and circled about it easily when it was travelling at 68 miles per hour. This and other observations seem to give approximately 70 miles per hour as the normal rate at which some swifts feed and travel, a speed that can be accelerated to fully too miles per hour for pleasure, or in case necessity arises to escape from danger. E. C. Stuart-Baker ${ }^{\mathrm{I}}$ in India timed two species of swifts (Chaetura nudipes and $C$. cochinchinensis) with stop watches over a two-mile course and found that they were able to cover this distance in from 36

I British Birds, xvi, 1922, p. 31. 
to 42 seconds, or at the rate of I 7 I. 4 to 200 miles per hour. These figures may offer some solace to those who, like myself, have expended considerable ammunition in collecting specimens of the whitethroated and other swifts as they circled in the wind over high ridges or mountain headlands.

Most birds when frightened are capable of increasing their speed above the figures indicated, to enable them to escape momentary perils, - perhaps for short distances to double the normal rates, - but cannot long maintain such exaggerated efforts. It is certain that migrations are performed at the usual rate of normal flight, as by pursuing this steady course birds conserve their strength and avoid the fatigue and exhaustion that undue speed would entail. Eagle Clarke has recorded that migrants passing lightships flew without hurry or strain to attain speed, though their flight was attended by businesslike method, without delay.

If we consider ten hours as a fair stretch of flight over land, the speeds cited would carry crows 3 IO to 450 miles in a ten-hour day, the smaller birds from 200 to 370 miles, ducks from 440 to 590 miles, and geese from 420 to 550 miles - considerable distances when direct airlines are considered, that would cover the ordinary migration route from Canada or the northern states south to the Gulf Coast, Central America, the West Indies, or even 
northern South America, in a relatively short time. It is highly probable that most migrations are performed in a leisurely manner, and that after a flight of a few hours, the bird pauses to feed and rest for one or several days if it finds itself in congenial surroundings.

\section{The Sense of Direction in Birds}

No less wonderful than the fact of migration itself is the regularity and system with which birds pursue journeys that in many cases cover thousands of miles across the earth's surface. Let us consider for a moment the instance of a white-throated sparrow (no. 38r60), banded by Mr. S. P. Baldwin on an estate near Thomasville, Georgia, on March 5, I9I6. As the white-throat nests in the northern portion of eastern North America, from Massachusetts, New York, Michigan, Minnesota, and northeastern Wyoming, north to Great Bear Lake and Labrador, this individual was in its winter range when captured in Georgia. Subsequently this identical bird, identified by its numbered band, was trapped on March 7 and 19, I9I7, on several occasions from February 25 to March 22, I920, and on March 27, I92I, in each case within one hundred yards of the spot where it was first secured. Since this was its winter home, we must assume that on each of the years from IgI6 to I92I this bird had migrated 
north to breed, and had subsequently returned to spend the winter in one particular area of thicket, brush-pile, and open glade in southern Georgia. Such precision of movement impresses one as truly remarkable.

The regularity with which birds move, appear, and disappear during migration has naturally occasioned much comment, and has resulted in various theories that attempt to explain it. Thus a peculiar magnetic sense whereby birds are attracted by the magnetic pole; a special nasal sense that enables identification of air-currents and other phenomena; the direction of regular winds; the angle or direction of the sun, and of light rays; a reflex attraction, masked by one author under the caption of tropism; memory of routes once traversed; telepathy; direct perception of the point toward which the journey is directed; and hereditary memory of the route to be traversed, all have been put forward as hypotheses to explain the facility with which birds reach distant points. All have had their champions, and with all this divergence of opinion, it must be admitted that the matter is as yet far from definitely settled.

Mr. A. H. Clark ${ }^{x}$ has presented a clear statement of what he considers to be the method of pathfinding employed by the golden plover in its journey south to South America. This he attributes to a course

$$
\text { I } A u k, \text { I } 905, \mathrm{pp} . \mathrm{I} 34^{-\mathrm{I}} 40 .
$$


laid in accordance with prevailing winds, as he considers, from observations made in the West Indies, that the birds tend to travel across the wind, which thus shapes their line of direction. On this basis he considers that, on leaving the coast from Labrador south to Nova Scotia, the birds travel southeast across prevailing southwesterly winds. This would change to a southwest course when the northeast trades were encountered at a point east of the Bahamas, and so carry the birds to the northern coast of South America.

Some have considered that birds are sufficiently observant to be able to guide a course by the sun by day, or by the moon and the stars by night, a proposition with certain merits, that has been set forth recently by Mr. William Brewster in his posthumous work on the Birds of the Lake Umbagog region of Maine. ${ }^{\mathrm{I}}$ Mr. Brewster considers it possible that birds make note of the heavenly bodies and direct their courses accordingly. This may be wholly probable in some instances, but fails as a final, complete explanation when we consider the regular flights that are carried on during cloudy or rainy weather, when the sun or the stars are obscured, or the apparently marvellous way in which some species travel without hesitation through dense fogs. Though many become lost at such times, particu-

I Bull. Mus. Comp. Zoöl. (June, 1924), lxvi, 32, 33. 
larly where puzzled by lights, others move without difficulty. Mr. Brewster cites the ease with which common terns return to their nesting-ground on Muskegat Island through the densest fog, and such phenomena are of common occurrence with the auklets and murres of Alaskan waters, as these birds drive directly for their island rookeries, without any apparent hesitation, through the thickest weather imaginable. In fact, the courses that they take are often serviceable to sailors bewildered by fogs as they indicate the direction of land.

As a basis for consideration of the problem of how birds find their way, it will be profitable first to consider the case of the homing pigeon, and the little that is definitely known of the method of its homing activity aside from the fact that it is capable of returning to its cote without great loss of time from distances up to 1,000 miles. Those interested in the sport of racing pigeons recognize individual ability among their birds, and develop strains rated high for the number of birds produced that are able to compete successfully in distance flights. Birds that are to be used in races each year are put through a regular course of training that involves flights, first of a few miles, and then others of increasingly greater distance. One fancier thus regularly flew his birds over courses of 9, 18,33, 45 and 66 miles, after which the distance was increased to $100,200,400$, 
600 , and finally, in some instances, to r,000 miles, all in more or less the same direction. The percentage of returns and the short periods required for the journey in case of some of the longer flights are truly marvellous.

Two factors seem to enter, first, some peculiar attribute that for lack of a better name we may term a sense of direction, which drives the flier on the proper course, and, second, a memory of place that enables the pigeon to recognize landmarks in the vicinity of its home when it has arrived.

It must be admitted that, though recognition of landmarks that guide the bird on its journey are of assistance in travelling air-lanes crossed on previous occasions, this cannot wholly explain the ability that enables a bird successfully to drive across unfamiliar areas a hundred, or several hundred, miles in extent. In most instances there can be no dependence upon sight recognition of distant landmarks, as many experiments, in fact the main ones that have been reported in this country, have been carried out in regions of low relief, where landmarks would not be visible beyond 25 to 50 miles even from a point a thousand feet or more above the earth. Furthermore, experiment has shown that in good strains of homing pigeons it is possible for a fair proportion of young birds to return to their homes from a distance of I 5 to 20 miles, when they have not had the ad- 
vantage of special training for racing, and even where their previous flights have been limited to short distances. A faculty of perceptive orientation, in which the bird makes conscious or unconscious note of the direction travelled, may however figure, as in experiments by Hodge some years ago, pigeons carried in an open cage to a point some distance from their cote started for home without great delay, while others whose cage during transit was covered closely by a black shawl seemed bewildered for a time.

The case of the migratory small bird is the more complex since it performs much of its migratory flight at night, indifferently in the light or dark of the moon, at times under weather conditions when landmarks cannot be visible for any considerable distance. Also many of these flights carry the voyagers across broad stretches of open sea where there are no lines of guidance of any description, if we except certain steady winds that prevail in some latitudes, or the possibility of following the lines of ocean currents.

Some have considered that birds that have previously made the southward journey serve as guides for the young and inexperienced, which may be true in a few cases but cannot be accepted as the full and final explanation, since frequently old and young birds migrate at different times. Adult cuckoos are 
said to leave England several weeks before the young essay migratory flight. The young cowbird of the United States, reared by a foster-parent, flocks with other young of its kind when grown, and in many instances can hardly have adult guidance in migration. Nor can we fall back upon guidance through leadership of experienced birds of other species, since all birds do not follow the same route. It is difficult to explain under the guise of leadership the difference in line of flight between the Baird's sparrow, which passes to the southwest from the prairies of Dakota, and the Leconte's and Nelson's sparrows, which fly directly south or southeast from the same point. Under these circumstances one must think that under leadership of other forms there would be constant sad confusion among young birds, which does not happen.

The movements of many seabirds are still more in point. Two species of albatross, the wedge-tailed shearwater, and the white-breasted petrel, nest on certain islands in the Hawaiian Bird Reservation. During part of the year these birds travel to distant points on the open sea, yet return to the same low sand islands each year to nest. The reflection of the green water inside the coral reefs, thrown on the sky, perceptible to those accustomed to it when the atolls are below the line of vision, might explain the return to islands within 20 or 30 miles, but will not 
serve as an explanation of the instinct that guides these birds in their return to the general region from a distance of hundreds of miles.

Still more remarkable is the case of the Mother Carey's chicken, and other petrels and shearwaters that nest near or in Antarctic regions, and after the breeding season spread northward until they cross the Equator. As these birds may spend most of the resting cycle between periods of reproduction out of sight of land, no one can allege that any recognition of a route once traversed guides them on their return to their nesting grounds.

Penguins, birds with wings developed as paddles that have entirely lost the power of flight, nest on various islands, mainly in Antarctic regions. Some species at least perform wandering migrations which carry them for considerable distances across open seas during seasons when they are not breeding. As the birds have not been thoroughly studied these movements are not well understood, so that much remains to be learned of the distances that they wander. It is known that the Magellanic penguin, which breeds on islands in the Straits of Magellan and elsewhere in the south, comes north regularly in winter to the coasts of the Province of Buenos Aires and eastern Uruguay, and even to Rio Grande do Sul in Southern Brazil. I have seen dead bodies of many which had perished from some cause, cast on 
the beach at La Paloma in eastern Uruguay. The regress of these wandering individuals to their proper breeding ground can hardly be attributed to any use of landmarks, since they swim at sea. Yet they return regularly to their homes. At the Falkland Islands penguins, though present throughout the year, come in abundance for the breeding season. The return of these voyagers seems wholly mysterious unless we assume that they have some instinct of direction to guide them.

As further instances of the homing habit we may cite the case of the frigate-bird, which in the Tuamotu, Gilbert, and Marshall Islands, and probably elsewhere in the tropical Pacific, has been utilized by natives as a carrier of messages between islands far distant from one another as regularly as pigeons were utilized for a similar purpose in the Middle Ages, in Persia, Serbia, and Egypt. In fact, the frigate-bird may be termed the carrier pigeon of the Pacific. The great birds are reared from the nest, tamed, and accustomed to certain perches. Carried to other islands, they are released with messages which in a few hours they carry to their proper home. Mr. W. G. Anderson of Honolulu, tells me that formerly he tamed frigate-birds on Fanning Island near the Equator, and that when he crossed to Washington Island, eighty miles distant, he regularly took one of these birds and released it on his arrival with a mes- 
sage which it carried to his family on Fanning, out of sight below the horizon.

Certain experiments in the homing instinct made by Dr. J. B. Watson on noddy and sooty terns at the Dry Tortugas Islands, off the southwest coast of Florida, are highly pertinent in this connection. It may be noted by way of introduction that these two terns are tropical species that here occupy their most northern breeding point in these seas. They come to these islands from the south, and are not known to wander any appreciable distance beyond them to the north.

In one case twelve sooty and twelve noddy terns captured on the Tortugas, and marked to enable subsequent identification, were conveyed on a ship en route to Galveston, and released at distances varying from 400 to 800 miles from their nesting colony. Thirteen of these birds returned to their nests on the Tortugas, three of them from the greatest distance mentioned. These experiments differ from the observations given for homing pigeons, and it is concluded that these two species of terns may return from a distance of $\mathrm{I}, 000$ miles to their nesting site, over an open sea that is supposed to be wholly unfamiliar to them. Watson is unwilling to hazard a statement as to the actual cause of this homing ability, but it may appear that it comes from what may be termed a sense of direction. It is significant 
that, though these birds were kept below decks, where they had no opportunity to orient themselves, on release they started flight to the east, in the proper direction to carry them toward their home.

If we are willing to attribute a sense of direction to some mammals, including man in certain instances, I see no reason why we should deny its development in a high degree in migratory birds. Most of us are familiar with incidents of homing in domestic cats and dogs, and may apply the same principle to birds. Certainly an instinct for direction should excite no more astonishment than the instinct for nest-building or the care and rearing of young, found among all birds, or the ability to swim and dive inherent in young grebes, ducks, and sandpipers, when they have burst the shell and are strong enough to move. A young great blue heron that I reared from a tiny chick grew up in a laboratory and its vicinity wholly removed from the influence of others of its species. The fact that, when nearly grown, it evinced an instinctive interest in fish, and for hours at a time remained motionless watching the movements of chubs swimming below a bridge, seems more remarkable to me than the fact that it ultimately left me and wandered as do other herons in autumn. The entire problem of orientation is one that may be cleared eventually by experiment, but up to date has no lucid explanation. 


\section{CHAPTER III}

\section{Regularity of Migration}

7 HE regularity of travel when birds are on mi-

1 gration constitutes one of the most interesting facts in connection with this phenomenon and is one familiar to all ornithologists. Through years of observation average dates of spring arrival and autumn departure have been established for many localities, and birds come and go with surprising regularity on their appointed dates. Arrival in spring is particularly punctual with the majority, and unusual is the season when the first of the travellers fail to put in their appearance within a few days of the average date. Observations on dates of migration over a considerable period of years are now available for the United States and Canada, and similar data have been recorded abundantly for western Europe. At Washington, D. C., the barn swallow, on the average, arrives April I2, the least flycatcher May 2, the chipping sparrow March 22, and the house wren April 18. On or near these dates one is always sure to find them. Individuals which breed about our homes, which arrive often with the bulk of the flight following a few days after the earliest arrivals, come 
with particular promptness on their appointed days. Severe indeed is the weather that delays them for any length of time.

Departure for the south in autumn is prompt, but has greater range of variation, particularly in middle latitudes, as prolonged mild weather may induce birds to remain beyond their custom. Many late fall records are based on individuals that have been injured, have not moulted properly, or for other similar reason have delayed their departure. Many of these are unable to migrate, and may linger along until winter, or may possibly endure through the cold weather. Ducks with broken wings, or other injuries from the hunting season, often winter where they can find open water, and instances of winter occurrence of unusual birds are frequently recorded. Catbirds, gnatcatchers, and tanagers have all been found in the north in midwinter, and in December, when the ground was covered with snow, the Cape May warbler has come to the window-sills of the National Museum. The red-headed woodpecker is a bird that may or may not retire southward, apparently more or less through whim. When it remains to winter in the north, it does so when acorns are abundant; on other years, when mast is equally available, it retires southward.

As a general rule, among small birds the seedeaters compose the early migrants in spring as they 
may subsist on seeds from the previous season. Insect-feeders of necessity come later, when the weather has moderated to permit the development of plant growth that may shelter and feed insects. In autumn the process is reversed, as the insectfeeders leave for the south early and others linger. The phoebe is one insect-eater that arrives early in spring, but usually its arrival comes shortly after swarms of hardy stone-flies begin to emerge from the larval state in which they have lived through the winter beneath waters of streams, and fly about, or gather on shrubs, trees, and stones near the water, where they furnish a food-supply. Some other birds, as the myrtle warbler, may turn to a vegetarian diet of dried berries, and so eke out the insect food that they take in summer. A few, as the brown creeper and golden-crowned kinglet, have specialized methods of search for spiders and insects in a state of hibernation. The Carolina wren is a strictly resident form that feeds mainly on animal matter, which it secures in winter by search under fallen leaves and other vegetation, and in crevices about logs, sticks and stones. Cold seems to have little effect upon it; but when heavy snows come and remain for several weeks, these wrens are in hard straits and many are killed. Those that survive may be seen searching the eaves of buildings, curls of birch bark, or drift left by heavy floods in the limbs 
of trees, for what food they may find. Near the northern limit of their range deep snows periodically reduce them almost to extinction, yet they do not attempt a southward flight to escape.

Abundance of birds during migration is also a point of considerable interest. Observers record two distinct stages in the movements of migratory birds on their return north in spring, the date of first arrival, when possibly a single individual may be seen in some particularly favored haunt, and the date when the species becomes common, which represents a period when seasonal conditions become generally favorable. Some birds arrive in numbers when first noted, but usually the date of bulk arrival is deferred for a few days or a week, or, rarely, for as long as a month after the first have been seen. With birds that do not nest at the point of observation the period of bulk arrival is followed by a time during which the species is seen regularly; and then suddenly the majority disappear and only stragglers may be found until finally the last of these are gone. Counting early and late stragglers, the migration thus may extend over a period of two, or even three months, but its main part is usually crowded within ten to twenty days at the time when conditions are most favorable. The length of time of possible occurrence, of course, decreases steadily in species of late average arrival. 
In general in spring migration there are two main periods of abundance in the central portions of the United States, the first of which is in early spring as soon as snow leaves the ground. Crowds of hardy migrants arrive, and hordes of species uncommon in winter pass from more southern regions. In inland areas the period is one of abundance for finches and sparrows. As spring opens in full, and the weather moderates at more northern points, the crest of this early wave passes, leaving summer residents to seek their breeding grounds and later arrivals to straggle through. The first week or two of April often represents a slack period, when bird-life seems scant after the previous abundance, though arrivals of new species are noted constantly. These later migrants increase steadily until about the middle of May, when the great seasonal rush of the year is noted, with the passing of warblers, flycatchers, vireos, and many others; and it is then that we hope to make our largest lists of species, since early laggards and late arrivals mingle in the greatest abundance of the year. By May 20 this rush is abated, and by the end of May birds are on their breeding grounds and belated migrants are few in number.

The autumn migration pursues a more even course. The earliest arrivals among northern shorebirds are noted on mud-bars or sandy beaches dur- 
ing the first week in July, hardly more than a month after the last of their kind were recorded in northward flight. The yellow warbler completes its breeding and starts south during the latter part of this month. Other wood warblers begin to travel in August, and in mid-September pass in abundance, with vireos, flycatchers, and similar tree-haunting birds. October, particularly in the Middle West, is preëminently the month of migrant sparrows, which form a wave of migration equalled only by the gatherings of wild ducks on some of the northern marshes. In eastern Kansas near the tenth of October I have found sparrows in mixed bands containing thousands of individuals, scattered through hedges, marshes, and weed patches. On such occasions I have in the course of a day recorded five hundred or more LeConte's sparrows, with many hundreds of song, Lincoln, white-crowned, and Harris sparrows, and juncos, and smaller numbers of more unusual species. From the close of this month the number of migrants steadily decreases, until the flood of movement is almost stilled by the arrival of winter. Irruptions of northern species, as pine and evening grosbeaks, redpolls, siskins, snow buntings, and longspurs, may continue, however, until the opening of spring.

There is cessation of migration in fact only during the period of nesting, and even at that time there 
may be casual wandering among individuals that for some reason are not breeding. Observations on migration may thus be made throughout most of the year.

\section{Segregation during Migration}

Many birds are distinctly segregated from others of their kind during their migrations by certain individual peculiarities. Nighthawks fly in separate companies because of their erratic flight. A similar restriction is found in swifts, whose rapid movements through the air and habit of roosting in hollow trees or chimneys cause them to travel apart from any other birds. Glossy ibises, crows, kingbirds, crossbills, waxwings, and bobolinks, for reasons some of which may not be easily apparent, usually are found gathered with others of their kind during their travels.

Flocks of swallows, on the other hand, often travel in mixed companies composed of several species, as do blackbirds and grackles, shearwaters, and wood warblers. Similarities of size, form, and method of search for food draw them together. It is probable that many sparrows migrate in mixed companies as they are associated thus by day; but there is no means of observing definitely their nocturnal passages except through the medium of their call-notes, 
which seem to indicate that they travel in flocks composed of several species.

Some birds in migration maintain a close flockformation, as is seen in shore-birds, blackbirds, waxwings, longspurs, and snow buntings. Others travel in loose order, as turkey vultures, bluejays, warblers, pipits, horned larks, and bluebirds. Still others, like great horned owls, winter wrens, shrikes, grebes, and kingfishers, travel alone in ordinary circumstances, and appear in a close proximity that might indicate flocking only where abundant food or other unusual condition draws them together. There is some geographic variation in this regard, as red-tailed and rough-legged hawks in eastern North America travel singly, but in the middle west, may be found in large flocks.

Migrations among males and females of the same species may take place simultaneously, or the two sexes may move separately. In many species in spring migration the males are the first arrivals on the nesting ground, as under the territorial theory each one is under necessity of selecting a site for summer occupancy. Early migrant robins are usually males, the first song sparrows to arrive in spring greet us with cheerful songs that betray their sex, the first tanagers and rose-breasted grosbeaks are usually males; in the two last-mentioned I have seen whole flocks made up of these bright-colored indi- 
viduals. In a few species male and female seem to arrive together and proceed at once to the business of preparing a home. This is especially true of some shore-birds, that go to the far northern tundras, where mating may take place almost on the day of arrival.

In late summer, after the nesting season, males frequently flock by themselves and remain in bands until autumn. Yellow-headed blackbirds elect such segregation, as do most of the surface feeding ducks, in which males desert the females before the eggs are hatched. Such bands tend to hold their coherence until time for departure for the south, and so the sexes may in part travel in separate bands. Especial attention has been paid to ducks in this regard, and it has been found that often males will pass in flight a.t certain times to the exclusion of females; again the flocks will mix, or bands of females will outnumber the males. Once they are near the winter home, all this changes and the sexes intermingle. In fact, some of the preliminaries of pairing, or actual mating itself, are carried on in the south. Black ducks are frequently found in pairs as early as January, with female leading and the male following as they take flight, a certain indication that the birds are paired. These paired individuals naturally migrate north in spring together, though among other ducks of the same species that are not mated the sexes may fly separately. 
Among northern shore-birds the earliest arrivals in autumn are quite likely to be females, who press southward immediately when eggs have been deposited. I have suspected that these early migrants may be those whose nests have been destroyed in some way, though certain observations hint that a number of shore-birds share in part at least the habits of phalaropes, a group in which the female leaves the care of eggs and young wholly to the male.

Where there is segregation of the sexes, the young often accompany the female. In fact, we may explain the flockings of such ducks as mallards if we consider that the autumn flocks of males are mainly the old drakes that have remained banded together since the breeding season, while the mixed flocks of early fall are females accompanied by young of both sexes.

When young are grown, in many cases the parents drive them away to avoid their ceaseless calls for food, and so force them to shift for themselves. Many times bands of juvenile individuals are built up, which must retain some coherence in subsequent migrations. In Alaska, in August, I have found young Alaskan longspurs banding in flocks in the vegetation back of the beaches, with hardly any adults among them. Young cowbirds may forsake their foster parents to flock together in bands that travel south in company, though perhaps joining 
adults later. It is said that in England adult cuckoos depart early for the Continent, leaving their young to follow as best they may. As a contrast to this indifference, we may look to the Canada goose, in which families remain together through the summer, adults shedding their feathers and undergoing the wing moult that renders them flightless during the period of growth in their offspring, so that old and young emerge strong on the wing at the same time.

Abundance of individuals of a species during migration depends upon a number of factors. Kirtland's warblers are seldom seen, because they are few in number and have a restricted range. Philadelphia vireos and Cape May warblers cover a wide area, but are so scattered that it is unusual to see more than two or three in a day under the most favorable circumstances. An abundance of food may draw together short-eared owls, bitterns, or great blue herons, species normally of solitary habit, until many are assembled in a small area. This same factor may assemble birds of true flock habit in tremendous numbers. On Great Salt Lake I have seen northern phalaropes in bands of well over one hundred thousand, drawn together by an abundance of brine shrimp and alkali fly larvæ. The same food attractions cause assemblages of eared grebes in that locality.

In species of restricted range abundance is ob- 
viously to be sought near the center of the migration path, and individuals will become increasingly rare as the borders of the range are approached. In the Plains region aquatic birds are abundant in autumn migration if autumn rains fill ponds and marshes so that suitable feeding grounds are available. In dry seasons few or none are seen, as there is nothing to attract them. The assumption is that in dry seasons they pass overhead but, as there are no feeding grounds do not descend. In this same region in spring these water-birds abound, since the winter snows and rains have provided a suitable habitat.

\section{Migration among supposedly Resident Birds}

There are in all temperate regions certain birds which, as a species, are resident, but yet among whose individuals there is a certain amount of migratory movement. Bluejays and woodpeckers, nuthatches and chickadees, may be present constantly through the year, yet the individuals seen in winter are not always the same as those observed during summer.

The white-breasted nuthatch is an excellent illustration of slight migratory movement among individual birds of resident species. In the vicinity of Washington the land shows two major topographic 
features - the edge of the Piedmont plateau with its line of falls, and below it the coastal plain, stretching out toward distant arms of the ocean. The nuthatch nests regularly in the higher region, and may be resident there in part, since the same nuthatches (marked by bands) come to my window feeding-shelf summer and winter. In the coastal plain the nuthatch is absent during summer, except rarely, but in late autumn appears in fair abundance in wooded bottoms, and remains until the following March or April. Even as far up the Potomac as Plummer's Island, which is within the break of the fall line, there is noted an increase in its numbers in winter. In fact it is usually absent there in summer. Obviously in this species there is a spread or migration outside the breeding range. The source of the winter immigrants may be determined only through banded individuals.

The black-capped chickadee in winter on occasion invades the ranges of the more southern Carolina chickadee, as the blackcap has been recorded at Chevy Chase, Maryland, a suburb of Washington, though it is not known to breed at any point nearby.

The bluejay is a species of secretive disposition but showy form that is present in most of its range throughout the year. Yet at Washington, with the coming of cool weather, at the end of September, or in October, there begins a steady southward flight of 
bluejays that is unquestionably a migration to some winter range. Similar flights have been recorded at other points, and it is hoped that eventually records from banded birds may throw some light on its extent. So far as observed this movement is diurnal, and I have seen no indication of night flight in this species. The course pursued at Washington is toward the south and southwest, and the steady passage of birds, flying from 50 to I 50 yards from the earth, is as noticeable as the migration of sharpshinned hawks that often takes place at the same time.

Washington also marks a point near the northern extension of the southern subspecies of the common crow (Corvus brachyrhynchos paulus), a form marked by small size, that ranges from Alabama north to southeastern Kansas, Maryland, and Virginia. In winter we have an influx of the larger northern bird, which arrives in flocks, and which, until disturbed by building operations in suburban development, formed great roosts within the limits of the District of Columbia itself. With the opening of spring weather in March the resident birds begin the aerial gyrations and the peculiar calls that mark their pairing and mating. I have watched these mating evolutions among birds circling over low hills near the Potomac River, while on the tide-flats below I had before me scattered flocks of the northern birds 
working soberly across the mud-bars in prosaic search for food, unaffected as yet by the warming weather, since their own nesting grounds in the north were still covered with inhospitable ice and snow. It is of interest in this connection to record a crow banded in January near Stillwater, Oklahoma, and recovered April I5 near Woodstock, Minnesota, as indicating the extent of the migrations in this species.

In eastern Kansas, where the downy woodpecker is a common resident, it has on occasion been almost exterminated by protracted ice storms, which for weeks at a time covered all trees and shrubbery with a coating of ice that sheathed food-supplies for these woodpeckers as if beneath a coat of steel. In the summer season following such a severe winter, these woodpeckers may be very rare; but after the first week in November, when winter conditions come in states to the northward, downy woodpeckers become fairly common, indicating migration among them from some region to the northward. The actual journey of such birds again may be determined only through banding operations.

Species like the bobwhite, mockingbird, and Carolina wren appear truly sedentary, except for a certain amount of post-breeding wandering in the wren and mocker, and some casual flying in early autumn on the part of the quail, during which ran- 
dom individuals may be found in cities, towns, or other untoward neighborhoods. With others that seem equally sedentary it appears that there may be true migration in greater or less extent. What movement there may be in central latitudes among such species as meadowlarks, song sparrows, flickers, robins, and many others that are present through the year, is as yet purely a matter of speculation.

Many insular birds appear wholly sedentary, in that there is no interchange of individuals between islands which often lie within sight of one another and are easily reached by moderate flights. In eastern Porto Rico a species of crow (Corvus leucognaphalus) is found in forested areas, but makes no attempt to cross to the island of Vieques, in plain sight only fourteen miles away. Bones of this species are known from St. Croix, indicating that it was found there in ancient times, but it has never been reported there as a living bird by modern naturalists. Still more strange is the case of a land-rail (Hypotaenidia wakensis) found on the isolated island of Wake in the Pacific Ocean between Guam and Honolulu. The atoll at Wake has three islands, arranged in the form of a horseshoe surrounding a broad lagoon, separated from one another by narrow channels not more than 100 yards wide. The rail is found on the northern and eastern islands but does not occur on the one to the southwest. That 


\section{MIGRATION AMONG RESIDENT BIRDS 89}

the bird is flightless is not an adequate explanation of this curious distribution, since the channel separating this island from the one on the east, where the bird is common, is practically dry at low tide, twice in the course of every period of twenty-four hours. Food and shelter conditions are identical on all three islands, so that there is no apparent reason for the anomaly.

The curious hoatzin (Opisthocomus hoatzin) of northern South America is an excellent example of sedentary habit in a species with continental range. The bird is one with very weak powers of flight, so that it progresses mainly by clambering about through the branches of the thickets in which it feeds. It is said in certain instances to move less than a mile during the entire period of its life, merely coming out in the open in morning and evening, and seeking shelter under leafy branches in the heat of the day.

\section{Irregular or Vagrant Migration}

Irregular movements among birds may begin, as has been indicated, in wandering of adults or young from the vicinity of the nest site, and may vary in extent from a few hundred yards to many miles. During late summer species that have regular biannual migrations may wander in search of food, or young birds may stray from their accustomed range. 
As a feature of local migration movement there may be noticed the interesting summer flights of herons. In the southeastern United States the little blue heron (Florida caerulea) is common near the coasts, and nests in colonies, sometimes with or near the snowy heron and the American egret. The immature little blues (which are often pure white except for more or less slaty wash on the tips of the primaries, so that they may be mistaken for egrets) wander regularly after they are grown, and, strangely enough, at this season many of them penetrate to the north far beyond their breeding range. At the end of July scattered birds begin to appear along the Potomac, the Patuxent, and the Susquehanna rivers, tributary to Chesapeake Bay, and in many years the birds become common in August. With them come snowy herons and egrets in casual company, and all three travel north on occasion as far as New England. In the Mississippi Valley they are found regularly north to southeastern Kansas and Illinois. In September most of these birds disappear, and it is presumed that they return to the south.

Similar vagrant wanderings are recorded for white herons in Europe and Asia, and apparently hold true in the reef heron (Demigretta sacra) of Australian coasts and a broad range among islands in the South Pacific, which is recorded as a wanderer at many points. 
Others of the larger herons seem to have similar wandering habits, as they nest in retired colonies, and after the breeding season the young in particular range far and wide wherever they find feeding grounds. The yellow-crowned night heron, also a form with southern breeding range, comes north casually, while in the case of the black-crowned night heron, northward wandering has been proved to be the usual course from records obtained by marking the young. Thus young birds marked by Dr. Paul Bartsch near Washington, D. C., have been taken in Maryland and New Jersey, while others banded by different observers in the colony at Barnstable, Massachusetts, have wandered north into southern Maine. The distances covered in these instances are not particularly great.

It is probable that great blue herons also range northward, since a specimen of the subspecies that breeds in the Great Basin (Ardea herodias treganzai), which I banded near the northern end of Great Salt Lake, Utah, was killed subsequently near Billings, Montana. From available evidence it appears that the post-breeding movements of these herons is explosive, that is, the birds spread in all directions from their breeding grounds, regardless of direction. It may be considered as migration governed only by the availability of food and safety trom enemies, which is counteracted in autumn by a directive 
migratory impulse that carries these birds that have attained northern latitudes to a winter home somewhere in the south.

At the beginning of August, I925, a Bewick's wren appeared for a day in one of the courts of the United States National Museum. The species does not now nest within forty or fifty miles of Washington so far as known, so that this individual must be considered merely a vagrant. On one occasion, at the same season of the year, I found a canyon wren in a barn standing on a broad plain in northern Utah, fifteen miles from the nearest mountain haunt of the species - also an instance of a wanderer detected perhaps in a journey between the mountain ranges on either side of a wide basin.

Such examples, however, are merely casual and are not to be compared to the irruptions of certain northern birds that sweep down over the south at irregular intervals. Crossbills furnish classic examples of such flights, as the curious bills of these birds invariably attract attention. In ancient chronicles in England we find flights of crossbills recorded in the years $125 \mathrm{I}, \mathrm{I} 593$, I757, I79I, I82I, I $829,1846, I 853$, and at numerous other dates from the year last mentioned to the present. On many occasions they established themselves, bred for several years in succession, and then disappeared. Matthew Paris, Monk of St. Albans, already men- 
tioned, has chronicled the invasion of crossbills in the year I25I, his attention being attracted to them by their attacks on apples, a fruit which in the thirteenth century had attained a certain importance in the western counties of England. "In the course of this year," he writes, "about the fruit season, there appeared, in the orchards chiefly, some remarkable birds which had never before been seen in England, somewhat larger than larks, which ate the kernel of the fruit and nothing else, whereby the trees were fruitless, to the loss of many. The beaks of these birds were crossed." On a subsequent visitation in I 593 they are also reported to feed upon appleseeds, a habit so common in England that at one time the crossbill was often called "shell-apple." In the record of this occurrence, couched in the quaint phrases of ancient English, it is said that "it seemed they came out of some country not inhabited; for that they at the first would abide shooting at them either with pellet, bowe or other engine, and not remove until they were stricken down. . . . They were very good meate." Crossbill years have been recorded regularly in modern times in the United States, and have frequently carried the birds well south into the Carolinian life-zone. In the Middle West, in Kansas, where the birds are rarer than in the east, flights have included the subspecies known as Bendire's crossbill, which breeds in the Rocky 
Mountain region, as well as the ordinary form from the north, indicating a migration from the mountains out across the plains. From this it appears that these movements may be true wandering without definite direction. In the winter of I9I6 there occurred an irruption of the white-winged crossbill that brought these birds south as far as the city of Washington, where the species, though rare, has been found occasionally in the summer season.

At irregular intervals too come great flights of goshawks that spread across the entire northern half of the United States, and penetrate south to California and New Mexico. During a recent irruption the eastern form of this bird was recorded west across the Rocky Mountains into California, thus covering the usual range of the western form. The coming of hordes of this predatory bird is fraught with danger to the ruffed grouse of Michigan, Wisconsin, and the New England States, as the hawks hunt the grouse relentlessly, and have on occasion reduced these game birds almost to extinction. With the goshawks often there arrive many snowy owls and unusual numbers of great horned owls.

As irregular movement in a northern direction I may cite the case of the thick-billed parrot (Rhynchopsitta pachyrhyncha), resident regularly in the mountains bordering the Mexican Tableland, which at intervals of a number of years comes north across 
the border and invades the isolated mountain chains of southern Arizona, where it has been reported on several occasions from the Chiricahua Mountains, and more recently, in 1917 , from the Huachuca, Dragoon, Graham, and Galiuro ranges. The birds appear in late summer in roving bands that may include several hundred individuals.

In July, I9I7, such an invasion came in the southern Chiricahua Mountains, and by August had penetrated to Pinery Canyon at the north end of the range. Mr. Frank Hands, a close observer, informed me that he was certain from the condition of their plumage that many were young which had been hatched that year. The birds remained here through the winter, feeding early in the season on cones of the Chihuahua pine (Pinus chihuahuana), and when these were gone, on the acorns of various species of oaks. By November they had decreased in abundance, but a few remained until March, I9I8; in May of that year a few appeared in the Galiuro Mountains farther north, and remained until early autumn.

The flights of birds that have been mentioned have been a puzzle to naturalists from the irregularity of their occurrence, and have been explained on the hypothesis of failure of food supply, increase in numbers beyond the capacity for support of the normal range, and severe cold. Failure of food seems 
the most potent cause that may be given, and has certainly been the active factor in many cases. It may be mentioned particularly in connection with the periodic invasions of unusual numbers of the goshawk and snowy owl, as these seem to come during years when disease has destroyed the northern hares that form their usual food supply. On these occasions, Indians, lynxes, and other hunting mammals are often hard put for food, while the hunting birds exercise their powers of flight to carry them to other regions where food may be procured.

Less certainly has the coming of crossbills been attributed to failure of their normal food supply of cones in the north - a factor that may perhaps operate with the thick-billed parrot, which also feeds on the seeds of pines as well as on acorns.

Of interest in this connection are the movements of the sand-grouse of Eurasia, curious birds with many attributes of grouse and shore-birds, that seem anatomically most closely allied to the pigeons. Sand-grouse are regular inhabitants of the high plateaus or steppes of central Asia, but may range in great flocks through the surrounding territory. Henke found them in 1876 breeding in numbers on the Kirghiz steppes, where nomadic tribes told him they had been unknown before. In the spring and summer of I 863 a flight of these birds spread across western Europe, reaching the coast of Donegal in 
Ireland, the Adriatic Sea, northern Italy, across France, and north into Sweden. By February, I 864, the unusual visitors had disappeared. Though a few pairs were known to breed, the majority in the European invasion seem to have been merely vagrant.

In 1888 there occurred another irruption of the Pallas's sand-grouse that was even more important. Flocks spread throughout western Europe, and the birds became so firmly established in the British Islands that a special act of Parliament was put into effect to protect them during an adequate closed season. Subsequently, however, they disappeared. Except to a few Russian naturalists who had observed it in its Asiatic haunts, the species was practically unknown, until 1848 , when it was found in south Russia, and I859, when it spread into western Europe. It seems, therefore, to have been in a state of unrest for the past seventy-five years or more, but has not succeeded in establishing itself permanently in the new territory to which it spread. Without interference by man it might possibly have been more successful. It has been supposed that the movements of sand-grouse, like those of lemmings, are due to surplus production of individuals, leading to undue congestion in the native haunt.

Other birds are subject to similar movements, as 
Gätke at Heligoland has recorded incredible numbers of the European jay in passage for three days in October, I882, while in subsequent years only one individual was seen.

It is probably true that many vagrant individuals are carried so far beyond the usual range that they fail to make any attempt to return, and many others perish through unfamiliarity with the dangers of the new environment into which they have come. It is probable from the records available that most of the sand-grouse in the invasion mentioned in 1863 and I864 perished, since everywhere the strange birds were hunted and killed.

Wastage of individuals among migrants is extensive, and affects vagrants as well as those regular in travel. It would seem to operate with greater severity among those of irregular movement, as such have established no regular annual margin of safety. We may look then upon these periods of vagrancy to cut down the number of individuals among the species concerned. These erratic spreads have probably served to extend the range of some species, and may still do so, though since the rise of man this has become difficult except in the case of inconspicuous forms.

Flights of snow buntings, longspurs, pine siskins, redpolls, and many others that penetrate irregularly to the southward during severe winters may hardly 
be considered in this category of vagrants, since they are regularly migratory toward the south, and on occasion merely extend the length of their journeys. Part of their journey is regular, though its extent may be subject to variation.

\section{Casual Records}

The student of local avifaunas, intent on maintaining a complete list of the birds of his region, with notes on their abundance and occurrence, is always elated to detect the unusual visitor. Some unexpected stranger well repays hours or days passed in careful scanning of abundant birds of usual occurrence, whose habits and movements are wholly familiar. A glance through any state list or comprehensive check-list reveals frequent instances of this sort, and almost every number of the current magazines dealing with ornithology records others. The steady increase of record of such unusual occurrences is due to the steadily increasing number of persons interested in observing birds - a factor that submits the avian population to close scrutiny and offers more frequent chance of detection of the unusual.

Casual or accidental records are, roughly, of two kinds: first, birds recorded just beyond the margins of their normal ranges, and second, birds from distant areas whose occurrence is wholly fortuitous. It 
is perhaps trite to state that the majority of accidental visitors appear during the seasons when they are in migration. The first group - those found casually a short distance beyond their normal range - may represent attempts at extension beyond present boundaries, which, if successful, may result in final establishment of a species in a new area. Dr. J. Grinnell ${ }^{\mathrm{I}}$ has discussed this matter rather fully as regards the State of California, and considers these accidental occurrences as representing a trial and error method whereby a part of the surplus of the stock of any particular species pushes out into new territory where it may be lost or may survive. Wastage is severe, but is of small moment in the working of the laws which through the ages control distribution of millions of individuals. Again, these accidental records may represent sporadic attempts of a species to reëstablish itself in regions from which it has been forced to retreat.

Of another kind are records of birds at points far from their normal range, which are assumed to represent individuals that have wandered unintentionally from accustomed paths through the agency of storms or other untoward circumstances that they have encountered. These may include strange visitors of every description, sea-birds found far inland, land-birds blown at sea, or tropical and sub-

$$
\text { I } A u k, \text { 1922, pp. 373-380. }
$$


tropical species encountered in temperate regions. Though conceivably such birds may occasionally have established themselves in new ranges, this would happen far less frequently than with birds working out short distances beyond the edge of the normal range. To this agency, however, we must look to explain the presence of small land birds on oceanic islands, where there has never been continental connection, as in the Leeward Islands of the Hawaiian group, where a finchlike bird of the family Drepanididae, another smaller species of the same group, and an Old World warbler, are found on the island of Laysan, an isolated bit of sand built up through filling in an atoll, with less than two square miles of land surface. (The warbler, Conopoderas familiaris, and one of the Drepanidids, Himatione fraithii, are now extinct.)

Dr. Grinnell ${ }^{x}$ has stated that of the 576 forms of birds recorded for the State of California to I922, there are 35 that have been found on only one occasion. These represent mainly casual visitants far from their usual range. A few more-ten, to be exact - have been detected twice, while for six there are three records of occurrence. On the basis of observations extending over thirty-five years, he finds that new additions to the list for the state have come at the average rate of $I_{5}^{3}$ per year. Since these

\& $A u k$, 1922, pp. 373-375. 
casual visitants may come from anywhere on the continent, he estimates on the basis of these figures that there is a possibility of record of occurrence for the entire group of birds known from North America north of Mexico in the course of a little more than 400 years.

Casual records of straying birds in continental areas are subject to considerable chance, since the area suited for them is broad. Species of striking appearance are more liable to be noticed than those of ordinary character, since the latter merge with the ordinary avian population. The frigate bird of subtropical and tropical seas has been found in the interior in Kansas, Iowa, Wisconsin, Ohio, and Nova Scotia, the fork-tailed flycatcher in Mississippi, Kentucky, Maine, and Bermuda, and a form of kingbird (Tyrannus melancholicus satrapa) of the tropics has been taken recently at Scarboro, Maine. These are all single instances. Occasionally flocks of sea birds appear inland as, for example, the dovekie, Wilson's petrel, and others.

Detection of straying migrants in insular areas is more usual perhaps than on continents, since in limited land space strangers become more conspicuous. The list of birds known for the British Isles in I 9 I 5 numbered 475 , of which I 49 had been recorded as accidental visitors. In this list, in addition to forms from near-by continental areas, there are 
included the American pipit, the yellow-billed and black-billed cuckoo, the American duck-hawk, the blue-winged teal, the green-winged teal, American widgeon, ring-necked duck, bufflehead, hooded merganser, American bittern, and a long list of shorebirds from North America.

Small islands are even more productive, since they offer havens to birds blown to sea. In IgI I I found three individuals of an Asiatic bunting (Hypocentor rustica) on the island of Kiska in the outer Aleutian chain, two of them dead and the third flitting about in the grass. The Pribilof Islands in Bering Sea have yielded a considerable number of birds that have come as strays, since of the total list of $\mathrm{I} 37$ forms recorded up to 1923 , there are 80 which are of purely casual occurrence. These include a considerable number of Asiatic birds that have been found nowhere else in the area included in the limits of the list of North America. The majority of these strays are birds that breed in northeastern Asia, which have wandered from their usual track toward the south. Among them may be mentioned the widgeon, falcated teal, Old World forms of the golden-eye and pintail, a cuckoo, the brambling, swift, Japanese hawfinch, and sea eagle. These islands lie in a belt where they are usually surrounded by fogs during the period of migration, so that, though visible for a long distance when the weather is clear, this occurs 
so seldom during the season of migration that we may wonder how wandering birds come to them. E. A. Preble has called attention to the fact that, during the seasons when most of the small birds are migrating, the beaches of the Pribilofs are crowded with thousands of fur seals and sea lions, gathered in noisy herds whose roaring and bellowing in combined chorus produces a clamor that is audible distinctly at a distance of several miles. There is no question, he states, that many feathered wanderers are guided by these uncouth sounds to a haven where they may rest and recuperate. Casual visitants among land birds found here must be considered as true strays, since these lonely islands do not lie in any regular migration path except for some groups of sea fowl. All land birds found, therefore, are storm blown or lost from some other cause. Even the yellow wagtail and willow warbler, which cross each year from Asia to nest in Alaska, travel by some other route, since they have not as yet been recorded from the Pribilofs.

Birds of strong flight often appear at points far distant from their customary haunts. The ruff of Europe has been recorded on several occasions from Barbadoes, Trudeau's tern of Argentina and Uruguay has been found in New Jersey, and the Bartramian sandpiper has been taken in New Zealand. 
The facts outlined will give some idea of the manner in which birds may wander when out of their accustomed courses, and of the difficulties that beset them during their travels. It is safe to say that more than 90 per cent of casual records represent strays during periods of migration. 


\section{CHAPTER IV}

\section{Altitudinal or Vertical Migration}

SOME species of birds fly hundreds of miles across more or less level land to reach a summer or a winter home, while others attain the same objective by moving through a space of a few miles which carries them up or down the sides of mountains. A few hundred feet of altitude in these instances corresponds to hundreds of miles of latitude. Wherever large mountain ranges are found in temperate regions we find regular migration taking place up and down their slopes.

Such migration may be noted in India, where bird migrants from Siberia mingle on the plains with others that have merely descended the near-by Himalayas. Species of rosy finches, other finches, and the snow partridges, from the higher altitudes, migrate in winter into the foothill region, and then with the coming of spring move back into the higher country to breed. With them come woodcock, jackdaws, and the sprightly whistling thrushes. ${ }^{x}$ Borders of streams are frequented by flocks of wagtails from

I Hingston, R. W. G., A Naturalist in Himalaya, p. 258. 
the north, while bands of snipe and duck, bred in Arctic regions, swarm in the marshes.

Similar movements occur in the Andes of Argentina, where grebes and coots nest in mountain lakes and winter in alkaline marshes on the plains, or in the Rocky Mountains of our own country, where the rosy finches, juncos, pine grosbeaks, and siskins descend the mountain slopes in autumn and ascend them in spring. In the Great Basin I have seen the violet-green swallows leave their lowland haunts in May for their breeding grounds in the hills, and then during a late storm, which covered the mountains with snow but in the valleys fell as cold rain, return again to the lowlands. Such interchanges meant only a few miles of flight and were accomplished with ease.

In species of birds that inhabit or frequent both hills and plains it has been noted in spring that first arrivals may be seen near the foothills and from there work upward. In autumn early migration may be observed on the slopes of mountains or at their bases, depending upon the species. There is, however, much variation in this, depending largely on local conditions. In field work in the foothills of the Front Range in Colorado, R. B. Rockwell and I found that spring migration in the same species was approximately a week later in the hills than on the plains east of Denver, indicating apparently that 
many birds came north along the plains and then spread back into the mountains. Certain species, as some of the juncos, which had wintered in the foothill region, in spring moved down toward the level country and then migrated northward toward their summer home. There were evident thus two lines of movement, one that carried incoming migrants up the gulches into the mountains, and one that brought winter residents down the gulches toward the plains. In August in this same region, such species as the Williamson's sapsucker and western wood pewee, which had nested in higher mountains to the west, moved down to lower regions, and at the same time broad-tailed hummingbirds, western chipping sparrows, and mountain bluebirds increased in number, apparently from influx from the same higher regions. There was a distinct tendency among young of the mountain-breeding birds to work down the mountain slopes as soon as the breeding season had closed - a movement that became intensified with the beginning of migration from the north in September.

Similar movements among different species of birds have been observed in many localities. Especially noticeable in autumn are the sudden increases among birds in the edges of the foothills when cold spells occur that spread frost or snow in the higher regions. 
In some cases we find altitudinal migration affecting birds of limited range, which nest in the higher zones of mountains and winter near their bases, or perhaps pass farther south. With some species, as the pipit of this country, a suitable breeding range for some is found in the Arctic-Alpine zone of the Rocky Mountains, from Colorado northward, while others seek a similar zone in the tundras of Alaska or British America.

After the breeding season some species of birds regularly work upward, to spend the late summer on the higher slopes of the mountains. Such movement has been recorded in the western house wren, and has been observed in western kingbirds and in other species. In the foothills of the California mountains, where the late summer and early autumn are extremely dry, T. I. Storer ${ }^{\mathrm{I}}$ has recorded that such supposed permanent residents as the spurred towhee, wren-tit, bush-tit, and Vigor's wren, regularly perform an altitudinal migration, as in late summer, after the breeding season, they move up the slopes into the higher zones of the mountains, where they remain until the coming of autumn rains breaks the drought at the lower levels and so makes conditions of life there easier. A fascinating account of altitudinal migration remains to be written when the late summer movements of hummingbirds in the

${ }^{I}$ Univ. Calif. Publ. Zool. (1925) xxvii, 3. 
mountains of the southwest are better understood. In July and August, when flowers bloom in abundance in mountain parks at altitudes of 7000 to 9000 feet in the Chiricahua, Huachuca, and near-by mountain ranges, hummingbirds of several species fairly swarm. Many do not breed here but come from near-by, though as yet the exact status of such species as the white-eared hummer is uncertain.

\section{Rapidity of Migration Movement}

The rapidity with which migration progresses when birds are passing to the north in spring seems to depend to a considerable extent, among small species at least, upon whether migration begins early or late in the season. Professor W. W. Cooke, in his studies on bird migration, gathered and published numerous data on this point from records furnished by a large corps of observers scattered through the country, who made careful record of dates of first arrival in their vicinity. Professor Cooke found that the average rate for the month of March, when early migrants were retarded by frequent periods of bad weather, was considerably less than that for April, while in May all migrants seemed to travel at a much more rapid pace. From this it is deduced as a general rule that those species that start their migration late in spring travel to their breeding grounds at a much more rapid rate 
than those that leave their winter quarters earlier in the year.

Part of our black and white warblers (Mniotilta varia) winter in Florida and southern Texas, but the majority pass on to the West Indies, Mexico, and northern South America. Migrants on their way north are recorded at the lighthouses of southern Florida about March 4, but migration does not extend beyond the northern limit of the winter range into southern Georgia until about March 24, so that these early migrants travel at an average rate of only 20 miles per day through this area. Between southern Texas and northern North Dakota, this bird averages about 22 miles per day, but from that point north to the limit of the breeding range the rate of speed is almost doubled.

The gray-cheeked thrush, on the other hand, which does not reach the southern United States from its winter home in South America until late in April, arrives a month later in extreme northwestern Alaska, so that it covers a 4000-mile journey on this continent at an average rate of I 30 miles per day.

Professor Cooke has figured the average speed for small birds in general in passing up the Mississippi Valley at 23 miles per day. In addition to the species that have been mentioned he gives some interesting figures for a few others. The black-poll warbler, in its northern flight from South America, arrives on 
our southern coasts in April. In travelling north to the northern boundary of the United States the birds move at a rate of 30 to 35 miles per day, but from that point north the speed increases tremendously, as black-polls appear in a week's time in the central Mackenzie Valley, and in another week arrive in northwestern Alaska. It appears that some at least must average 200 miles per day for the latter part of the journey. The species requires 30 days to cross the thousand-mile interval from the Gulf coast to southern Minnesota, and only a little more than half that time to traverse the 2,500 miles that separate that point from the extreme limit of its range in Alaska.

From the same source may be taken some interesting data on the spring movements of the robin. In the east, migrant robins come north at a leisurely rate, travelling through New England with the slow advance of spring, so that to their northern breeding limit in Newfoundland they average only I7 miles per day. In the west, the western form of the robin winters north into British Columbia and has to perform only a short migration to pass into Alberta and Saskatchewan, to which it moves at an average advance of only 8 miles per day. In the interior, the eastern subspecies moves from its winter range north to central Minnesota at the rate of I 3 miles perday, a rate that is doubled in the course to south- 
ern Canada. Here a part of the birds turn to the northwest and move at an average rate of 50 miles per day, and finally accelerate to a rush that carries them across a space of 70 miles in twenty-four hours, and at this increased speed arrive at their limit in Alaska. Professor Cooke finds that their northward movement coincides closely with the passage of the isotherm of 35 degrees Fahrenheit, which brings spring throughout the country. The differences noted in average speed through our continent are thus correlated with the average advance of spring, so that the robin merits its reputation as the herald who announces the close of winter.

In connection with rapidity of migration it may be well to note that there is often a distinction between the rapidity of movement in the bulk of the species as a whole and of single individuals. At the opening of migration a few birds of a species may appear, but it may be a week or a month before the bulk begins movement and the bird becomes common. Thus a few blackbirds reach our marshes early in spring, but the return of cold weather may retard the flights of their fellows for some time. Practically nothing is known as yet of the manner in which single birds travel, since our observations to date have been restricted mainly to group identification. Early stragglers form the vanguard in most of our birds. It is apparent thus in many cases that cou- 
riers of migration advance rapidly and cover a considerable extent of country, perhaps reaching well through the range long before the main army begins to move. This is often true in fall fights where there is no climatic bar to progress. Juncos appear in middle latitudes in September, but do not become abundant until the middle of October or the first part of November. Yellow-legs start south in July, and by the end of that month may reach South America, though the main flight does not appear in the extreme south until September or October. Travel into the northern zones in spring, early in the season, is retarded of course by the continuance of cold in the north, so that the earlier movements must await thaws.

In early migration, there is much lingering along the way to feed and rest, particularly among those birds that travel long distances. In Argentina and Uruguay I found migration northward among shorebirds beginning at the end of January and well under way in March, though the final rush did not come until April. As this final flight coincides with the initiation of migration among these birds in the United States it will be seen that those who responded early to the migration impulse were slower in progress than those that started later.

Definite data for the rate at which birds travel south in autumn are lacking, as at that season birds 
are quieter than in spring and more difficult to observe. The journey in many cases also is irregular and prolonged. We may look to data secured from bird banding to give more definite information as to the rapidity of migratory movement in individual birds, and we shall turn to that source especially for the movements of autumn migrants when sufficient records have been amassed.

\section{Distances travelled by Migrants}

The length of the migration route is a highly variable factor, depending upon local conditions and the species of bird concerned. In the mountains of Himalaya, as winter approaches, the snow partridge may descend a few hundred feet in altitude, to a winter ground, merely by travelling a mile or two, or, in this country, the long-tailed chickadees of the Rocky Mountains may drop down from the aspen groves at 8,000 feet, where they have nested, to creek bottoms a few miles distant in the foothills. Flights that may be covered in a few minutes place these birds in regions where they find conditions suitable to their needs for winter. We may contrast these flights with that of the Arctic tern, which nests in the most northern land known (the first nest discovered is said to have been only $45^{\circ}$ miles from the North Pole) and which spends the winter in seas skirting the Antarctic continent, with an air line I I,000 miles 
in length between its summer and its winter residence. (See Fig. 3.) It has been truly remarked that this tern probably experiences more daylight than any other living creature, since it lives in regions where the midnight sun is its constant companion in both north and south, and only in travelling does it encounter any extended periods of darkness.

Many birds nest in the northern United States and Canada and pass south toward the Gulf of Mexico to winter. As well-known examples may be cited such winter residents as the white-throated, white-crowned, and tree sparrows, juncos, brown creepers, golden-crowned kinglets and robins, with hordes of grackles, redwings, and cowbirds among our smaller birds, and various species of ducks, the woodcock, and many others, among larger ones. Such migrants include the hardier species, some of whose individuals may linger in protected places well within the reach of severe cold.

Many of our small birds travel much greater distances for no apparent reason. Many species of wood warblers nest in the northern United States and Canada, and fly in winter to the West Indies, leaving perhaps a few of their individuals to linger in the southern states. Black and white warblers range in winter season from extreme southern Georgia southward into the West Indies; some, undismayed by broad waters, cross to Venezuela and 


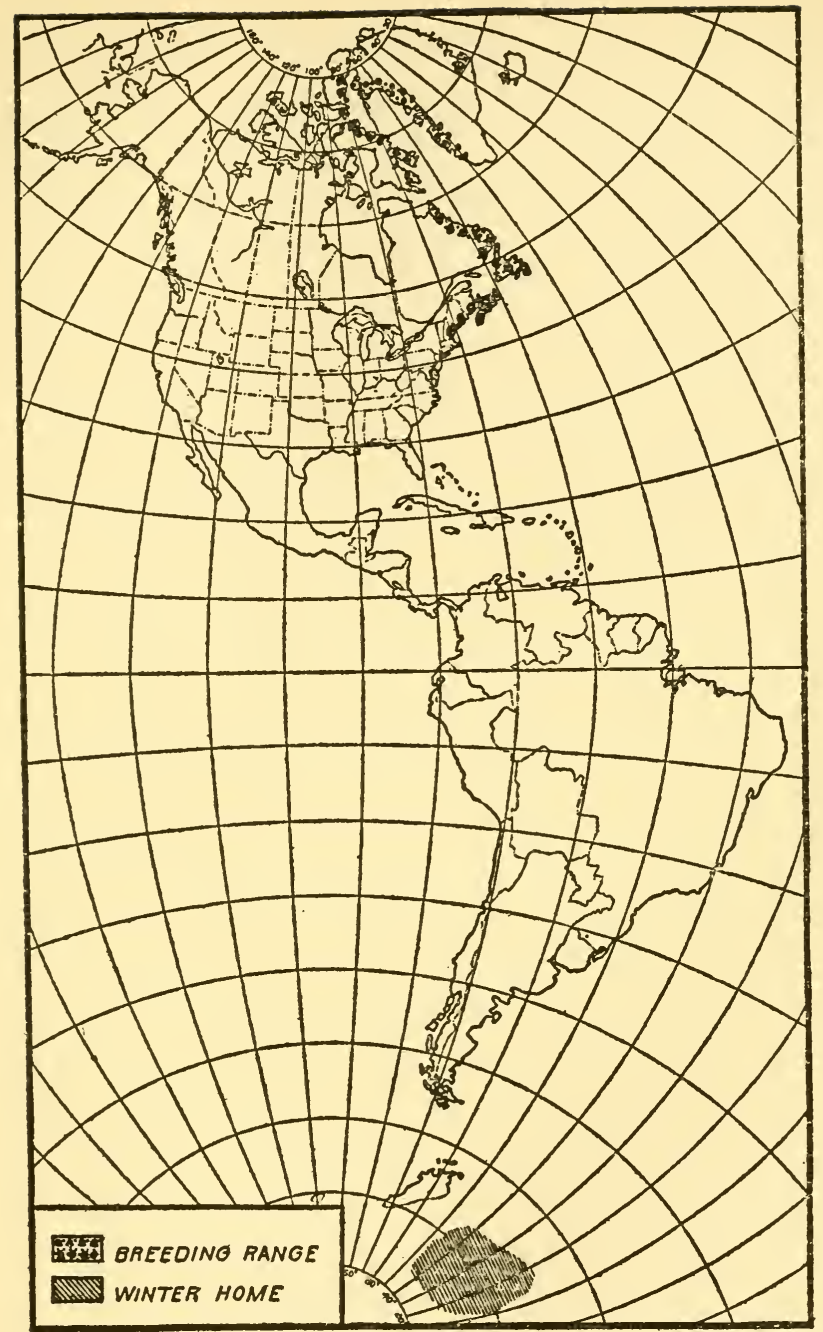

FIGURE 3

Map to show migration range of the arctic tern (Sterna paradisaea).

(Courtesy of Bureau of Biological Survey.) 

penetrate even as far as Ecuador. Part of the yellow warblers travel even farther, as they range south in to Brazil. The last species mentioned is one of the earliest to begin its migratory movements south, as it is recorded in southward flight in Florida at the end of July.

The nighthawk that nests on the upper Yukon may winter in Argentina, while the marsh wren of the upper Mississippi Valley, with wings apparently weak, may fly south in autumn as far as central Mexico. The migration routes of some of the wagtails, the common swallow, the willow warbler, and the spotted flycatcher, which pass from northern or central Europe to South Africa, may be cited as among the longest journeys for small land birds of which we have knowledge. Some of these long flights must be performed without great delay en route; for I found the North American barn swallow in western Paraguay shortly after the twentieth of September, when no doubt a part of the species had not yet left the United States.

A number of birds that have extended breeding ranges withdraw in autumn to the south, to concentrate in the southern portion of the breeding area, or spread only a short distance farther south. This is true of the rock wren, the black-capped chickadee, the black-headed grosbeak, the field sparrow, and the migrant shrike. In such forms the entire group 
is confined within a limited area for the period of winter, and then spreads to reoccupy the full range with return of warmer weather.

The difference between subspecies has made possible the discovery of interesting facts indicative of length of migration in a number of species. As an example may be cited the yellow-throat of Florida (Geothlypis trichas ignota), marked from other forms by a more rounded wing, which is strictly sedentary, but in winter has as its companions yellow-throats from the north, some of which cross to the Bahamas and Cuba. In England, an insular area where such matters are readily detected, resident forms of the greater spotted woodpecker, the dipper, the robin red-breast, the song-thrush, the great titmouse, and others, are joined in winter by individuals of continental subspecies from the north, which return to their proper haunts at the opening of the breeding season. Similar instances may be found in many areas in the temperate zones both north and south of the Equator.

Very often individuals of a widely distributed species from the northern part of the range tend to migrate farther south than those trom intermediate regions, instead of there being a uniform shift of northern birds to the central portion of the range, to replace others that have gone on southward. In other words there is a tendency for birds living 
under fair conditions to migrate only a short distance, while others which are forced, or choose, to migrate, pass on to distant unoccupied areas for winter. Mr. H. S. Swarth has shown an excellent example of this in his discussion of the races of the fox sparrow, of which there are sixteen forms recognized at present. Our familiar eastern bird nests from northwestern Alaska to Labrador, and concentrates in winter in the southeastern portion of the United States, so that it travels a long route each year. On the west coast of North America there are six subspecies of this bird which in summer are established in definite breeding ranges from Unimak Island, at the end of the Alaska Peninsula, south to the region of Puget Sound. Beginning at the north these forms are known as Passerella iliaca unalaschcensis, insularis, sinuosa, annectens, townsendi and fuliginosa. (See Fig. 4.) The three northern races, unalaschcensis, insularis, and sinuosa, which occupy complementary ranges extending from the Alaska Peninsula east to the region of Prince William Sound, migrate to a common wintering ground in southern California. The next form, annectens, breeds in the Yakutat Bay region of Alaska and winters almost entirely in the coastal region of central California. The form known as townsendi, which nests in the coast region of southern Alaska, winters in the coast region of 
northern California, being found only casually south to the region of San Francisco Bay; while the last of the forms under consideration, fuliginosa, from Vancouver Island and the Puget Sound region, may perform a vertical migration down mountainslopes, but aside from that wanders only a comparatively few miles beyond its breeding range. The northern forms thus pass completely over those in intermediate regions in veritable leapfrog fashion.

We can readily understand why birds might wish to leave the inhospitable north with the coming of winter, but why many individuals press on across the equatorial region to south temperate lands can be explained only by ease in accomplishment of flight, and an instinct to wander. Any one who has worked among the diversified faunas of the tropics will agree that in the region of the Equator may be found areas suitable to almost any species of bird, where there is no question of crowding or shortage of food supply. Insects swarm, and vegetable food, in form of seeds and fruits, is abundant. A climate that varies from humid to arid fosters heavy forests, dry, open scrubs, broad savannas with high growths of grasses, or areas of plain with herbage in tufts or clumps. Sandy beaches, or broad mudflats with low growths of mangroves, are found on the coasts, and lakes and streams are common. Where a local dry season is encountered, it is necessary only 


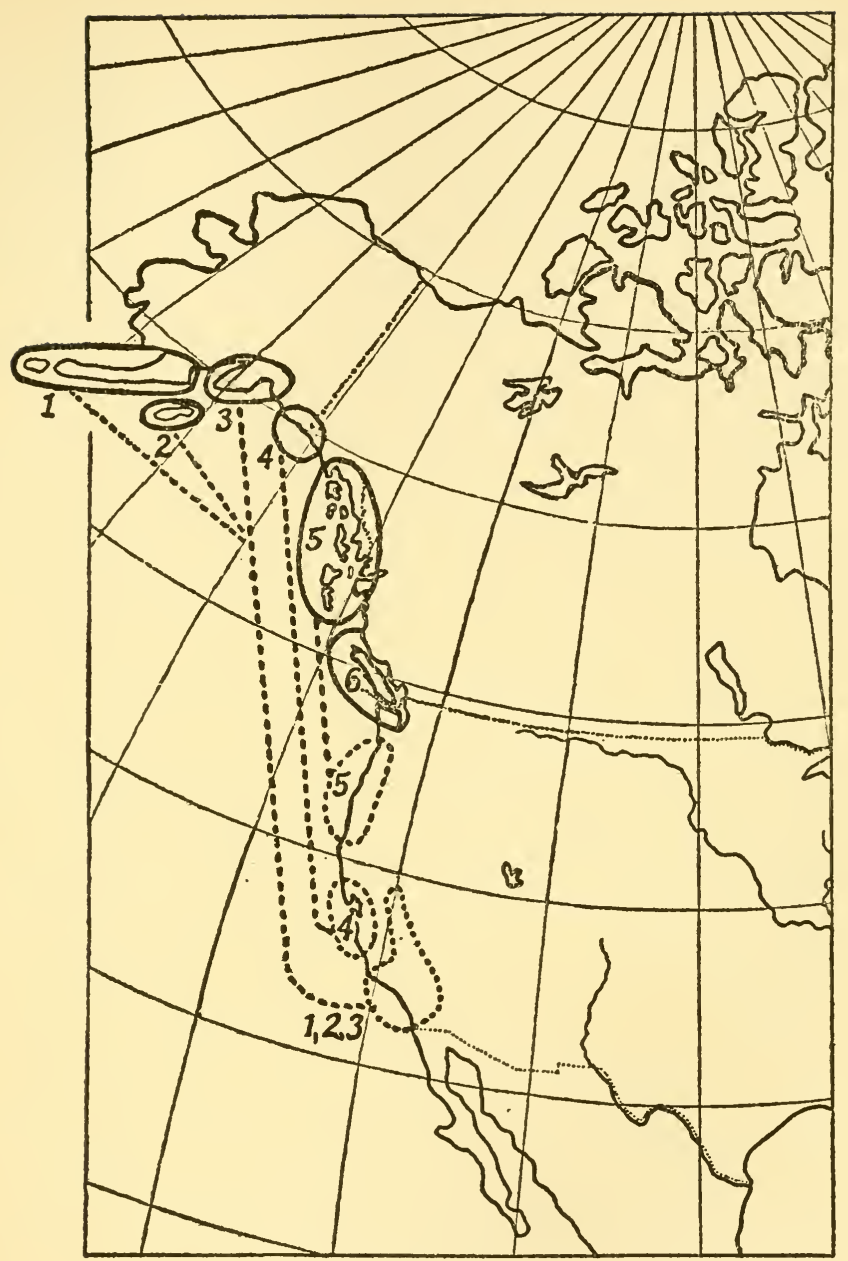

Figure 4

Map to show migration of western forms of the fox sparrow (Passerella iliaca). Breeding range in solid lines and winter range in dotted lines. Numbers represent subspecies as follows: 1 , unalaschcensis; 2 , insularis; 3 , sinuosa; 4, annectens; 5 , townsendi; 6 fuliginosa. Taken from Swarth. (Courtesy of Museum of Vertebrate Zoölogy, University of California.) 

to shift a short distance to an area where rains are prevalent, if such change is desired. It would seem that any bird could choose among these diversified haunts one suited to its needs, and in fact many do linger in such regions. That others press on in to the summer weather of the south temperate region may be explained only by belief that flight is not laborious, and that they delight to wander. It is possibly merely an outgrowth, or, better, a continuation of the wandering instinct that has carried them to breeding grounds in areas where for part of the year the season is inhospitable.

\section{Mortality Among Migrant Birds}

Without great reflection it is obvious that the migrant bird, in traversing hundreds, perhaps thousands, of miles of land and water, is subject to many more perils and dangers than if the same individual were able to remain in one locality. Storms, unfamiliar coverts, and exposure to the attacks of winged and four-footed enemies, to say nothing of the possibility of becoming lost while crossing broad stretches of water, annually destroy our smaller migrants in untold thousands. To enable maintenance of a species at the necessary maximum to prevent its disappearance from the earth, it is required that each pair shall produce a sufficient number of 
offspring to permit the annual toll of death and to leave a pair to begin the next breeding season, with a certain ratio of additional individuals to fill the gaps left among breeding birds that chance to be killed before they have accomplished the act of reproduction.

It has been noted that many birds of continental areas in the Tropics are sedentary, or that, where there is wandering among them, the distance covered is comparatively slight and is traversed more or less in the shelter of their usual cover. Storms and the crossing of broad waters do not figure in the migratory movements of these, nor are they in danger of becoming lost. As a corollary, we find the rate of reproduction low; from two to four eggs constitute a set, with two or three as the usual number. Broods may come at irregular seasons, but apparently it is normal for them to have but one breeding period each year. Among exceptions to this rule may be recorded honey-creepers of the genus Coereba, which in the West Indies rear brood after brood throughout the year, and are in consequence overwhelmingly abundant in comparison with other species. This, however, is unusual among tropical birds.

The case of the small migrant perching bird of the northern hemisphere is far different. Families of three to six are the rule, with four or five as the aver- 
age. Some are restricted to one annual family, many species rear two, and a few of the more common ones three broods a season. In spite of their apparent prolificness, these birds do not increase appreciably in numbers unless there is some change in conditions that affect them. The family in the song sparrow, for example, which begins the season with two individuals, by August, if there has been no summer mortality, with an average family of four to the brood has increased to ten or to fourteen, depending upon whether two or three families have been produced. In other words, unless deaths begin early, the summer season closes with the original pair of adults augmented by from eight to twelve young. This increase represents the margin of safety in this particular species, and illustrates the tremendous annual mortality among song sparrows as a group. Ducks rear a single brood, with six to twelve or more young, but maintain themselves in spite of the vicissitudes of travel and the slaughter of the hunting season. Most shore-birds, with four young or less as the annual addition, are unable to withstand destruction by man in addition to the other perils that they encounter, and have to be carefully protected to avoid actual extermination. The slow production to offset death in the passenger pigeon, which laid but a single egg, was unquestionably the cause of extinction of this species, as excessive hunt- 
ing, in addition to the usual dangers it encountered, destroyed the delicate balance that controlled its existence as a species, leaving man as the ultimate cause of its destruction, much as shamefaced humans would like to attribute the ruthless extermination of this fine bird to some catastrophe of nature.

When birds have become accustomed to toll by man, protection has at times brought a prompt reaction, as may be seen in the case of the eastern robin. For generations the winter flocks of this dooryard intimate of the north were sought by hunters in their southern migrations as basis for delectable potpies. Unfamiliar with the confiding habits of the birds on their breeding grounds, men had no scruples in shooting them for sport and food. With the operation of the Federal Migratory Bird Treaty Act the robin, considered under the law as a beneficial song bird, has been afforded protection throughout its range, so that it has increased in many regions, with the result that now serious complaints are made of its depredations on small fruits in the north. It is even stated that farmers in some sections of New Jersey have given up the culture of strawberries, as they have been unable to cope with the appetite of the robin for that excellent product.

Natural agencies at intervals take tremendous toll of bird-life, as is shown by the casual instances in which this destruction comes under the observation 
of man. Sudden storms overtake hurrying clouds of migrants, and batter them by the thousands into lakes or seas where they drown miserably, leaving windrows of bodies cast on lonely beaches as mute witnesses of tragedy. Unseasonable cold may attack birds in or near their winter homes and destroy them in countless numbers. Such accidents have beset our eastern bluebird, and on one occasion reduced its numbers appreciably for a period of years. Cold, with consequent lack of food, has been recorded as the cause of death of myriads of swallows in the Chaco of Paraguay, where most of the victims were species migrant from south temperate regions, but among them were undoubtedly individuals of our own barn swallow.

W. E. Saunders ${ }^{\mathrm{I}}$ has recorded a catastrophe that overtook bands of fall migrants passing across Lake Huron in October, 1906. A sudden drop in temperature, followed by a fall of snow ranging from two to eighteen inches according to the locality, apparently caught a heavy rush of migration across the lake. Thousands of birds fell into the water and were drowned, to be cast up subsequently along the beaches, where their bodies in places were said to lie piled one on another. At one point the dead were estimated at I,000 to the mile, and at another place at 5,000 to the same distance. The bulk of the birds

I $A$ uk, I907, pp. 108-1 Io. 
were juncos, tree sparrows, white-throated sparrows, swamp sparrows, winter wrens, and golden-crowned kinglets, with scattering rusty grackles, saw-whet owls, brown creepers, hermit thrushes, and miscellaneous warblers, vireos, finches, and others. Their total number was not computed, but must have been tremendous.

Of maximum extent for one species are the catastrophes that have beset migrant Lapland longspurs in the Middle West on their northern flights in very early spring. In the plains regions this species congregates in enormous numbers where food is obtainable. I have seen more than one hundred thousand gathered in a single field, to feed on various weed seeds. In their northward flight on occasion these birds have encountered blinding storms of wet, clinging snow, which at night bewildered the travellers until they flew into various obstructions, or sank to the ground and there perished. In such a catastrophe in Minnesota, in March, 1907, Dr. T. S. Roberts has estimated that 750,000 of these birds lay dead on the ice of two lakes, each a mile in extent. The area where dead birds were reported in greater or less abundance on this occasion covered over I,500 square miles. It is astonishing to note that in the second winter following I found longspurs on the prairies of eastern Kansas in even greater numbers than usual. Similar catastrophes 
have been reported recently from eastern Colorado and Nebraska, so that the destruction of individuals in this one species has been almost inconceivable, running to many hundreds of thousands in these known instances. It is of interest to observe that among these longspurs and in the instance noted for other birds on Lake Huron, destruction took place during a fall of snow. It may be suggested that the snow was the active factor rather than the cold, and that the steady fall of flakes, more or less visible, brought such confusion and uncertainty that the birds flew downward rather than directly ahead and so came to their death.

Ducks in various places in the west have perished in multitudes from poisonous alkalis concentrated in or about lakes or ponds in which on other years the birds have fed with impunity. In part this has been due to the agency of man in withdrawing water from streams for irrigation thus lessening the supply of fresh water that had formerly washed alkaline flats. Such has been the case around Great Salt Lake in Utah, where ducks and waders have died in tens of thousands since I9IO. Similar conditions occur regularly from the natural desiccation of alkaline lakes at scattered points throughout the Great Basin, a condition that has probably continued since long before the advent of civilized man. Although these conditions operate against resident 
birds, they are most serious in connecticn with migrants, as migration carries thousands of individuals through these regions and augments the number affected many fold.

Destruction of migrants through striking lighthouses has been tremendous. Clarke has described graphically such experiences at the Eddystone Light on the coast of England, when hour after hour bewildered birds by scores hovered mothlike about the light, eventually to fall exhausted and perish. At the Kentish Knock Lightship conditions were similar. During heavy migrations losses were appalling, as birds continued to strike the lantern and fall into the water for hours; on one occasion, in mid-October, such destruction continued for ten and one-half hours. The following quotation from his observations at this lightship is of interest:

Seen from the deck the three beams from the lantern appeared to be thrown towards the surface of the surrounding waters at an angle of $45{ }^{\circ}$ The birds-brilliant glistening objects-seemed to ascend, as it were, these streams of light by a series of short jerky flaps performed by wings which appeared to be only half spread for flight. Some of them paused when within a short distance of the lantern, remaining almost stationary, as if to sun themselves in the radiance of the slowly passing beam. Others were bolder and approached the light more closely, but ere they reached it spread their tails like fans, in order to check at the last moment their 
perilous onward course, and then sheered off, returning in a moment or two to repeat the performance. . . . Others, again, approached the light gently, and either fluttered against the glass, or, as was particularly the case with the starling, perched on the iron frame work of the lantern windows and seemed to revel in the light. In this respect the starling differed from the rest, and when one brilliant beam had passed, the bird craned its neck and appeared to gaze longingly toward the next, which was slowly approaching. Indeed, the actions of the starling in particular showed the birds under the spell of some overpowering fascination. A number of the visitors made their début with a wild dash for the light, and these, if they struck the glass direct, were killed outright; while if the contact were made obliquely, they glanced off stunned, and, slightly injured, descended with a curious zigzag flight which sometimes carried them some little distance ere they were lost amid the waves. . . . To complete the scene there was the singular effect produced by its central feature - namely, the great lantern, which, placed high up on the mast, swung slowly to and fro among the glittering hosts that danced attendance upon its mystic charms. On occasions when the rays were not particularly conspicuous, the migrants flew aimlessly around, passing from ray to ray, sometimes for many hours. It is extraordinary how long some birds will fly round a light without resting. As a good example may be mentioned the case of a Kestrel, which appeared at 8.00 P.M. . . . and careered around without a break or rest of any kind until I.30 
A.M. . . . This bird of ten came close up to the light, but checked itself by spreading its tail; and it also frequently flew to windward, and then dashed back over the lantern at a tremendous pace. It paid no attention to the few birds which were sometimes present during its prolonged visit. ${ }^{\mathrm{I}}$

Mr. William Brewster, in an article on bird migration published by the Nuttall Ornithological Club, ${ }^{2}$ has given a graphic account of observation at a lighthouse on Point Lepreaux in the Bay of Fundy, in August and September, I885. Many birds struck the light during the first week in September, when wood warblers, red-eyed vireos, and gray-cheeked thrushes were in migration. Mr. Brewster describes his observations on the night of September 4 in the following words:

Above, the inky black sky; on all sides, dense wreaths of fog scudding swiftly past and completely enveloping the sea which moaned dismally at the base of the cliffs; about the top of the tower, a belt of light projected some thirty yards into the mist by the powerful reflectors; and in this belt swarms of birds, circling, floating, soaring, now advancing, next retreating, but never quite able .... to throw off the spell of the fatal lantern. Their rapidly vibrating wings made a haze about their forms which in the strong light looked semitransparent. At a distance all appeared of a pale, silvery gray color, nearer,

× Clarke, Studies in Bird Migration (1912), ii, 22, 23.

${ }^{2}$ Mem. Nuttall Ornith. Club, No. I, 1886, pp. 7-8. 
of a rich yellow. They reminded me in turn of meteors, gigantic moths, swallows with the sunlight streaming through their wings. I could not watch them for any length of time without becoming dizzy and bewildered.

When the wind blew strongly they circled around to leeward, breasting it in a dense throng, which drifted backward and forward, up and down, like a swarm of gnats dancing in the sunshine. Dozens were continually leaving this throng and skimming toward the lantern. As they approached they invariably soared upward, and those which started on a level with the platform usually passed above the roof. Others sheared off at the last moment, and shot by with arrow-like swiftness, while more rarely one would stop abruptly and, poising a few feet from the glass, inspect the lighted space within. Often for a minute or more not a bird would strike. Then, as if seized by a panic, they would come against the glass so rapidly, and in such numbers, that the sound of their blows resembled the pattering of hail. . . . At times it fairly rained birds, and the platform, wet and shining, was strewn with the dead and dying.

Birds are attracted to lights in greatest numbers on dark nights when the air contains quantities of moisture, not necessarily in the form of fog or mist, but often when it is suspended invisibly. The great destruction at lighthouses and lightships has aroused considerable interest, especially since it was found that many birds were not actually injured but merely fluttered down to fall into the water beneath. 
In England and elsewhere in Europe shelves and perches in some cases have been placed below the lights, to afford resting places for birds, on which they can remain until they have overcome their bewilderment. These have been of great service in the conservation of life, and at a number of points where birds in former years were killed by thousands now few dead are found. Many modern lighthouses have lights of an intermittent type, arranged to flash at regular intervals, and often alternate colored rays with the usual beams of white light. These intermittent flashes, particularly where they are not white, are not so attractive, so that at many lights the danger has been largely eliminated.

It would appear, too, that birds may learn to avoid such dangers. The Washington Monument, a square pillar rising to a height of 555 feet, was noted for years for the destruction that it caused to small migrants, particularly in autumn, and thirty or forty years ago it was not unusual to find seventyfive or one hundred dead warblers, sparrows, and other small species about its base following a rainy or foggy night. Since I 910 this destruction has practically ceased, and it is now unusual for even a few birds to strike under the conditions mentioned. I have watched this monument in recent years during the time of migration, and have made many visits to it to look for birds, but have seen very few. 
MORTALITY AMONG MIGRANT BIRDS I33

All of the dangers that have been discussed are those that regularly beset birds in their travels, and many of them may not be eliminated, since our feathered friends are not amenable to traffic regulations which might promote the safety of their journeys. 


\section{CHAPTER V}

\section{General Observations on Lines of Migratory Flight}

$\mathrm{F}^{\mathrm{ROM}}$ previous statements it will be realized I that there is infinite variety in the distances travelled by various birds in migration, and in the choice of the routes that are followed. In fact, the variety is so great that it almost seems as if the methods employed in migration by no two species exactly coincide. One species travels farther than another, one passes south and another southwest, one begins migratory movement early and another procrastinates, and so on in a highly varied assortment of differences. There are factors, however, that tend to throw floods of migration along certain lines and to leave other areas occupied to a less degree, so that there are certain general lines of migration that may be traced.

Much has been written about these paths of migration, and it is generally recognized that birds in migratory flight tend to follow lines of major topographic relief on the earth's surface when these trend in the proper direction. Lanes of migration 
may be relatively narrow, depending upon the habitat chosen by birds as a place to live, as exemplified by the knot, the purple sandpiper, the surf-bird, and others which, except when on their breeding grounds, normally are found along sea-coasts, where their chosen home is bounded on one side by broad reaches of salt water and on the other by land or fresh water, both equally unsuited to furnish the food and haunt desired by these species and necessary to their well-being. The knot ventures somewhat casually inland, but the bulk of its flight is coastal. The others are strictly maritime in distribution except in their northern homes. These birds travel in narrow lanes from which there is no pronounced deviation.

In those species that migrate habitually overland the case is quite different, since here the migration path is broad and diffuse, with indefinite boundaries. Throughout the entire northern hemisphere, with the exception perhaps of such tremendous altitudes as are encountered on Mount Everest, there is in all probability no point at which migrants do not pass. In or over prairies or forested areas, mountains or valleys, deserts or marshes, lakes or plains, we find migrant birds at some time during the year, or under proper conditions hear their calls as they pass overhead at night. It is true that there are lines of pronounced concentration in migration marked by some 
river valley, mountain range, or other feature, but such flight lines must not be visualized as narrow paths or arterial traffic lanes, similar to the highways of humans, designed especially to carry avian travellers north and south; they are merely favored passageways in one broad fly line that is continent wide in extent. It is only at such places as Point Pelee in Lake Erie, or Whitefish Point in Lake Superior, that there is any true semblance to a narrow lane.

It must be borne in mind, then, in subsequent discussion that the lines of flight suggested are merely broad lanes in which migration tends to concentrate, or general tracts through which flight is particularly abundant. Quite often we find that early arrivals among birds are noted first at points in the concentrated lanes, and that only with the rush that marks the passage of the mass of individuals of a species do they appear at stations at the side. In some forms the first bird will be seen in the course of some broad north and south river valley, and it may be several days before there is a spread to points at either side. In other species movement may come on a broad front extending indifferently across the land, so that arrivals are noted simultaneously across the line of advance.

The accompanying diagram (see Fig. 5) to illustrate the author's conception of the main migration 


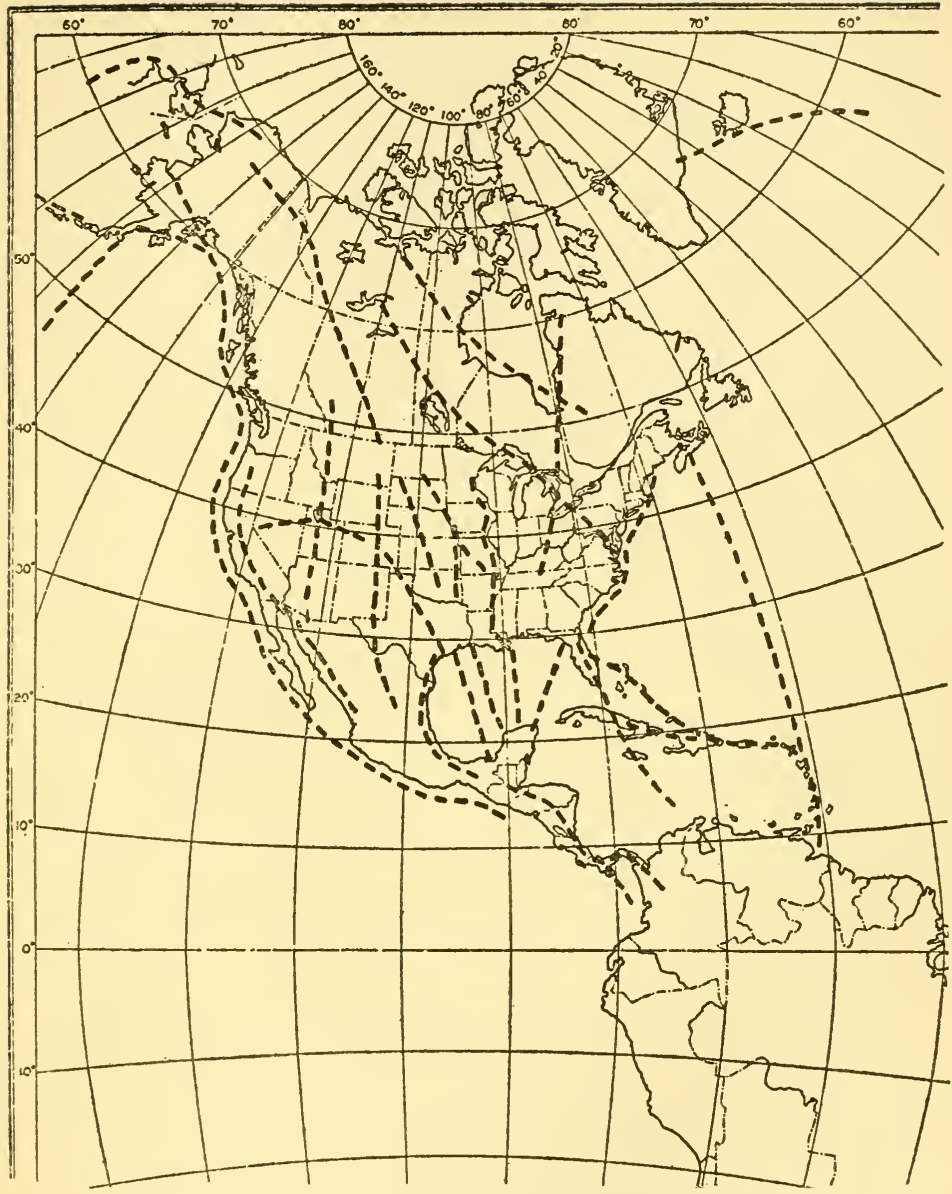

Figure 5

Main migration routes in North America, from present knowledge. Broken lines indicate the course of broad flight lines that extend at either side. Certain minor channels not as yet perfectly understood are purposely omitted to avoid confusion. 

lines of North America has been made with careful consideration of known facts. Professor Cooke, in his studies, plotted seven main lines of flight in which more modern knowledge has suggested modifications, and has added several minor or subsidiary lanes.

It must be emphasized that the dotted lines on the accompanying diagram represent direction of flight. They must not be construed as narrow pathways. Migration movement is continent wide, so that the flow of migrants resembles a tremendous stream in which currents tend in different directions, with the difference that with birds we may see distinct crossing of lines of flight. To avoid confusion as few lines have been used in the diagram as has been found practicable. Thus the line paralleling the eastern coast represents southward flight along the coast and in the interior, and lines in the interior are intended to convey the idea of movement through broad adjacent areas.

In following paragraphs the discussion is directed mainly to the southward flight in autumn. Northward migrations, except as elsewhere noted, flow in general through the same channels.

To begin in the east, the first of the major north and south lines is one that leads directly south across the Atlantic Ocean from the coasts of Nova Scotia and Labrador through or past Bermuda, perhaps 
extending in part through the Bahamas and the larger West Indian Islands, to the Lesser Antilles, and then down the course of these small islands to the mainland of South America. No land birds are known to make the long sea flight that this journey entails, but it is a regular route in autumn for thousands of water-birds, of which the golden plover is the best example. The route seems to be used by many other shore-birds, which pass directly south without troubling to follow the eastern coast line of the United States, as distance means little to these strong flyers. It is also the passage taken in part by such sea-birds as jaegers, and perhaps by the Arctic tern. As it lies at sea, it is known definitely only at the terminals or at the intermediate lands that offer points of observation. Some shore-birds that nest on the Arctic tundras of northwestern North America in autumn fly southeast to follow finally the sea road that has just been outlined.

Another regular lane extends down the eastern coast of the United States, restricted for some species to the immediate vicinity of salt water, while for others there is available inland a broad stretch of land along which minor routes of travel may be established. Many coastal points in this line are famous as points of observation both for land and water-birds as they offer a considerable diversity of natural conditions. The shore-birds that have been 
mentioned, so far as known, return north in spring by routes that carry them along or over the land, so that the outer sea lane is used apparently by few individuals in returning to the north.

From the interior basin that drains into Hudson Bay and the Arctic Ocean many birds converge in southward flight on the Great Lakes, and then pass directly south, as is the case with the blue goose, which travels from its breeding grounds somewhere in western Keewatin to this point and then drives south to the Gulf coast of Louisiana and Texas. Others from this same point, including many ducks and geese, pass directly southeast toward the head of Delaware and Chesapeake bays and ultimately reach Currituck Sound and the coast of South Carolina. There is also migration, not indicated on the map since it is only partly understood, among a few birds from the interior plains region to the southeast that brings such species as LeConte's sparrow to the coast of South Carolina.

Migrants that continue to wintering grounds beyond Florida and the Gulf Coast have now a choice of three travel lanes. One of these leads through Florida, Cuba, the Bahamas, Santo Domingo, Porto Rico, and the Lesser Antilles, to South America. Though a considerable number of migrant land birds embark on this passage the majority are content to linger in Antillean islands, and few seem 
to traverse the entire route. Many wood warblers pursue this course in both spring and autumn, and are found abundantly in passage. More popular is the direct line from Florida to Cuba and Jamaica, with a long stretch of five hundred miles which reaches across the Caribbean Sea to the coasts of Colombia and Venezuela. Our bobolink, transformed in fall into a dull-colored, sparrowlike reedbird or rice-bird, seeks this line of flight and seldom varies far from it, as only once has it been recorded east as far as Vieques Island east of Porto Rico. The chuck-wills-widow, a whippoorwill-like bird of the southeastern states, in part crosses this route, though some individuals remain to winter in the West Indies. Yellow-billed and black-billed cuckoos, the gray-cheeked thrush, the bank swallow, and the black-poll warbler, may traverse this road, but on the whole it is not popular except with the bobolink.

Fear of a sea-passage cannot account for the comparatively small number of birds that cross the Caribbean Sea from Cuba, since to the westward from Florida to Texas the path of the main flight of birds that passes to Central America leads across the width of the Gulf of Mexico to Yucatan and Vera Cruz, a journey necessitating navigation of an open area of sea as broad as the Caribbean. This route seems to receive migrants that pass south through 
the coastal plain and Piedmont plateau east of the Alleghany Mountains, those that come down the broad reach of the Mississippi Valley, and many that come south through the Plains region. Millions of birds then cross the stretch of five to seven hundred miles of open water across the Gulf of Mexico, to reach southern Mexico, where there is land over which they may continue to Central America or to South America. The Isthmus of Panama offers a narrow passage, but apparently many birds scorn its protection and fly directly across the Bay of Panama. I have seen barn swallows in such flight, and have examined in the flesh a Traill's flycatcher killed by striking a ship crossing this bay at night. Hosts of warblers and others of our smaller birds cross the Gulf of Mexico direct, and comparatively few take the more roundabout channel through Florida to Cuba and from Cuba to Yucatan, though for many years this was assumed to be the regular channel for our eastern birds that winter in eastern Mexico. It seems simpler for the travellers to attempt the direct journey in spite of the fact that on the Cuban route it would be necessary to cross barely one hundred miles of open water.

In the northern portion of the broad central area of North America there is a distinct trend of migration lines in spring toward the northwest (and in autumn to the southeast), which carries many dis- 
tinctly eastern forms to the Mackenzie River Valley and even into Alaska.

In western North America we find, in general, a wide, poorly defined flight line, which carries birds through the Plains area or the Rocky Mountains southward into Mexico. The northern portion of the Great Basin, particularly the region about Great Salt Lake in Utah, has proved to be an area of concentration in autumn migration, particularly for migrant ducks and shore-birds coming from the north. Such birds concentrate in these great marshes, and then in subsequent flight may travel southeast, south, or southwest. There appear to be two main flight lines, one that crosses the mountains to the western border of the Plains and then sweeps southward, and another that passes to the west and southwest through areas of desert, to cross the Sierra Nevada and pour a vast flood of birds into the trough of the interior valley of California east of the Coast Range. The return flight in spring, while abundant, is of somewhat different character, since many birds that come south through this region seem to migrate north by other lines. The early spring flights have not been adequately studied, and will no doubt with close observation yield unsuspected facts. It is possible that a number of northern water-birds not supposed to pass commonly through the interior use the Bear River marshes at the north- 
ern end of Great Salt Lake as a regular stopping station in the spring of the year.

Some migrants through the Rocky Mountain region continue south into Mexico, but few seem to penetrate far beyond the Mexican tableland. Study of migration in that part of the Rocky Mountain region south of the area where severe winters come to the valleys is complicated by many altitudinal movements, in which birds merely move up and down the mountain slopes as the seasons change. The greater part of the species found are not extensive travellers except for those finches, sparrows, shrikes, thrushes, and water-birds that nest in the far north and winter in this region.

West of the Rocky Mountains there is a broad line of flight down the Sacramento and San Joaquin valleys in California, which is scarcely separated by the coast ranges from a coastal line that passes south to southern California and for some birds continues down the coast of Mexico. This coastal line is marked strongly by species of migrant water-birds which are restricted to the vicinity of salt water in their search for food. Some of these are truly shorebirds and follow the beaches. Others are maritime, among which are included great numbers of shearwaters and fulmars, and many auklets, that pass at sea.

Many peculiarities of distribution due to migra- 
tion lines are found in western North America, particularly in Alaska and British Columbia. The eastern robin travels north to the headwaters of the Mackenzie River, then swings over into the valley of the Yukon and continues to the Kowak River in northwestern Alaska. The western robin, a subspecies characterized by somewhat greater size, paler coloration, and lack of white spots on the tail, when compared with the eastern bird, though found in British Columbia and Saskatchewan, in Alaska covers only the coastal district of southwestern Alaska and does not penetrate into the interior.

In work on the Stikine River region of northern British Columbia and southwestern Alaska, Mr.H.S. Swarth has found that certain migratory forms of the interior cross the mountains to the valley of the Stikine (which flows into the Pacific), and penetrate far down the river into territory that would in most cases be assigned on geographic grounds to the forms of birds found in the coast region proper. The northern flicker (Colaptes auratus borealis), the eastern nighthawk (Chordeiles m. minor), Hammond's flycatcher (Empidonax hammondi), the Canada jay (Perisoreus c. canadensis), the rusty blackbird (Euphagus carolinus), the eastern chipping sparrow (Spizella $p$. passerina), the eastern yellow warbler (Dendroica a. aestiva), and the redstart (Setophaga ruticilla), here all cross the mountains and establish 
breeding stations from twenty to one hundred miles from the point where the Stikine debouches into the Pacific. In the valley of the Skeena River, two hundred miles south of the Stikine, the catbird, kingbird, and red-eyed vireo, all eastern forms, penetrate to within one hundred and eighty miles of the sea. In normal migration these retrace their route across the mountains and move south along the broad interior flight lines.

In considering North America as a whole, we must mention also two important terminals, one on the northeast and the other on the northwest, where a few extralimital birds come to our shores to breed and then in fall return to Old World wintering grounds. In Ellesmere Land and Greenland, for example, we find the wheatear breeding regularly; and J. C. Phillips, reasoning from the many records of the European widgeon in the eastern United States, is inclined to believe that this duck has a breeding colony in Greenland.

In western Alaska Kennicott's willow warbler and the Alaskan yellow wagtail nest each summer, and then return westward, to migrate south through eastern Asia, while the European teal (Nettion crecca) crosses to breed in the Aleutian Islands, but is not known to reach the mainland. The Old World warbler and the wagtail mentioned have had their Alaskan colonies so long established that birds from 


\section{I46 THE MIGRATIONS OF BIRDS}

Alaska now differ sufficiently in color from Siberian stock to enable them to be distinguished as subspecies. This indicates long residence, yet we find them following a perilous migration route across the stormy, often fog-bound waters of Bering Sea to an Old World winter home, when a safer route to the south in the New World is open to them. Still more intriguing and exciting to the imagination are the birds that nest in Alaska, or in Siberia, and migrate south across the open sea to winter in the islands of the Pacific. From the American side these are mainly water-birds whose movements will be discussed in another connection later.

Migration routes in Europe have been worked out in considerable detail, while those of Asia have been indicated, but are less certainly known. A hasty review will give some of the interesting points concerning the main channels.

To begin in the west - there is a broad zone of flight that extends from the Arctic islands of Spitzbergen and Nova Zembla south, by way of the Scandinavian peninsula, to the British Isles, a line that receives certain tributary flight from Greenland and Iceland. In England lines of flight extend along the coasts, carrying large numbers of birds, while others spread back inland throughout the island.

Another broad line is supposed to cross from the shores of the White Sea in Russia to Holland, or to 
pass via the valley of the Rhine to the shores of the Mediterranean. Of special interest are flights east and west across the English Channel from the French and Flemish coasts to England. A complicated line of flight is indicated also south and southwest through Russia. Many of the migrants from Europe find congenial winter quarters by flights across the Mediterranean Sea to Africa, where there is a vast land area offering them choice of highly diversified land conditions.

In Siberia the valleys of the Obi, Yenesei, and Lena are supposed to offer broad pathways south, which may swing migrants down past the Black Sea into Egypt, via the Caspian Sea, to the shores of the Persian Gulf, or through mountain passes in to India or the Malayan countries. The wintering hordes toward the east are swelled by a flood of birds that come south from Kamchatka, eastern Siberia, and Manchuria coastwise into Japan, the Philippine Islands, Malaysia, and the islands to the south.

The flights indicated are broadly outlined, without reference to many cross lines and minor divisions which are not pertinent in the present work. They may be dismissed with the statement that they seem more complicated than those known in North America.

Winter migrants from the north are abundantly evident in many of the East Indian Islands at the 
proper season. In the Philippines hundreds of wagtails, pipits, and waders appear during autumn migration, some to remain for the winter, others to pass on to points farther south. In the Celebes, in addition to these northern migrants, there are recorded various movements among local birds which shift to some extent with the seasons. With the flowering and fruiting of certain trees small parrots of several species (Trichoglossus ornatus, Eutelipsitta meyeri, and Loriculus stigmatus) are abundant in Manado in March, April, or May, and then disappear, while a weaver-finch congregates in Makassar during the rice harvest in June and July, and then disperses. Certain large pigeons, as the nutmeg pigeon and some of its allies, travel widely through the East Indies, where they wander with the availability of food, but resort at the proper season to restricted areas to nest. The Nicobar pigeon in particular has this habit, and may spread through an area of broad extent during its wanderings.

South of the Equator we find few published data that give definite routes of migration, and those few are so widely scattered that it is not practicable to summarize them completely here. Merely a hint of the main routes followed may be traced in statements in paragraphs that follow.

From North America a number of species of birds come annually to winter in South America, but com- 
paratively few of these pass beyond the tropics. There are some however that go south regularly to the South Temperate Zone, and among those that perform this extended flight are a few birds of comparatively small size. The barn swallow migrates in part to Paraguay and Argentina, and may be found in the southern spring hawking about with flocks of native swallows, some of which later may retreat to Patagonia to breed. The bobolink is more worthy of mention as, though the barn swallow ranges from the West Indies southward in winter, the bobolink withdraws entirely into Brazil and the Chaco.

The cliff swallow, the olive-backed thrush, the yellow-billed cuckoo, the nighthawk, and Swainson's hawk are regular, though not abundant, arrivals as far as northern Argentina, while along the coasts of the Province of Buenos Aires we may expect parasitic and long-tailed jaegers, and Cabot's, royal, and arctic terns. The bulk of North American migrants here, however, is composed of shore-birds, of which some species, as the golden plover, the upland plover, Baird's, white-rumped, buff-breasted, and pectoral sandpipers, the Hudsonian godwit, and formerly the Eskimo curlew, find in the pampas and in Patagonia their winter metropolis. A few individuals of these northern species arrive in the south in July and August, but the main southward flight occurs from September to October. In other words 
these shore-birds pass south with the coming of autumn in the northern hemisphere, cross the Equator, and then follow the advance of the southern spring to their winter home, where they live amid summer weather. At the close of the southern summer, with the coming of colder weather in February and March, they withdraw northward and again cross the Equator, to follow the northern spring in its advance to their breeding grounds in the northern United States, Canada, and Arctic America. Their journey thus is timed to take advantage of the shifting seasons of both hemispheres.

In their movements through South America these northern species have three main routes, one along the Atlantic Coast, one that skirts the Pacific Coast line, and a third that follows north and south along the great interior river system of the Paraguay and Paraná. There is also migration, not well understood, across the high plateaus of the Andes, particularly in the vicinity of Lake Titicaca.

With regard to the movements of native birds in South America, there are many observations on record in the writings of Dabbene, Gibson, Hudson, and others, while J. L. Peters has given an account of the spring arrival of a number of species in northern Patagonia.

Migratory movements are as readily evident to the field observer as in northern regions. Flocks of 
various species of ducks, seed-snipe, small flycatchers (Lessonia rufa), that run about on the open ground, a migrant form of house wren, with other birds, appear in the Province of Buenos Aires from more southern regions at the beginning of winter, and as summer approaches, again withdraw to the southward. A goatsucker (Thermochalcis longirostris) is a regular summer migrant from Brazil to Patagonia. Occasionally one becomes lost in passage across the pampas and descends in some Argentine estancia, where it is greeted with amazement by wondering peons, who seek its feathers as a potent charm by whose force a suitor may hope to gain favor in the eyes of his inamorata. Near Buenos Aires the jacana, the sulphur-bellied flycatcher (Myiodynastes solitarius), two species of martins (Progne elegans and Phaeoprogne t. tapera), and a small swallow (Iridoprocne albiventris) are summer visitants, which at the approach of cold retire to the north, as does the bulk of some other species, a part of whose individuals are sufficiently hardy to brave the moderate cold of winter in that latitude.

Even in northern Paraguay, in the edge of the tropics, the spring migration is easily evident, as with the advance of September Podager nacunda, a bird related to the nighthawk, passes in regular evening flights toward its summer haunt in the pampas, hawking for food as it travels in rapid zig- 
zags across openings in the forest; a kingbird ( $\mathcal{T} y$ rannus $m$. melancholicus) appears and continues south into the scantily wooded area of central Argentina; and a little goatsucker (Setopagis parvulus) arrives from winter quarters in Bolivia and Brazil, to utter its tremulous calls at evening.

The low woodland of the level reaches of the interior Chaco, which lies west of the Ríos Paraná and Paraguay, from Santa Fé in Argentina to southern Bolivia, with its dense jungles impervious to cold winds, and its tangled openings where the rays of the sun are warm even on frosty mornings, harbors many winter visitants from the more open country, or from the mountain slopes to the west. Here small flycatchers, warblers, and other insect-eating birds rest in comfort, remaining quiet during brief spells of cold, and becoming active when the sun appears. Broad stretches of dense scrub that cover the low hills east of the mountains from Tucuman northward, also offer secure coverts where small birds at times fairly swarm.

Altitudinal migration is easily evident in the Andean foothills from Bolivia southward, as in autumn flycatchers and other small birds work down the mountain slopes in little bands which travel down to the plains and then pass on northward. With heavy storms at high altitudes these movements are especially marked and may include birds 
from the hills, which migrate temporarily to the warmer lowlands and then return to higher regions after the stress of weather has passed.

In considering migration among birds of this portion of the southern hemisphere we must not neglect to examine the remarkable habits of some of the shearwaters and petrels. The sooty shearwater, for example, nests on islands in New Zealand seas and in the vicinity of Cape Horn, and in May, after the breeding season, migrates northward, to cross the Equator through both great oceans, and reach the latitude of southern Greenland and the Kuril and Aleutian islands. In September, it returns southward. The slender-billed shearwater, at the same season, from breeding grounds in southern Australian and New Zealand waters, comes north along the western side of the Pacific, and in May passes south along the eastern shores of that ocean. One or the other of these two species in Alaskan waters, ranges in flocks numbering tens of thousands. Wilson's petrel, the little Mother Carey's chicken of the sailor, also nests in extreme southern latitudes and passes north in March, April, and May, on erratic flights that carry it through the oceans of the entire world with the exception of the North Pacific. These species and some others penetrate as far north of the Equator, as some terns, jaegers, and shore-birds which breed in the Arctic travel south of it. 


\section{54}

The migrations of birds in Africa are comparable to those recorded for South America, though, as on that continent, information available from the tropical area is meagre, since ornithologists interested in the subject have seldom been resident for sufficient time to make prolonged observations. As a winter resort for migrants from the Northern Hemisphere, Africa is more popular than South America, probably because of the comparative ease with which it is reached by cautious wayfarers. Spain, Italy, and near-by islands, and Arabia, offer passageways on a broad front for birds that do not care to attempt directly a crossing of the comparatively narrow width of the Mediterranean. If blown aside by storm, migrants have fair chance of a landing somewhere on the broad land area of either the northern or southern continent, so that the dangers of crossing are little more than those incurred in flight over land. The physical barriers imposed against migrants are thus more favorable than in the New World, where the Gulf of Mexico and the Caribbean Sea extend at an angle, with a narrow line of islands, separated by considerable distances in some cases, forming the only barrier from the open sea on the east. It has been said that more migrants cross the Mediterranean Sea than any other sea in the world though whether more pass than fly across the Caribbean and the Gulf of Mexico combined is perhaps open to question. 
In the Cape region of South Africa W. L. Sclater has recorded seventy-six migrant species from Europe and Asia that come for the period of the northern winter; while J. P. Chapin, working mainly in the forest belt of equatorial Africa, has recorded approximately fifty visitors from the Palaearctic region. On the face of it one might suppose that the great desert of the Sahara would interpose a barrier to flight as perilous to cross as that of some great sea, but apparently this is hardly true since, though bird life is scant in areas of shifting sands, zoölogical exploration of recent years has yielded a varied avifauna in many districts in the Sahara. Hartert has recorded 24 or more Northern Hemisphere migrants in Aïr in the central Sahara, where they were associated with many obviously tropical species; and there are broad areas where desert mountains and semi-arid valleys offer favorable conditions. To the eastward the Nile Valley and the eastern coast-line offer ready fly lines, which lead as far south as the bird may care to go. The valley of the Nile in particular is favored by multitudes of shore-birds, cranes, ducks, and other fowl that nest in northern Europe and Siberia.

The northern migrants that reach southern Africa arrive in October and leave for the north in March and April. Among them are included such wellknown European birds as the golden oriole, four 
forms of wagtail, the red-backed shrike, the willow wren, the spotted flycatcher, the swallow, the Egyptian kite, three marsh harriers, the white stork, five plovers, and an assortment of other shorebirds. In southern Africa Sclater finds 21 native species regularly migrant toward the north at the close of summer, which return in spring to breed. They are supposed to winter in central Africa. Curiously enough, of the entire number of these migrants no less than nine are cuckoos. These are accompanied by three native forms of swallows, a swift, a roller, a wryneck, a falcon, Abdim's stork, two coursers (Cursorius temminckii and Rhinoptilus chalcopterus), and a wattled plover (Afribyx senegallus lateralis).

Local migration is, however, more extensive in southern Africa than the list just enumerated would indicate, since there are about fifty additional forms a part of whose individuals remain in winter when others travel to the north. Movements among these are dependent in part upon rains or other conditions. Some, as the wattled starling and Nordmann's pratincole, wander, when not nesting, with the appearance and disappearance of the hordes of locusts for which these regions are noted. The white stork, a migrant from Europe, joins them in their travels during the season that it is present. Andersson, in studies of the birds of Damaraland, 
recorded a number of species which were present only during the rainy season, a condition that may hold as well in other parts of Africa.

In the northeastern section of the Congo Basin Chapin, during observations that covered three successive years, has recorded nearly forty species of truly African birds which he considered more or less migrant. Most interesting among these is the pennant-winged night-jar (Cosmetornis vexillarius), a remarkable species in which the adult male has two of the inner primaries (the second and third) greatly elongated, so that they measure two and one half times the length of the bird from the end of the bill to the tip of the tail. Though strictly tropical in its range, this striking species migrates regularly back and forth across the Equator twice each year. From September to November it breeds in the open country south of the equatorial forest, from Angola and Lake Tanganyika to Damaraland and the Transvaal. A few birds remain throughout the season in the northern edge of the breeding zone, but the majority migrate northward in February to Uganda and the grass country adjoining the forest on the north. Its movements correspond with the seasonal appearance of termites in the two regions concerned, so that in the activities of these insects, which form a valuable food, we may see a reason for the shifting in range on the part of the goatsucker. 
An allied species, the standard-wing night-jar (Macrodipteryx longipennis), has somewhat similar habits, and a like migration is suspected in the case of other birds.

Before leaving the subject of Africa it may be mentioned that thirty-six forms of sea-birds are found on the southern coasts, most abundantly in the winter period from March to October, which in the breeding season leave for islands far distant in the ocean, where they rear their young. The majority of these - twenty-nine to be exact - are petrels, shearwaters, and albatrosses, while the others are mainly terns.

Perhaps there are fewer data assembled on the migration of birds in Australia than on this phenomenon in any of the other continents, yet a study of the movement of birds here is highly important, in the evidence it offers that may throw light on the possible origin of migratory movement. There are, as in other southern continents, a small number of species that come in search of winter quarters. Thirty of the migrant forms, other than pelagic wanderers among sea-birds, which seem thus far to have been recorded at all regularly, are shorebirds or their relatives, while one of the remaining three, the white-winged black tern (Chlidonias leucoptera), is found only rarely in North Australia. This leaves the spine-tailed swift (Chaetura cauda- 
cuta) and the Pacific swift (Micropus pacificus) as the only other species that perform regular flights to this far-distant land, where they remain during the northern winter. These two occur regularly and penetrate to the southern portion of the continent. There are a few other species as the corncrake (Crex crex), a yellow wagtail (Budytes flava simillima), the parasitic jaeger (Stercorarius parasiticus) and the upland plover (Bartramia longicauda), which have occurred in Australia casually, but cannot be considered regular visitants. Few of the winter residents go farther than Australia, so that records of northern migrants for Tasmania and New Zealand are in the main casual or accidental, and are based on few occurrences. In New Zealand the only regular migrant seems to be the Pacific godwit (Limosa lapponica baueri), though there are a few records for the knot, curlew sandpiper, and the Pacific turnstone, which indicate more or less regular arrival among these birds. The corncrake, the two swifts that come to Australia, the parasitic jaeger, and a long list of shore-birds have been included in the New Zealand list but only on basis of from one to three records.

Among native Australian birds there may be recognized two groups, a small band that is regularly migrant with the season, and a greater number that are so irregular in occurrence that they have 
well been called nomadic. Among regular migrants may be noted the dollar-bird (a roller, Eurystomus pacificus), and the channel-bill (Scythrops novaehollandiae), a large cuckoo, which, according to North, arrives in Queensland and New South Wales in August or September, and departs with the coming of cold weather in April. The sacred kingfisher (Sauropatis sancta) in New South Wales comes in August and September, and, after breeding, departs in March. A few remain throughout the winter, and the migration of this species is not far, as it is said to be resident in northern Queensland. The spotted harrier (Circus assimilis) reaches New South Wales in August and departs in February. The slate-breasted rail (Rallus $p$. pectoralis) appears on the Adelaide Plains in August or September and leaves in November. Of greater interest are the movements of the bee-eater (Cosmaerops ornatus), of which two forms are known, an eastern and a western, of which the last may be sedentary. Though a few of the eastern subspecies may remain throughout the year in the northern portions of Australia, the majority migrate to New Guinea, possibly to other islands, as they have been seen in flight past Thursday Island, and at other points in Torres Straits. Some are said to make a direct flight to eastern New Guinea, without troubling to pass north to the narrow pass at the end of the York Peninsula. 
There are four species of swallows that reach South Australia, three of which are certainly migratory. The welcome swallow (Hirundo neoxena) a species that received its common name through the pleasure that its appearance gave early white settlers, has been recorded by Morgan near Adelaide throughout the year, but is less numerous through the winter period. Some of those that remain are not seriously inconvenienced by cold, as occasionally they breed at that season. However, it has been stated that after cold nights ten or a dozen of these swallows have been found dead in the reed beds to which they resort to roost. The fairy martin (Lagenoplastes ariel) is a strictly migratory species, while the white-breasted swallow (Cheramoeca leucosternon) at Laura, I 40 miles north of Adelaide, where at an altitude of 700 feet the winter is cold, is strictly migratory, though at sealevel, at Port Augusta, only sixty miles away, where the winter air is milder, the birds are resident. It is possible that here they perform only a brief altitudinal flight. The welcome swallow and the whitebreasted swallow cross to the island of Tasmania to breed but return to the continent to winter.

In New Zealand the Australian avocet, an Australian heron (Notophoyx novaehollandiae), a nightheron (Nycticorax caledonicus), the Australian treeduck (Leptotarsis eytoni), a teal (Nettion castaneum), 
a pochard (Nyroca australis), and a darter (Anhinga novaehollandiae), are noted as irregular visitants, indicative of slight migratory wanderings among these species, which carry them beyond their native continent of Australia. In New Zealand, too, we find two cuckoos (Lamprococcyx lucidus and Urodynamis taitensis) which are present only in summer and disappear in cold weather. The long-tailed cuckoo migrates through the Pacific Islands to Fiji and beyond. The winter home of the other species is not certainly known.

Considerable numbers of birds found on the Australian continent are so distinctly irregular in their occurrence that they may be best termed nomadic, since they wander with climatic changes and are not seasonal in their occurrence. Many of these are directly affected by rains in their movements, as failure of water supply in the more arid sections may drive them to more favored areas, while conversely an excess of rain recalls them. A gallinule (Tribonyx ventralis), according to Captain S. A. White, visits South Australia every few years, where it remains from July to November. After appearing regularly for a time, it may be absent entirely for a number of years - an erratic habit that is apparently common to it throughout the continent. Various lorikeets are said to be governed in their nomadic forays by the blossoming of the 
eucalyptus, on whose flowers they depend for food. In New South Wales in favorable years T. P. Austin has found the musk lorikeet (Glossopsitta concinna) arriving by thousands with the blossoming of these trees. At times they soon disappear, though in some years a part remain to breed. In other seasons very few are seen. Similar habits are recorded for the little lorikeet (Glossopsitta pusilla) in the same region. The cockatoo parrot (Leptolophus hollandicus) comes usually to Victoria in summer, while the grass parrakeet (Melopsittacus undulatus) is found to be irregularly migrant in many localities. Like the lorikeets, certain of the honey-eaters (Meliphagidae) shift about with the flowering of eucalyptus, and are present or absent in accordance with the status of these trees.

The arrival of birds in abundance with the coming of rains has been recorded on numerous occasions in the more arid sections, while it is stated that, if proper conditions continue, these birds breed and may continue their presence for two or three years. The condition is highly peculiar, in that the nomadic habit is not confined to a few species as in the northern hemisphere, but is widespread and dominant among non-sedentary forms, so that it supplants the regular north and south movements found in other continents except in a comparatively few forms. It differs from regular migration in that 
I64 THE MIGRATIONS OF BIRDS

there is no hereditary tendency toward regularity of movement. It may be considered as one of the preliminary stages leading to the development of a regular seasonal movement when it becomes necessary to adjust to regular seasonal cycles. 


\section{CHAPTER VI}

\section{Migration Among Shore-birds}

SANDPIPERS, snipe, and plover, and the other $S$ forms that comprise the group of shore-birds are renowned among ornithologists for their powers of flight and the distances that they cover in migration. Approximately seventy of the two hundred or more that are known nest in Arctic regions and are forced to migrate each year. The distances they cover are marvellous, as a number pass south to winter in the southern hemisphere. One or two species, as Peale's sandpiper (Aechmorhynchus parvirostris) of the Tuamotu Archipelago in the South Pacific and an allied species (Prosobonia leucoptera) of Tahiti, - the latter now perhaps extinct - are, so far as known, entirely sedentary. A few other forms of sandpipers perform limited migrations, but such appear unusual in an assemblage of species noted for the extent of their semi-annual flights. As a group the shore-birds cover greater distances in the aggregate in their spring and autumn flights than any other birds.

The purple sandpiper (Arquatella m. maritima), breeding in the northern hemisphere, in eastern 
North America is found in winter from Greenland south regularly as far as Long Island. Its western forms, the Aleutian sandpiper (Arquatella m. couesi) and the Pribilof sandpiper (A.m. ptilocnemis), which breed on islands in Bering Sea and the Northern Pacific, come south only in to southern Alaska. The American woodcock (Rubicola minor), nesting mainly in northeastern United States, winters in the southern states largely east of the Mississippi River. In South America there is a peculiar three-toed sandpiper (Phegornis mitchelli), found at high altitudes in the Andes, which seems to content itself with a limited migration down into valleys; while another, the so-called sociable plover (Pluvianellus sociabilis), ranging near the Straits of Magellan is not known to migrate at all.

Among North American species of shore-birds there are twenty-three forms which are found in winter from our southern states south to South America, four others which fly south through the Pacific Islands, and ten, in addition to those already mentioned, which retire wholly to South America in winter. It is possible that this last number may be increased to twelve, since the winter range of the red and northern phalaropes is not certainly known.

The majority of our shore-birds nest in boreal regions, and many seem to remain on their breeding 
grounds a very short time; for the spring migration does not close until the end of May, while in some species early migrants begin to arrive from the north by the first week in July. In the case of the Wilson's phalarope (Steganopus tricolor) in Utah, I have definitely established that there are many that do not breed each year. At the northern end of Great Salt Lake this species nests in small colonies where marsh conditions are suitable. During June, in addition to the breeding colonies, I found large flocks composed entirely of non-breeding individuals (as was shcwn by examination of the sexual organs in a considerable number) congregated on the lake front where food was abundant. On one occasion I estimated that between 20,000 and 30,000 were gathered about shallow pools on one stretch of alkali barrens, and it was impossible to say how many more were concealed in the shimmering heat haze that concealed all low objects beyond a distance of half a mile. Strangely enough more than ninety per cent of these birds were females, which leads to an assumption that there may be a preponderance of that sex in the species under discussion, as mated pairs at the time were on their nesting grounds in nearby marshes.

It is not improbable that some of the early migrants which are recorded among other shore-birds are also non-breeding individuals, or are perhaps 
those whose eggs have been destroyed and their attempts at rearing a family thus frustrated. With no further cause to remain in the north, these may push rapidly southward and form our early migrants. However we may attempt to explain the phenomenon, the facts remain that many birds of this group start south very early, so that by the middle of July in the northern United States migration is well under way in a number of species. It is of interest to note that passage southward in many individuals is rapid. In I9I 2 , in Porto Rico, the spotted sandpiper arrived from the north on July 9, and the solitary sandpiper on July 29. In I920, in southern South America, I noted the beginning of migratory movement from the north among these birds on July 3I, with the arrival of the lesser yellow-legs on lagoons near Las Palmas, Chaco. The solitary sandpiper reached the town of Formosa on the Río Paraguay on August 23; while during the first week of September, when I had penetrated north to Puerto Pinasco in northern Paraguay, migration began in earnest, and a steady stream of sandpipers and plover passed southward through the Chaco throughout the month. This southward movement was still in force during October when I was in the open pampas of eastern Buenos Aires, and continued without appreciable abatement until the close of the first week in No- 
vember. By the middle of November, arrivals from the north ceased and birds of this group were settled on their winter resting grounds.

Changing conditions in this far distant region have affected many of our North American migrants, which go there to winter, as seriously as the persecution of guns to which they have been subjected in the North. Broad areas of dry or marshy pampa, under primitive conditions the winter homes of myriads of golden plover, upland plover, and Eskimo curlew, are now devoted to raising wheat or to the pasturage of great herds of cattle and sheep. Added to this change in ecological conditions, there has been persecution by man because certain of these birds became famed for the delicate flavor of their flesh. The Eskimo curlew, unable to adapt itself to changing conditions, is practically, if not actually, extinct; while the upland plover, greatly reduced in abundance, at present aided by protection from gunners in the United States and Canada, is holding its own though its fate is doubtful, since in South America it has inherited the name and epicurean fame that proved the downfall of the Eskimo curlew. The golden plover is in better state, since it lives on the broad coastal mudflats as well as on the open prairies, and in the former locality is less accessible. It was strange to find the white-rumped sandpiper, a speciss known well to 
few ornithologists in the United States, the most abundant of the wintering shore-birds on the pampas.

On the eastern coast of the province of Buenos Aires, while living in a lonely herdsman's hut among sand dunes, far from other habitation, I witnessed an interesting example of crossing lines of migration in these birds. Apparently many shore-birds drive down the broad interior basin of the Río Paraguay and continue straight south in their rapid flight, until they reach the coast in the vicinity of Bahia Blanca. Here some remain, some pass on south, and a certain number swing around to follow east and then north along the coast to wintering grounds near the mouth of the Río de la Plata. At the camp mentioned I noted these birds driving by toward the north, while at the same time little bands of sanderlings, occasional knots, and a steady stream of jaegers came directly south by the coastal route. Thus I had spread before me the spectacle of two lines of migration flight, both emanating originally from the same northern sources, but here, near the end of their long journeys, meeting and passing in directions diametrically opposite - one of the most interesting sights that has come to my attention during long years spent in field observation.

Once established on their wintering grounds, these birds become quiet and more or less sedentary. 
Heavy rains that flood new areas in the pampas may frequently bring small flocks of shore-birds in search of new feeding grounds, but such movements are of slight extent and affect comparatively few individuals. A period of moult is at hand and the birds are inactive. Change in behavior is especially marked in the two species of yellow-legs, which become as quiet in notes and demeanor as small sandpipers or plover, quite in contrast to their noisy greeting of intruders in their flights north of the Equator. They remain thus during the months that mark the northern winter.

The impulse toward the return flight to the north comes early; for at the close of January in I92I I noted a slight movement among golden plover on the eastern coast of Uruguay. On February 7 upland plover began passing northward in small numbers through eastern Uruguay, and on the following day pectoral sandpipers began their flight. These early individuals must make frequent long stops, so that their northward flights extend over a considerable period of time, since their breeding grounds are not open to them until a much later date. Slow increase in northward migration was observed during February, and by the close of the first week in March the movement was in full swing. The first week in April marked its culmination, and by the end of that month decrease in shore-birds 
was easily apparent. Many northern shore-birds however linger in the central portion of South America until May, when they must drive swiftly northward, with comparatively little rest, to reach their northern homes by the opening of the brief period of summer.

There is also evident migration among a few South American forms that belong to the shorebird group. What is known in Spanish as the Chorlito invierno, "the little winter plover" (Zonibyx modestus), and the Falkland plover (Charadrius falklandicus), nest regularly from Patagonia southward, and with the approach of cold weather migrate north in company with foreign species as far as the pampas, but there linger. With them come a few individuals of a larger form (Oreopholus r. ruficollis). These southern species are not known however to reach the Equator in their northward journeys. Migratory flight of a similar nature is known in the Paraguayan jack-snipe (Capella paraguaiae), but its extent has not been definitely ascertained.

Brief mention has been made previously of migration from Arctic regions into the oceanic islands of the South Seas, a wintering ground that reaches to the eastern atolls of Polynesia, far distant from any continent. The Pacific golden plover and the turnstone regularly perform this flight, while with them come the bristle-thighed curlew, the wander- 
ing and Eastern tattlers (Heteroscelus incanus and $H$. brevipes), the sanderling, the Pacific godwit, and the sharp-tailed sandpiper. These pass to the far south, the godwit regularly reaching New Zealand, while some of the others penetrate irregularly or casually to that group of islands. The Pacific golden plover is a regular migrant to the islands of Hawaii, and winters there in some abundance on grassy uplands; others of the subspecies pass on far to the southward. In the passage south, if these birds touch at the Aleutian Islands, they have a distance of nearly 2800 miles across open seas before they reach a safe haven of land. As in this great stretch there are no landmarks, they must revert to some sense of direction to guide them safely.

Among hunters on the island of Barbadoes in the British West Indies there is current belief that shorebirds migrant to that island alight to rest on the surface of the ocean; and it is the custom when shooting to taste the axillar feathers of birds killed. If these have a flavor of salt, it is assumed that the bird has recently arrived, and the salty taste is attributed to immersion in the ocean. Though it is not impossible that shore-birds might alight on the water to rest and then fly again, there is no observation known to me to prove that they regularly do so. The salt taste alluded to could easily arise from a deposit from vapors blown by the wind, as 
it is common in walking along sea beaches for lips and hands to receive a slight deposit of salt - a circumstance that must operate on the feathers of birds as well as on the skin of humans.

It has been my fortune to see wayfaring shorebirds make a landfall after a long trans-ocean flight. While cruising through the Leeward Islands of Hawaii in I923, I observed turnstones coming up from the south, where the nearest land, in the Gilbert or Marshall Islands, was a thousand miles away. The birds usually arrived in early morning. On one occasion in particular some turnstones came beating up from the south at daybreak, flying low in the trough of the waves to escape as far as possible the force of the wind. They seemed tired and passed rather slowly toward low islands in the atoll at Pearl and Hermes Reef a few miles distant.

Africa, like South America, receives many migrant shore-birds, as nineteen species that breed in the far north come there regularly to winter. Many others pass south through Asia to wintering grounds among East Indian islands, or penetrate to distant Australia. Northern shore-birds are found in abundance in the Philippines and Celebes, and Mathews records thirty species of this group that winter more or less regularly in Australia.

From this review it appears that many plover and sandpipers that breed in Arctic regions winter 
south of the Equator in the southern hemisphere, so that as a group they have longer migration routes than any other order of birds. Though the southern hemisphere has a number of peculiar forms some of which are more or less migratory, there are none that perform the extensive flights common among their brethren of the north.

In connection with this group, it may be well to consider claims that have been made that the godwits, yellow-legs, and plover found in South America in winter do not really come from the north, but that there are two groups in the species concerned, one that breeds in boreal regions and in winter migrates toward the Equator, and another that nests somewhere in Patagonia, the islands of Antarctic Seas, or even on the great Antarctic continent, and in cold weather flies toward the north to winter in Argentina. This belief has been based in part upon the irregular occurrence of these migratory birds during periods when all should have been on their northern breeding grounds, and in part upon disbelief in the power of flight in creatures apparently small and weak.

It may be said definitely that there has never been any proof of the breeding of such species as the golden plover, the yellow-legs, the godwits, or other similar species, considered as migrants from the north, during their sojourn south of the Equator 
in South America or elsewhere. Eggs of yellow-legs are said to have been found in Argentina, and Layard has stated that in New Caledonia he has seen the golden plover followed by a downy chick; but in these and similar instances on record supposed parentage on the part of the shore-birds concerned has been based solely on assumption and association, and authentic instances have never been produced. Layard, for example, did not collect the downy young that he supposed to be that of a golden plover; and eggs have been attributed to the yellow-legs in Argentina simply because those birds were seen near-by.

Double nesting periods have been claimed for the European bee-eater and some other birds in South Africa, but as our knowledge has increased, it appears that, with the possible exception of certain cuckoos, the birds that breed in Africa are a different set of individuals from those that nest in the north. In the New World the pied-billed grebe, the cinnamon teal, and the fulvous tree-duck have breeding ranges in both North and South America. In some cases individuals in the two groups differ slightly from one another, while in others, notably the cinnamon teal, they appear indistinguishable. Yet, so far as we know, the colonies are wholly distinct and have no interchange of individuals.

There are a number of shore-birds that remain in 
the south during the northern summer, as they have been recorded in South America, and I have personally seen golden plover, turnstones, and tattlers among islands in the Pacific at that season. Scattered individuals that I have examined were found to be wounded, sterile, or otherwise diseased individuals that were unable to perform the long flight to their northern homes, or from their condition lacked the physiological incentive to so do. In the Hawaiian islands it appeared to me that most of these lingerers seemed to feel a desire to travel northward, but were restrained by their condition from making the attempt. A number seen were individuals that had not been successful in carrying through the winter moult, and in consequence were in very ragged plumage. Imperfections in the flight feathers would weigh heavily against chance of success in prolonged flights to northern lands. We shall never know how frequently such imperfections result in slackened flight, which prevents such birds from reaching the safety of the distant land toward which they fly, as any that may fail disappear in the broad seas they are required to cross.

Of classic interest in discussion of the flights of American shore-birds is the migration route covered by the golden plover. The eastern form of this bird, from its breeding stand in Arctic America in late summer, migrates to the east and southeast 
to Ungava and Labrador, and from there embarks in a flight that carries it directly out over the open sea. It is uncommon ordinarily on the coasts of New England, and casual and irregular south to Long Island. From that point south, the bird is almost unknown. The migration route carries it past Bermuda, the Bahamas, and the Lesser Antilles, apparently in large part over the ocean, as few seem to alight. Colonel Fielden has recorded early arrivals at the island of Barbadoes in July and the first part of August, but finds that the main flight comes after the latter part of August. The course in flight across the island is from northwest to southeast, and if unfavorable winds prevail, many alight. The early arrivals are black-breasted birds, which indicates that they are adults. The young begin to appear about the twelfth of September, and continue in flight into October or even November. From here they continue south to the continent of South America, and finally reach a wintering ground in the Argentine pampas.

During the fall migration golden plover may be scattered over a tremendous range. In I920 I noted the earliest arrivals at small lagoons in the Chaco west of Puerto Pinasco, Paraguay, on the sixth of September. On this same date Dr. Francis Harper, travelling for the Biological Survey, reported golden plover in small numbers in the vicin- 
ity of Lake Athabasca in central Canada. In an air line the species was thus spread across more than six thousand miles of the earth's surface, while, by the actual line of flight which these birds pursue, the separation of northern and southern individuals was infinitely greater.

The flight of golden plover in spring begins casually at the end of January but is not fully under way until March and April, when they pass north with a rush to the northern coast of South America. From here, instead of flying north over the sea on a return journey by the course pursued in autumn, they cross to the Gulf coast of the United States and go north through the Mississippi Valley to their Arctic breeding grounds. Their spring route is thus over a course where the birds are entirely absent in autumn.

The Pacific form of this species, which nests along the Bering Sea coast of Alaska and in northeastern Siberia, travels south along the eastern coast of Asia as far as Australia, Tasmania, and New Zealand, and through the Pacific islands from Hawaii southward. The two groups of birds in this species thus pursue wholly different courses in their flights.

The turnstone is a species that is almost cosmopolitan in range as it nests in the far north, to 70 degrees North Latitude and farther, and migrates south throughout the World, though mainly along 
salt waters, extending in winter as far as South Africa, Australia, New Zealand, and Chile. The little sanderling covers a similar vast area, as it nests in the Arctic regions of both hemispheres, and in winter is found south to Patagonia, southern Africa, and Australia. These two species have a greater migration range than any others known, for they are found at one time or another on almost every seacoast in the entire world.

\section{The Seasonal Flight of Ducks}

With the advent of civilization feathered game invariably has decreased in abundance, yet our wild ducks, because of their wariness and the nature of their haunts, have remained common until to-day, and as a group probably show the most easily observed examples of the actual process of migration. Small birds as migrants, appear and disappear with their movements cloaked by darkness so that their flight passes unseen, except under the exceptional circumstances of observation of the face of the moon by telescope, or as the passage of migrants in the darkness is detected by their calls. Nearly all ducks fly regularly by day, travelling at heights where they are readily visible; and as most of us, if not hunters, possess traces at least of the hunting instinct, these flights attract instant attention. 
Though ducks fly often by day, they also migrate by night if conditions require it; northern flights late in autumn frequently come in during the night, though I have seen birds arrive from the north by thousands late in afternoon, when they came swinging down in long straggling flocks, 80 to 100 yards above the earth, and passed on to the south without a glance at the decoys set in front of my shooting blind. These birds had evidently come a considerable distance, and were on their way to points still more remote. Dr. J. C. Phillips has noted that the ruddy duck flies invariably by night, and says that he has seen them coming in to resting grounds at the first sign of dawn. This habit, however, is confined so far as I am aware to this species alone among our North American ducks. Southward flight of such species as scoters, which are largely frequenters of salt water, is mainly by day, and is easilyobserved, as during the time of flight the birds pass steadily.

In the northern hemisphere a few ducks nest in the marshes of middle latitudes, but by far the greater number breed in the sloughs and ponds of northern areas. Most species of ducks are hardy and do not flee from cold so long as food is available. Their movements, therefore, are governed largely by the presence of food and by search for areas where they may hope to escape from their greatest enemy, man. Though widely scattered for the 
period of breeding, during the remainder of the year they are concentrated in favorable areas, where they may assemble in tremendous numbers. In North America the marshes of Great Salt Lake, the interior valleys of California, the delta region at the mouth of the Mississippi River, the estuaries of the Susquehanna and Potomac rivers, and the region of Currituck Sound are all famous ducking grounds. It will be of interest to trace some of the migration routes by which ducks reach these regions. We have available for this study a fair amount of information based on birds that have been banded, so that some of the routes may be traced in some detail. It is interesting to find that a number do not tend in direct north and south lines.

The Bear River marshes at the northern end of Great Salt Lake have been known as one of the famous shooting grounds in the western states, but it was not until data became available from banded ducks that the importance of this region as a centre of distribution was realized. From I9I4 to I9I6 I was occupied during the months of summer and autumn in studies of the birds of these marshes, and banded some I 200 birds as an incidental part of other work in hand. Returns from these have yielded results of the greatest interest.

As a preliminary statement, it may be noted that many of the birds captured and banded at this point 
had nested elsewhere. It is a well-known fact that drakes in most of our species of ducks desert their mates shortly after incubation of the eggs is begun. These males, particularly in some of the surfacefeeding ducks, congregate at once in large flocks, and may at this time migrate to favorable localities where they pass the remainder of the summer. At the mouth of Bear River male pintails and mallards begin to congregate in these post-breeding bands at the end of the first week in June, and continue to gather from that time until autumn. By the end of June it was not unusual to find two thousand pintails or more in one flock, and their number increased regularly with the advance of the season. A careful canvass of the vicinity in May showed an average local breeding stock of only one hundred pairs of this species, so that the majority of these recreant benedicts had come from other regions, how far distant we may not say. It is interesting to note that observers in central and northern Canada and in Alaska have commented on summer flocking in this species with subsequent disappearance of a part, so that some of the Bear River birds may have come from a long distance. This, however, for the present is purely speculation.

Summering bands of males moult at once into dull summer or eclipse plumage, and then shed the flight feathers, becoming flightless for a period, 
whence their need of extensive marshes as hiding places. Females follow the males to the seclusion of the marshes when the young are old enough to shift for themselves, but have their moult delayed until late summer. This early separation of the sexes persists in part through the autumn, though mixed flocks of males and females are of frequent occurrence.

The duck population of the Bear River marshes continues to grow steadily beyond the normal breeding stock, until the first of September, with a sudden increase at the end of August, when hordes of young begin to arrive from other breeding areas. Between September I and Io fully two thirds of the ducks that have gathered migrate out to other regions. Cinnamon teal and redheads leave in a body at this time, and with them go many others. The sudden disappearance of the host of birds is easily noted, but others continue to arrive, and by October I enormous numbers are present. During the second week in October there is increase in flight from the north, which continues steadily until the close of the season. Ice closes the bays in part by Thanksgiving time, and between December I and I 5 the last of these birds are driven to other regions. Ducks that I banded at this point were killed subsequently over the entire western United States, from western Missouri and Kansas to California, 
and from the Mexican border to Saskatchewan. (See Fig. 6.) Analysis of the records gives a clue to some of the lines of migratory flight that are pursued. By way of introduction, however, it may be stated that ducks are birds of strong flight to which mountain barriers mean little, so that their journeys from the Salt Lake Valley do not necessarily follow uniform trails through the sky. Certain general routes however are indicated. There is one broad fly line that passes south over the Rocky Mountain plateau, used by a comparatively small number of birds, which carries ducks to the scattered lakes and ponds of central and southern Utah, New Mexico, and Arizona. To digress for a moment, it may be observed that this line of flight is the one pursued by snowy herons from the colonies at the mouth of Bear River; birds of that species, as shown by banded individuals, migrate south through southern Arizona, where one was killed on the San Pedro River in Cochise County, to a wintering ground on the west coast of Mexico. Returns from these birds have been interesting. A peon at Mexcaltitan, Territory of Tepic, found a bit of aluminum on the leg of a heron that he had killed to eat, and brought it to a Japanese labor contractor. The band had been preserved from curiosity, as the peon was unable to read; so that the merest chance brought a return from one of the snowy herons banded the year pre- 
vious in distant Utah. Another was reported, through the State Department, by the American consul at Acapulco, from a bird killed on the Papagayo Lagoon in Guerrero. A third, banded July 3, I9I6, was killed January 20, I923, near Escuinapa, in Sinaloa.

To return to ducks, we find indicated a general line of flight from the Salt Lake Valley to the west, which is followed by a large number of birds, among which may be enumerated green-winged teal, shovellers, and a part of the pintails and mallards. This flight strikes the broad valley of the Sacramento, and then spreads southward through the marshes and sloughs of the interior basin, south to southern California. Return records from birds banded near Great Salt Lake include a considerable number of green-winged teal taken in the region outlined in California.

Another group of birds passes to the eastward, to the Great Plains area, and continues south to Texas. There is indication that some of the ducks that take this route fly north through Idaho to the headwaters of the Missouri, and then follow down east of the foothills of the Rocky Mountains. At least, I have record of one pintail banded and released at the mouth of Bear River September 4, I9I6, which was killed eleven days later near Glasgow, Montana, and there are three returns of banded redheads from 


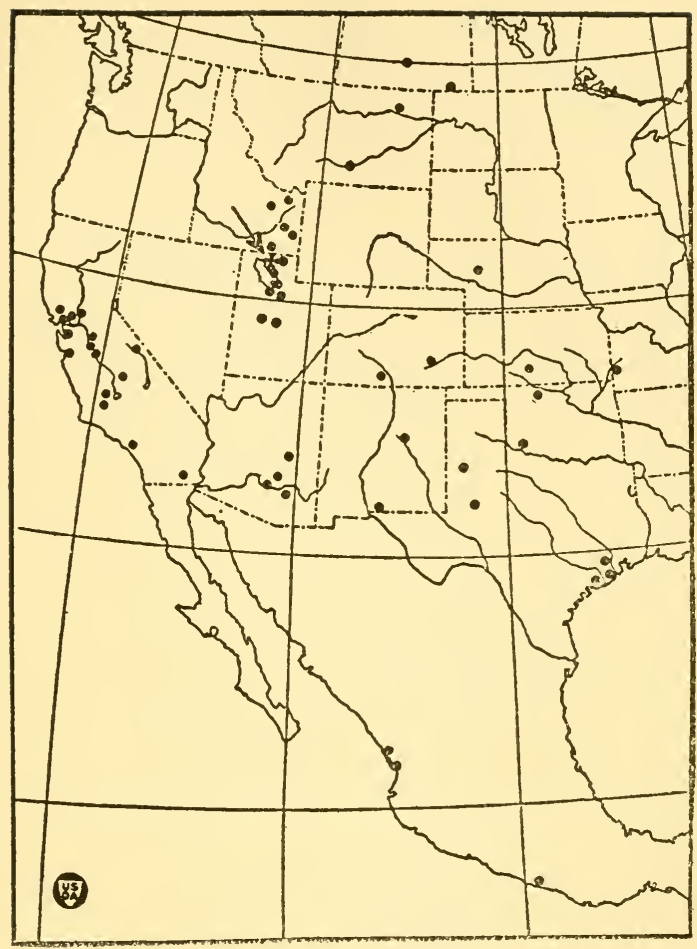

Figure 6

Map of part of western North America to show return records from ducks and other birds banded in the Salt Lake Valley, Utah. Point of release indicated by arrow. Return records marked by dots. (Courtesy of Bureau of Biological Survey.) 

Idaho. There is no reason to suppose, however, that a majority of these birds do not cross directly through the mountains. This southeastern migration seems to include many pintails, and the cinnamon teal and redhead.

Mallards seem to scatter widely from the point of release. A few remain in Utah through the winter, where warm springs afford them open feeding grounds, as several banded birds were taken in December and January in that state. One was killed in Owens Valley, California, another in southeastern New Mexico, one near El Paso, Texas, and one near Houston, Texas. These few records indicate a wide variation in habit and a wide range for this species, since some remain in the north, some cross to California, and some migrate to the plains regions east of the Rocky Mountains.

Pintails banded at this point have shown a remarkable distribution having been recovered throughout a wide range in the west. A few have lingered in Utah until December and January, though few ducks of this species can find suitable range so far north. Many cross to the interior valleys of California, where banded birds from Utah have been taken from the marshes above Suisun Bay south to the Imperial Valley near Calipatria. Migration to California may take place early, as one pintail, released on Bear River August 20, was 
killed near Dos Palos, in Merced County, California, on October I6. A part of the pintails from Utah travel to the Plains region east of the Rocky Mountains by routes not easily understood. Evidence at hand indicates a flight to the northward to the head waters of the Missouri River, and south over the Great Plains, since one marked bird was killed in eastern Montana, one in the sand-hill region of Nebraska, and another near the Gulf Coast of Texas. In spring flight several of these banded birds have been taken in Oklahoma, Kansas, Missouri, and Saskatchewan, indicating a flight north through the Plains region, in which the birds do not recross the mountains to the Great Basin.

From the evidence presented it seems that ducks concentrate in the Salt Lake Valley, and from there spread in migration over the entire western half of the United States. The region is highly important in the life of many species, so that it is unfortunate that, because of man's diversion of water from streams for purposes of irrigation, the bays inhabited by waterfowl in certain years become polluted with alkalis, so that ducks die there by the tens of thousands.

Interesting data on the movements of ducks from other regions are available through records assembled by F. C. Lincoln from banding operations under the Biological Survey. Of these, there may be 
mentioned returns from black ducks banded by H. S. Osler at Lake Scugog in south central Ontario. These returns divide into two more or less distinct groups, one from points to the southward in the drainage of the Mississippi Basin, and the second from New Jersey, Delaware, Maryland, Virginia, North and South Carolina - pointing clearly to a migration line directly to the southeast, which apparently may reach the heads of Delaware and Chesapeake bays and from there spread southward. A few returns from mallards indicate apparently similar lines of flight. It is interesting to compare these results with those obtained by Lincoln in a large number of mallards banded near Browning, on the Illinois River, in west central Illinois. Returns from these have centred near the Mississippi River, with extension to the Gulf coast of Texas, and straggling records from Georgia and Florida. From Browning it appears that the main flight is south, with only a few birds passing to the southeast. Black ducks and mallards banded by J. Pulitzer in Hancock County, Maine, and F. Thompson at Bar Harbor, Maine, have been killed in the coastal region to the south, none as yet having been secured trom the interior. The flight here thus seems to follow the trend of the coast to the south.

Migration of North American ducks southward beyond the limits of the United States is of uncer- 
tain extent. A blue-winged teal banded in September by Osler at Lake Scugog, Ontario, was killed the following December near Port of Spain, Trinidad. The species passes regularly south to the West Indies and to northern South America, and has been recorded in Brazil and Chile. Large numbers of northern ducks travel in winter to suitable points on the Mexican tableland, so that near the City of Mexico they are baited to small lakes and killed in hundreds by armadas - batteries made of a hundred or more gun barrels so arranged that they may be fired simultaneously. Pintails and scaup ducks travel into the West Indies, and with casual ducks of other species range down the eastern coast of Central America as far as Panama. The extent of this migratory flight is not, however, definitely known.

Ducks are capable of flying long distances over oceans also, as shovellers and pintails are regularly migrant in the Hawaiian Islands, and go south at least to the Line Islands near the Equator. They have also been recorded in the Marshall and Gilbert Islands.

Northward flights in spring do not necessarily follow the same lines pursued in autumn, since, as has been said, pintails banded in the Salt Lake Valley have been taken in spring in Saskatchewan. It is assumed that they migrated in autumn, to 
winter in the Mississippi River drainage, and then flew north in spring through the interior. The northward flight in spring through the Mississippi Valley is much more abundant than the southward movement through the same region, indicating that birds come in converging lines to favorable wintering grounds, where they concentrate, and then travel north in company. It is possible that the difference in spring and fall movement in this area is more apparent than real, since we find in autumn, through the Plains area in particular, that water is scarce, as that season of the year is usually dry. This would force waterbirds to drive on through without stopping, while in spring, after the rains and snows of winter, every pond and slough is filled with water and offers attractive feeding grounds. On rare occasions when early autumn rains fill the marshes which normally at that season are dry, the increase in ducks in southward flight is very noticeable. These birds undoubtedly have what may be termed "weather sense," which draws them to follow shifting seasons that offer conditions in their favor. In late December, I920, I was engaged in field observation in the western pampas of Argentina, in a region where no rain had fallen in months, and where lagoons and marshes were entirely dry. One evening there came a tremendous downpour of rain, a veritable flood, and on the following morning I 
flushed a South American pintail from a pond at the edge of the village where I was stopping. At that season males of these ducks were travelling about to some extent, and this and other individuals, which arrived a day or so later, came to new country as soon as local conditions had become favorable to them.

A northward flight through the interior of North America is indicated in some ducks that come south along the North Atlantic coast, as certain species common in that section in autumn are almost absent in spring.

In Europe, on the whole, it appears that ducks make shorter flights in migration than in North America since the extremes of northern climate are not so great and the birds do not have so far to move to find suitable wintering range. Records from western Europe from pintails banded by Professor H. C. C. Mortensen at the Island of Fäno, on the coast of Denmark, indicate that the birds migrated south through the valley of the Rhine, and along the Bay of Biscay south to the northern shores of the Mediterranean Sea from Spain to Jugoslavia. From this winter ground these birds passed north in spring into Lapland, Finland, and northern Russia in the vicinity of Archangel. Their flights thus covered almost as extensive a range as those of the American pintail spreading from a centralized area 
on Great Salt Lake. That sixteen of these banded birds were recaptured during subsequent autumn migrations at the point where they were originally marked indicates that western Denmark is on a regular fly line for this species.

The European green-winged teal, in appearance a close counterpart of our species, has been found in recent years to be the breeding species of the Aleutian Islands, but does not range to the mainland of Alaska. Though common in the Aleutians, in autumn migration it evidently crosses to the coast of Asia, as there are no certain records for it in the states of our western coast. This bird, in western Europe, migrates south from the Scandinavian peninsula, to winter in Ireland, the south of England, and France, as shown by birds banded in Denmark, and at two points in England. A few pass as far as southern Spain and Italy.

The mallard in western Europe has somewhat different habits from the two ducks just enumerated, since it is strictly migratory only in the far north. Large numbers of birds bred in England and Germany either proved to be strictly sedentary or moved only from fifty to one hundred miles during winter. The migration of this species in western Europe is later in autumn and earlier in spring than in North America. It may be noted that there is a very large form of wild mallard (Anas platyrhynchos conboschas) which remains in Greenland. 
Migratorial movements among some of the native ducks of southern South America are regular with the coming of colder weather. Males of some of these have the habit, which has been noted for other species, of abandoning the female so that these males band in large flocks in late summer. Their migration may come early: during the first week in November, in I920, I saw large numbers of South American pintails come from the south into a region of marshes and lagoons in the eastern part of the Province of Buenos Aires, following a tremendous storm of wind and rain that flooded the country. This flight continued morning and evening for three days and included many thousands of birds. The ducks travelled in small or large flocks, which flew steadily to the northward only thirty to sixty yards above the earth. During one forenoon I estimated the total number that passed my camp at between I 5,000 and 20,000, and believed that fully 95 per cent of them were males. Those that I shot were still in full breeding condition, indicating that they had only recently deserted their mates. The main flight comes later in the year, from March to May, when the hosts of young bred in the south come up to winter in the northern lakes. At this season the birds are found in tremendous numbers in suitable localities. 


\section{The Migrations of Some Other Birds}

Common birds that do not seem particularly strong in flight in many instances perform wonderful migrations of which we are only now gaining a true conception. Flight seems so much a matter of custom and habit, that even small birds are able to cover great distances without apparent over-fatigue so long as they can obtain proper food.

The chimney swift, found in summer throughout the eastern half of North America from Manitoba and Quebec south to the Gulf coast, has long been an anomaly, since, though abundant in numbers, its winter home has never been definitely located. In autumn, toward the close of their stay, the birds congregate at nightfall in large flocks, which roost in certain selected chimneys, or occasionally resort to some hollow tree after the fashion of their ancestors. Such resorts are visited year after year, and I recall particularly one large hollow tree that I knew in boyhood, to which these birds came in tremendous numbers for a few nights each autumn. Migrant swifts pass south to the Gulf coast, where for a time they are extremely numerous, and then disappear, to return at the close of March, and to work slowly northward during April to their breeding grounds. For many years they were wholly unknown south of our limits, but recently a 


\section{I96 THE MIGRATIONS OF BIRDS}

few have been recorded in April in Haiti, apparently in northward migration. We may suppose that their winter home is somewhere in the northern part of South America, though this remains to be definitely ascertained. Identification of swifts in regions of tropical forest is difficult, as the birds fly above the trees, where they are usually beyond gunshot. There are in the Tropics in addition, related swifts, which can not be distinguished from our northern species except with the birds close at hand, which still further complicates the case. In the Tropics there are few chimneys, so that we must picture the chimney swift in winter returning to former habits of roosting in hollow trees, as it did universally before the advent of civilized man. For six months of each year then it frequents settlements in the north, where it nests and roosts in chimneys, or, casually, in barns and outbuildings, while during the winter season it must revert to the ancient customs of its race, truly a curious mixture of habit.

Migrations among the strong-winged nighthawks of North America are of considerable interest, since these birds show a tendency to follow the general direction of river valleys more closely than there would seem to be need. Formerly these birds were far more abundant than at present, and for many years it was usual to shoot them in wanton sport, especially during their autumn flights, a custom 
that persisted for many years throughout the greater part of the eastern United States from Wisconsin to Florida. The birds were killed by thousands and became reduced in numbers, since they rear but one brood with a maximum of two young each season, and were unable to withstand the excessive drain upon their number by the constant shooting to which they were subjected. On the Potomac River above the city of Washington the scanty autumn flight that remains passes regularly down-stream toward the southeast, a direction that seems to be held until the birds pass beyond the limits of the Piedmont plateau and reach the level expanses of the Coastal plain. A number of years ago, while studying the birds in the plains region of central Oklahoma in late May, I found nighthawks very abundant. Most of those secured were of the form known as Howell's nighthawk (Chordeiles $m$. howelli), which bred locally, but among others I secured three specimens of the western nighthawk (Chordeiles $m$. henryi), which nests in New Mexico, Arizona, northern Chihuahua and Sonora. As the latter were at a point farther east than ever previously recorded, we can only suppose that they were in migration and were following the course of the South Canadian River through Oklahoma to its headwaters in the mountains of New Mexico. One year in the Bighorn Basin in Wyoming, I saw nighthawks arriving from 
the north during early June in a line of flight that carried them up the valley of the Big Horn River. It would seem that they may have followed west along the valley of the Yellowstone from the region of the Plains, and then turned off into the valley of the Big Horn, which flows to the north, so that the final portion of their spring migration carried them directly south to their breeding area.

The migration flights of the bobolink possess considerable interest, since the actual limits of the winter home of this species were for some time uncertain. The birds come north in spring, arriving in middle latitudes in late April or early May, with the males in handsome, pied summer plumage. With the settlement of the west it appears that this species has greatly increased in numbers in that section, if it has not actually extended its range, as in the Gallatin valley and similar areas in northwestern Montana it is now common, though formerly it was very local in occurrence. After breeding in northern meadows and hay-fields, where the musical songs and handsome appearance of the males endear them to all, these birds in late summer resort to marshes and grassy swales, where they pass through a moult in which the males assume a dull streaked plumage like that of their mates.

Southward migration begins about the middle of August, with August I 8 as the average date of arri- 
val from the north in the vicinity of Washington. Though a few straggle south into Colorado and Kansas, the majority of the birds from the northwest part of the range travel to the southeast, so that the main flight passes east of the Mississippi River, and concentrates especially along the tidal marshes of the eastern coast. When southward flight begins, it comes with a rush that distributes the flocks far southward, so that on the east coast the birds arrive at suitable points in the region from Maryland south to Georgia and Florida almost simultaneously at some date between the middle of August and the first of September. Bobolinks in flocks now frequent marshes and weed-grown fields in the lowlands, and formerly, when rice was extensively cultivated in the southeast, were very destructive to that crop. Where the grass known as wild rice (Zizania palustris) is abundant, the birds gather in large flocks and, under the name of reed-bird or rice-bird, are pursued by hunters. Outside of marshes they are seldom seen except as their call comes in morning and evening from flocks passing overhead. A part of the migration is regularly performed by day in both spring and autumn, so that the arrival and passage of the species is easily noted.

From the Gulf coast the bobolink crosses in autumn to Cuba, and from there continues directly 
across the Caribbean to northern South America, and then on southward to its principal wintering ground in the central portion of that continent. During winter it continues to frequent swamps and grass-grown marshes, and seems to have its centre of abundance in the Chaco, a vast area of poorly drained, swampy land, with broad grass-grown savannas, that extends west of the Paraná and Paraguay rivers, from northern Santa Fé in north central Argentina, north into Bolivia and Brazil. For untold years the bobolink had been safe in this winter home, as for human neighbors it had only scattered groups of Indians of nomadic habit who, though they probably killed a few of these birds with throw-sticks or other weapons, did not trouble to exert themselves particularly after such small game, and were too few in number to be any serious menace. Within the past ten years there has begun a change in this condition, which is bound to affect the bobolink sooner or later. Soil in the Chaco is fertile, and white men, who entered it first to obtain the valuable woods of its forests, have now begun to divide the land and put it under cultivation. Since the World War, colonization has been especially active, and great areas are now settled where a few years ago the only human inhabitants were a few Indians. Sadly enough it must be recorded that the cultivation of rice has begun in this area, and 
unquestionably the bobolink will flock to this crop as it did in former years in the southeastern United States when the rice industry was at its height in that section. In I920 I heard some complaint of it, and if the rice industry increases, the bobolink will come in for destruction. It must be noted too that many of the colonists are from southern Europe particularly from Italy, and that these peoples, as usual, have brought with them to their new homes the custom prevalent in their native land of considering all small birds as game. Hunters in the Chaco now kill all manner of sparrows, blackbirds, and flycatchers for the pot, so that, as the country settles, the bobolink will be subject to toll from this source. What the final result may be time alone can tell, but it is certain that hunting will press severely on the abundance and continuance of the species.

The bobolink on reaching South America seems to delay its southward flight. Todd has recorded its arrival in the Santa Marta District of Colombia on September II - an indication, by the way, of the rapidity with which the species travels south, since that date represents a point of maximum abundance for the species in Maryland and Virginia - and finds that it remains until October I4. Early arrivals come to the Chaco of northern Argentina (at Ocampo, Santa Fé) about the first of November; 
but from the little that we know at present, it appears that flocks wander to a considerable extent, since Venturi, at the point last mentioned, records a sudden increase in abundance about the first of January. In its southern home the bobolink is known to European settlers as charlatan from the pied dress of the male in breeding plumage, and many are captured in northern Argentina by birdcatchers who sell them throughout the country. I saw them offered in several Argentine cities and have known of their shipment across the mountains to Chile. In I 925 one that had been purchased in Valparaiso was brought to the National Zoölogical Park, in Washington.

Harris's sparrow (Zonotrichia querula), a species allied to the white-crowned and white-throated sparrows, but of larger size, with throat marked with black, is an excellent example of a species with limited distribution and migration. In summer it nests in a more or less unknown region in Hudsonian Zone, from Fort Churchill on Hudson's Bay westward, possibly to near Great Bear Lake. In September and early October it migrates south to a wintering ground from northern Kansas south to northern Texas. Migration is almost directly south and extends only through a comparatively narrow area along the eastern edge of the Great Plains. Stragglers come to eastern Colorado on the west 
and central Wisconsin and Illinois on the east, but the full migration centres through a narrow region comprising eastern Kansas and western Missouri. Here this fine bird swarms in thickets and hedgerows during October, and again in April, filling the air with its rollicking whistled calls. At the height of the migration thousands may be seen in a single day, but outside this strip, which is barely 250 miles wide, the bird is casual or rare. The cause for this limited distribution is wholly obscure, for areas at either hand seem equally suited for the needs of the bird, which has the habits of its congeners. No other bird has this distribution, which lies along the lines where forms of the eastern half of the country begin to disappear and those of the west to appear.

To observers in the eastern states the coming of the hosts of wood warblers (Mniotiltidae) marks the height of the spring migration. Trees and thickets are filled with small birds, flitting among the twigs, whose bright colors, revealed by field glasses or by favorable light to the unaided eye, come as a neverfailing and refreshing surprise. The very fact that more than thirty distinct species may be seen in a single day adds to the excitement of their identification and one never knows what rarity may appear among their ranks. The tree-hunting forms (mainly of the genus Dendroica) have the habit of moving in mixed flocks which may contain a dozen or twenty 
species, so that one must scan each individual to make sure that some species new to the day's list of birds is not overlooked. Their identification in spring is not difficult, save as it necessitates memorizing the characters that distinguish a large number of forms, as at this season males are in breeding dress and are marked by many beautiful patterns, which include combinations and blendings of five of the colors of the spectrum, blue, green, yellow, orange, and red. With these as a base the diversity of shade of markings and mixture of colors is almost endless. Though well marked in spring, in autumn these same birds are the despair of the beginner in field ornithology, as the young wear soft blended patterns and even the adults have subdued their brilliant colors or have discarded them for others of plainer hue. Particularly astonishing is the change in the chestnut-sided warbler, which in spring has a chestnut line on the sides and a yellow crown-cap and in autumn shows us a greenish back and a white breast, or in the bay-breasted warbler, which exchanges its handsome plumage for a duller streaked dress, in which many individuals can be distinguished from the related black-poll only by the color of the tarsus and feet. Without these active sprites, however, much of the thrill of autumn migration through eastern woodlands would be lacking, as their very elusiveness makes our wood warb lers the more attractive. 
The wood warblers are found only in the New World, where they have their centre of abundance in North America. A few are mainly sedentary, as is the case with the form of orange-crowned warbler (Vermivora celata sordida), found on the Santa Barbara Islands in California, which remains in winter on Santa Catalina, though migrants range to the mainland opposite, even as far as Haywards and Palo Alto. The yellow-throat of Florida (Geothlypis trichas ignota) so far as known is entirely sedentary, as are the yellow-throats in the marshes of the San Diegan district (G. t. scirpicola), and those of the vicinity of San Francisco Bay (G. $t$. sinuosa) in California.

The pine warbler of the east withdraws from the north to concentrate within the southern limits of the breeding range, the only one of our species that has this habit. It breeds north into southern Canada, and in winter is found north to Virginia and Illinois and, casually, farther. The few that cross into Tamaulipas in northeastern Mexico are about the only ones that pass beyond the southern limits of the breeding range.

The myrtle warbler is the only species that seems to be unaffected particularly by cold, as, though in winter it is found south to the Greater Antilles, Mexico, and even to Panama, it remains common in the southern United States, and winters regu- 
larly north as far as Mason and Dixon's line or even farther. Its western representative (Dendroica coronata hooveri), which nests in Alaska, winters from southern Oregon through the valleys of California. I have seen the eastern form in eastern Kansas in January during severely cold weather, and it is frequently common in the milder winter climate of Washington.

The two forms of the palm warbler winter regularly in the Gulf States, and in Florida are found with black and white, orange-crowned, yellowthroated, worm-eating, parula, black-throated blue, and prairie warblers, oven-birds, and northern water-thrushes. The black and white, Nashville, orange-crowned, myrtle, and sycamore warblers are found in winter in southern Texas, and the orangecrowned, dusky, Alaska myrtle, Audubon's, Townsend's, and hermit warblers occur at that season in more or less abundance in the lower portions of California.

Of our North American species and subspecies, as enumerated in the A. O. U. Checklist for I9IO, there are 22 that winter in the West Indies, 44 that are found in winter in Mexico, 37 in Central America, and 22 that reach South America. Four species winter almost entirely in South America. The majority have an extended range, which may cover the area from the Greater Antilles and Mexico south, 
through Central America and northern South America. Swainson's warbler retires in winter to the Island of Jamaica, while Bachman's warbler is known at that season only in Cuba. Kirtland's warbler, which nests in a limited area in the state of Michigan, goes southeast to concentrate in the Bahamas.

The Connecticut warbler is peculiar for the eccentric migration route that it follows. This bird breeds from the northern peninsula of Michigan to Manitoba in a decidedly limited area. In autumn migration it moves southeast or east, to cover the area from Pennsylvania to New England, and then follows south, east of the Appalachian Mountains, through Florida and the West Indies to its winter home in South America. On its return in spring it passes again through Florida, but then continues to the northwest, west of the mountains, through the eastern portion of the Mississippi drainage, to its nesting grounds. In the vicinity of Washington, it is found in small numbers during the autumn in dense growths of weeds or in thickets, but in spring it is so rare that it has been seen on few occasions.

The black-poll warbler is of peculiar interest for the length of its migration route and for the comparative rapidity with which it travels. The species nests mainly in Canada, from the northern border of tree growth in Labrador to Alaska, and winters 
entirely in South America, from Ecuador and Guiana to eastern Brazil. The migration flight is performed through the West Indies, so that birds from the northwest and northeast converge toward Cuba in southward flight. Both spring and autumn movements are comparatively late, and in spring, when the lazy song of the black-poll is heard, we know that the close of migration is near at hand. The rate at which the bird travels is rapid, so that for its entire course through the United States it advances at the average rate of about seventy-five miles per day. Professor Cooke estimates that the final spring flight through northwestern Canada proceeds at an average rate of two hundred miles per day.

Much of the migration of wood warblers is performed by night, but in spring or autumn we often find mixed flocks feeding along through tree growth in the general direction in which migration is proceeding. At times, late in the autumn, this movement is especially noticeable, and often warblers come flying in from the north, to work hurriedly through the trees for a few moments and then, with soft calls, rise and pass on out of sight to the south. Feeding flocks move rapidly in the same direction, so that the distance covered in the course of early morning and late afternoon, when the birds are particularly active, must be considerable. Flights 
of warblers have been seen also crossing ocean waters during the day. C. J. Maynard, at the close of April in 1884, while sailing through the Bahamas, recorded a considerable flight of warblers, most of them blackpolls, which were passing from the southeast. The birds were flying low, from six to twenty feet above the surface, and passed in little bands containing from two or three to one hundred individuals. They were flying against a northerly wind, which increased until it was quite violent, yet warblers continued to arrive and depart in great numbers from a small islet of two acres extent. This flight continued from April 27 to 29, a period of three days, during which many thousands of warblers passed. Maynard considered his centre of observation on Leaf Key as a point in a wide area through which this migration was passing, so that the total flight during these three days was truly enormous. Dr. F. M. Chapman has also noted day-flying flocks in early May, in crossing from Miami to the Biminis.

Mortality among these sea voyagers must be tremendous. Maynard speaks of finding several dead in the water or on shore where they had fallen. Ships passing through these areas are frequently used as havens of rest, and I have observed that many of the small birds that come to them seem utterly exhausted so that they may be captured in the hand. 
The cliff swallow, whose range covers the greater part of North America from Mexico north to Canada and Alaska, from the Atlantic to the Pacific coasts, has a peculiar line of migration flight, as birds from the east migrate westward, so that the species seems to go around the Gulf of Mexico instead of across it. This line, followed in spring as well as in autumn, accounts for the belated arrival of the species on the eastern coast, and may possibly have some connection with its rarity in recent years in eastern Maryland and adjacent areas. Its line of flight is the more peculiar since barn swallows cross regularly through Cuba and other Antillean islands to the mainland of South America. The cliff swallow in its chosen route is not governed by any dislike of prolonged flight, since after it reaches Panama it may continue south into Argentina.

Some observations on the spread of the common starling are of interest. It has been learned through banded birds that there is pronounced migration in this species from the Scandinavian Peninsula, Finland, and western Russia, south or sometimes southwest, since birds from this region, including northern Germany, have been taken in winter in Great Britain. Birds from Germany have migrated also into Spain, Italy, and even Tunis in northern Africa. On the other hand, the breeding starling of England seems to be rather strictly sedentary, since of a con- 
siderable number banded returns have come from comparatively near to where the birds were marked, only a few having crossed to Ireland, and one to the coast of France. Many have been taken in winter in the same locality where they were banded as nestlings. It appears then that northern starlings are migrant, while those of more temperate climate are usually resident.

In the United States successful introduction of the starling was made in two importations released in Central Park in New York City, one of eighty birds in April, r890, and one of forty birds in March, I89I. The point of origin of these is not definitely known, so that it cannot be said whether they were of migratory or non-migratory stock. It required ten years for the starling to establish itself firmly in New York City in the vicinity of Central Park, but since I 900 the spread of the species has been regular (see Fig. 7). In its dispersal the starling seems to have been largely vagrant, though until I9I 4 it remained in the main near the coast, and not until IgI6 was there pronounced inland invasion. Since that time it has moved rapidly westward, until it has crossed the mountains with outpost breeding colonies, and will unquestionably spread rapidly through the Mississippi Valley. It is interesting to note that until I 920 the distances travelled north and south from the centre of original dis- 
persal at New York are almost identical, as in that year it was breeding north to the coast of central Maine and south to northeastern North Carolina. This indicates a concentric dispersal in these two directions, though one would naturally suppose that the bird would travel more rapidly toward the south. There is evident wandering in late autumn and winter, so that casual occurrences have been recorded recently from Wisconsin, Illinois, Tennessee, and Mississippi. It is usually several years before breeding colonies are established in new regions. At Washington, D. C., in November, 1913, a flock of several hundred arrived preceding a storm from the north, and spent all one afternoon in whirling in the wonderful evolutions customary to this species back and forth over the Mall. Individuals were recorded all through the winter, but it was several years before the bird became established commonly as a breeding species. Now it is nesting all through the country in near-by Virginia and Maryland. In the United States the starling does not seem to have established any regular migratory habits, but seems to wander at random. It has been believed that a certain number have been carried southward in migrant flocks of grackles, cowbirds, or red-winged blackbirds, as starlings in autumn frequently roost with these species. This method of dispersal may be probable in some cases, though it cannot be con- 


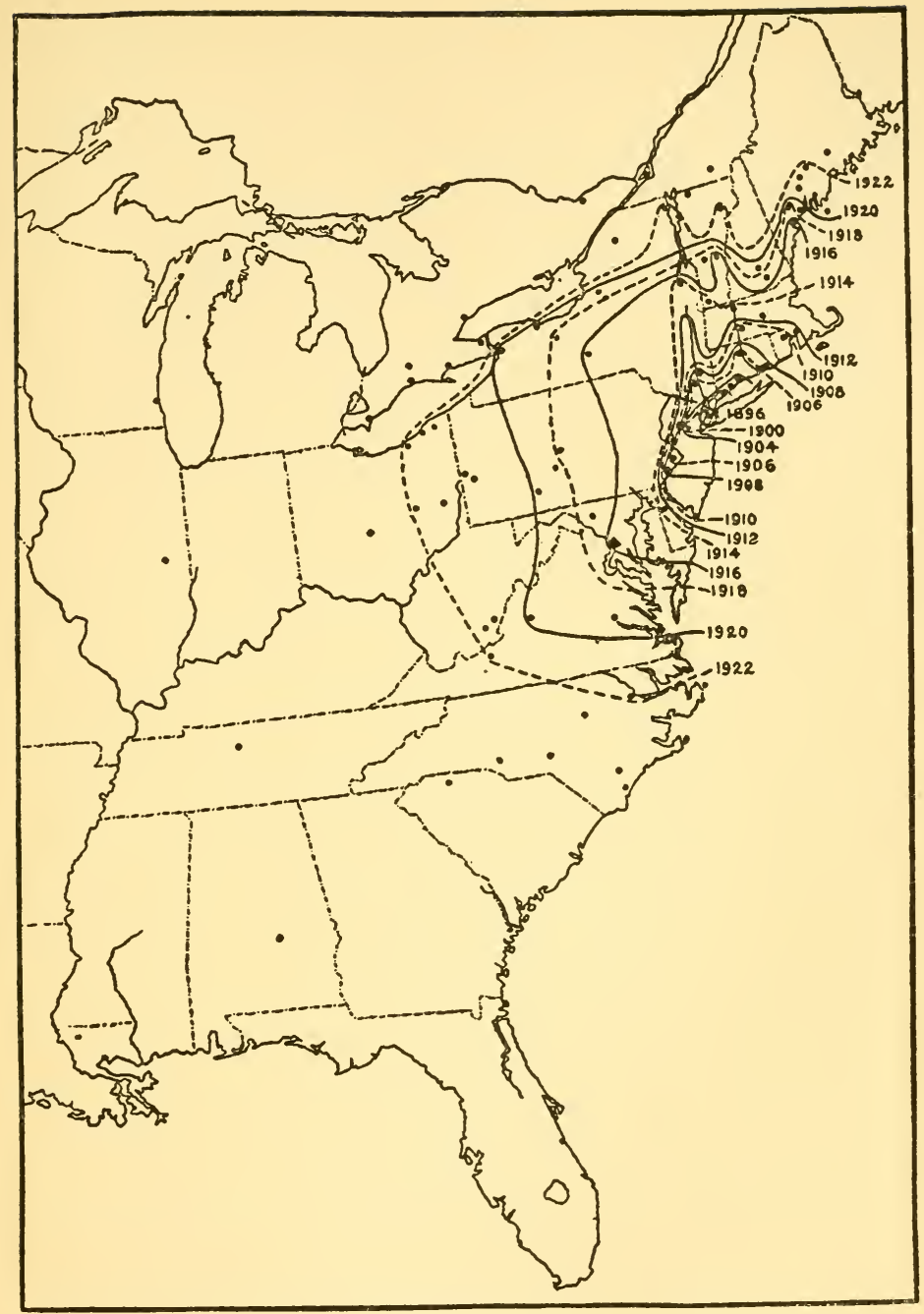

Figure 7

Breeding range of the European starling in North America to 1922. The species was originally introduced in New York City. (Courtesy of Bureau of Biological Survey.) 

sidered as usual as has been supposed. The flight of the starling is so much more rapid than that of the blackbirds that it would be difficult for it to accompany them for great distances. The blackbirds in question habitually fly from 22 to 28 miles per hour, while the starling as regularly travels at a rate of 38 to 49 miles per hour. The two speeds are so incompatible that it might be difficult for the species to keep together in prolonged flight. Furthermore, if starlings were to begin migration with flocks of grackles, there would be no incentive for them to drop out en route, as they would naturally accompany the other birds to the far south. If this method had been used in their dispersal, it is natural to suppose that they would have appeared early in the southern winter quarters of the blackbirds under discussion, which, as has been said, is not the case since the starling has spread gradually to the southward.

The migratory quail, already mentioned as a source of food to the starving Israelites during the exodus, comes south toward Africa in September in enormous numbers, when immense quantities are captured in nets for food. The birds are crowded into low narrow cages often so closely that they can barely stir, with the crates darkened to prevent fighting, and are sent alive to market. From the shores of the Mediterranean tens of thousands have 
been shipped to large cities, and it is said that in one year five million were shipped to England from Egypt. The birds often appear very tired on arrival after migration in their winter home, and at times descend in large numbers to alight on ships, though we may hardly credit the tale of an ancient historian who averred that they fell upon ships until the boats were swamped and sunk.

Migration among sea-birds is a matter of much interest. In the outer islands of the Hawaiian chain, there is found a series of islets given over almost entirely to birds, turtles, and seals; except for a cable station at the atoll known as Midway, there are now no permanent human inhabitants. Birds, however, have occupied these islands for a great many years, and gather there annually in tremendous colonies. Laysan Island, 850 miles northwest of Honolulu, is the most famous of these island rookeries, since it became known early through the value of its deposits of guano. To Laysan at the close of October and in early November each year come thousands of Laysan and sooty albatross to mate and rear their young. The chicks, as woolly as lambs, one in a family, are slow in development, so that they do not attain their growth until May or June. The parents care for them assiduously until summer, when the young are grown but are still unable to fly, and then wander off to sea, leaving 


\section{THE MIGRATIONS OF OTHER BIRDS 2I5}

the young to their own devices. For several weeks these immature birds wander about, without food, living on the fat stored over the body during the previous period of care, and finally teach themselves to fly by extending their growing wings in the steady sweep of the trade winds. When strong on the wing, they too leave the vicinity, so that after June it is rare to see an albatross near the breeding station. All are wandering at sea far from any land. Whether their migration is regular or nomadic we may only conjecture. Their return is regular, and we may marvel at the means by which they are able to find again the isolated islands on which they breed. Their migration is similar in its performance to that of land birds, except that the birds may possibly not move in any stated direction; but it is performed under wholly different conditions. The wanderings of the Laysan albatross are unknown, but the sooty albatross is seen following ships throughout much of the North Pacific, north to the Gulf of Alaska and the Aleutian Islands. It appears that a certain number do not nest each year, since some of the birds are found in small numbers in these distant waters when the majority of the species is in breeding quarters.

We are accustomed to think of autumn migration in the northern hemisphere as always towards the south, except for post-breeding wandering in late 
summer in herons and a few others, which is followed by a retreat south with the coming of cold weather. The various races of the large-billed sparrow (Passerculus rostratus) follow an unusual course, which is an exception to the general rule. For many years they were recorded along the southwestern coast of California and in Lower California, but their breeding place was unknown. Recently it has been discovered that the species as a whole nests from the mouth of the Colorado River south to the western coast of Lower California, and that in autumn, from this restricted breeding range, it migrates in part south along the coast of Lower California and Mexico, and in part north along the coast of California, as it is common on the coastal marshes of Los Angeles County and comes north regularly as far as Santa Barbara. A large number of individuals thus pass the winter a considerable distance north of their breeding ground. No other perching bird in the North American avifauna is known to have this habit.

Heermann's gull of the western coast has a somewhat similar migration, as it breeds on islands in the Gulf of California and on the western coast of Jalisco, and then migrates north as far as Vancouver Island in British Columbia. 


\section{Conclusion}

In concluding these observations, we may define migration among birds briefly as advance and retreat with fluctuation in conditions favorable to the various species. Each form has its own reaction to its environment, so that the movement found in migrant forms differs widely, and seldom do two present the same picture. Dr. J. Grinnell ${ }^{x}$ has defined migration as "a phase of distribution wherein more or less regular seasonal shifting of population takes place in response to precisely the same factors as hem in the ranges of sedentary species." It appears that the beginnings of the present instinct for $\mathrm{mi}$ gration, and the habit of its continuance, are so ancient that they are wholly obscure and may be interpreted only in terms of present conditions. The underlying cause is certainly complex and is due to multiple factors. We have in the past fifty years cleared away many uncertainties regarding it, but must look to the future to explain definitely the basic reasons for the institution of migration (particularly in species that seem to have no need for seasonal movement), the cause of the varying length of the journey in different forms, and the method of orientation followed in pursuing flight over courses which, to young individuals at least, are unknown. 





